\title{
WestVirginiaUniversity
}

THE RESEARCH REPOSITORY @ WVU

Graduate Theses, Dissertations, and Problem Reports

2002

\section{In vitro genotoxicity investigations of jet fuel}

Shawna M. Jackman

West Virginia University

Follow this and additional works at: https://researchrepository.wvu.edu/etd

\section{Recommended Citation}

Jackman, Shawna M., "In vitro genotoxicity investigations of jet fuel" (2002). Graduate Theses,

Dissertations, and Problem Reports. 1704.

https://researchrepository.wvu.edu/etd/1704

This Dissertation is protected by copyright and/or related rights. It has been brought to you by the The Research Repository @ WVU with permission from the rights-holder(s). You are free to use this Dissertation in any way that is permitted by the copyright and related rights legislation that applies to your use. For other uses you must obtain permission from the rights-holder(s) directly, unless additional rights are indicated by a Creative Commons license in the record and/ or on the work itself. This Dissertation has been accepted for inclusion in WVU Graduate Theses, Dissertations, and Problem Reports collection by an authorized administrator of The Research Repository @ WVU.

For more information, please contact researchrepository@mail.wvu.edu. 
IN VITRO GENOTOXICITY INVESTIGATIONS OF JET FUEL

\author{
Shawna M Jackman
}

Dissertation submitted to the

College of Agriculture, Forestry and Consumer Sciences

at West Virginia University in partial fulfillment of the requirements

for the degree of

\title{
Doctor of Philosophy
}

in

Genetics and Developmental Biology

Joginder Nath, Ph.D., Committee Chairperson

Geraline Grant, Ph.D.

Christopher Kolanko, Ph.D.

Walter Kaczmarczyk, Ph.D.

Knox Vandyke, Ph.D.

Donald Sens, Ph.D.

Department of Genetics and Developmental Biology

Morgantown, West Virginia

2002

Keywords: Genetic Toxicology, Aircraft Fuels

Copyright 2002 Shawna M. Jackman 


\title{
ABSTRACT \\ IN VITRO GENOTOXICITY INVESTIGATIONS OF JET FUEL
}

\author{
Shawna M. Jackman
}

The 60 billion gallons of jet propulsion fuels consumed worldwide create an exposure situation to over two million military and civilian personnel per year. The potential mutagenic, genotoxic and cytotoxic potency of military jet fuel was investigated in this study through in vitro systems such as human peripheral lymphocytes and metabolically competent hepatic cell lines. A battery of genotoxicological evaluations is employed, focusing on the comet assay to examine the induction of DNA damage. Cellular exposures to fuel were carried out directly and indirectly with an ethanol $(\mathrm{EtOH})$ carrier. The fuel was found to be nonmutagenic with and without metabolic activation in the Salmonella microsomal mutagenicity assay. Chromosomal aberrations were apparent through a slight but not significant increase in sister chromatid exchanges in peripheral lymphocytes directly exposed to the fuel. DNA damage was induced as a result of fuel exposure as measured by the comet assay in peripheral lymphocytes and cell lines investigated. DNA damage increases with increasing exposure to the fuels and the activation of repair processes was demonstrated. There was no evidence of the formation of bulky aromatic adducts from fuel exposure investigated through $\mathrm{P}^{32}$-postlabeling. However, evaluations of a fuel exposed hepatic cell line via oxidative comet assay showed an increase in DNA damage implying that oxidative mechanism have a role in the genotoxic effects of the fuel. The in vitro evidence of cytotoxic and genotoxic insult as a result of jet fuel exposure presented here, suggest a reevaluation of the fuel components and exposure limits. 


\section{DEDICATION}

To my loving parents, Paul and Nancy, and brother T.J. for providing me with every opportunity to succeed enhanced by the motivation and encouragement to do so.

"If you can imagine it,

You can achieve it.

If you can dream it,

You can become it. "

To Jay, together we traveled through this endeavor and found an extraordinary friendship 


\section{ACKNOWLEDGEMENTS}

I would like to extend my deepest gratitude to all those that provided me with encouragement and guidance throughout my scientific endeavors. Without their influences, the decisions on and accomplishment of my goals would have been much harder to achieve. They each have contributed greatly to my scientific and personal strengths in their own special way. I would like to especially recognize:

Dr. Nath for his support and mentoring throughout my graduate studies at WVU. One is truly blessed to have an advisor that is exhaustively dedicated to his students' research, success and general happiness. He has provided me with innumerable lessons and insights into science and life as a whole.

Dr. Geraldine Grant, a true inspiration and role model, for her immense moral support and incredible patience, her keen scientific insight and guidance, and for a remarkable friendship that will be cherished a lifetime.

Dr. Chris Kolanko for his relentless faith in my abilities to succeed in every

opportunity he has provided me with throughout the last ten years as my mentor. I am truly looking forward to the coming years as his colleague.

Center for Genomics and Bioinformatics at George Mason University for the fortunate opportunity to work in and become part of the lab. I enjoyed every moment with this group of energetic and driven scientists and appreciate their collective encouragement and friendships.

Dr. William Blakely and Dr. PGS Prasanna for their invaluable critiques, advice and instruction on concepts, methods and interpretation of data and for generously extending to me the use of their laboratories and equipment at AFRRI. 


\section{TABLE OF CONTENTS}

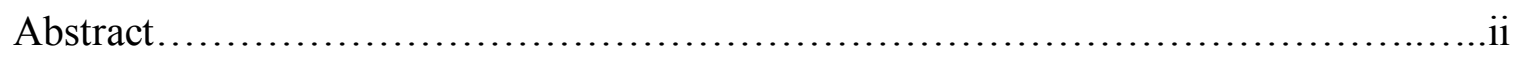

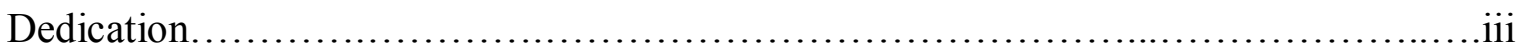

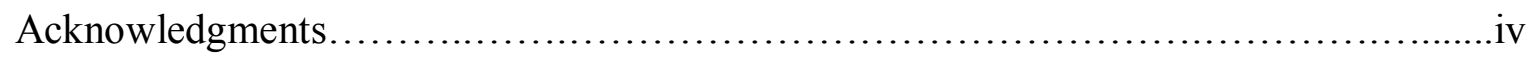

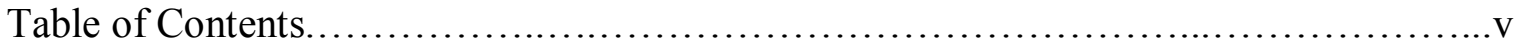

List of Abbreviations........................................................ vi

List of Figures.......................................................... vii

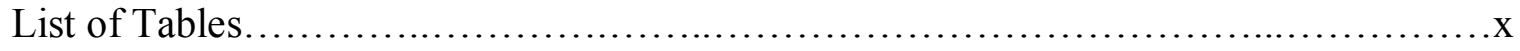

Introduction. ...............................................................

1. Literature Review....................................................... 5

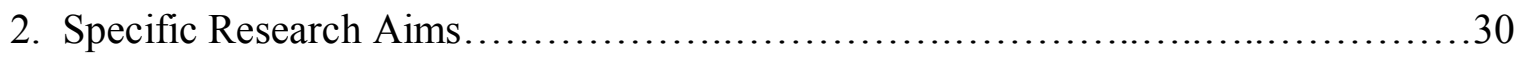

3. Materials and Methods...................................................... 31

4. Results.............................................................. 52

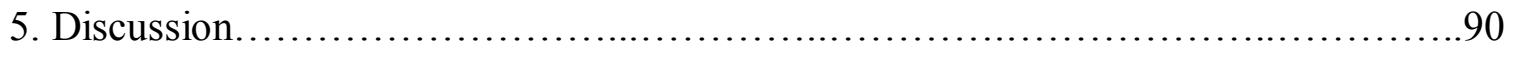

6. References........................................................... 120

Appendix A Buffers, Solutions, and Experiment Chart........................... 132

Appendix B Jet Fuel Components/Papers and Oxidized base examples..............136

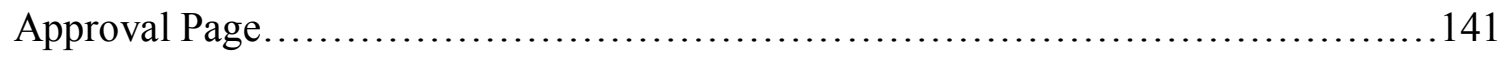




\section{LIST OF ABBREVIATIONS}

AFRRI

AFIERA

Ara-C

AP assay

AP sites

ATP

$\mathrm{BaP}$

BrdU

${ }^{\circ} \mathrm{C}$

d

$\mathrm{dbs}$

diEGME

DNA

DMEM

DMSO

DOD

EDTA

EtOH

FBS

FLARETM

FPG

$\mathrm{g}$

$\mathrm{h}$

HU

IPPSF

IL

JP-5

JP-8

JP-8+100

$\mathrm{kg}$

$\mathrm{L}$

LAI

$\mathrm{mg}$

$\mathrm{ml}$

MTT

$\mathrm{NaCl}$

$\mathrm{NADH}$

$\mathrm{NADPH}$

$\mathrm{NaOH}$

NATO

NRL

OD

PARP

$\mathrm{PAH}$
Armed Forces Radiobiology Research Institute

Air Force Institute for Environment, Safety and Health Risk Analysis

cytosine arabinoside

acid phosphatase assay

apurinic/ apyrimidinic sites

adenosine triphosphate

benzo [a] pyrene

bromodeoxyuridine

degrees Celsius

day

double strand break

diethylene glycol monomethyl ether

deoxyribonucleic acid

Dubeccos minimum essential medium

dimethyl sulfoxide

Department of Defense

ethylenediaminetetraacetic acid

Ethanol

Fetal bovine serum

Fragment Length Analysis with Repair Enzymes

formamidopyrimidine

gram

hour

hydroxyurea

isolated perfused porcine skin flap

interleukin

Jet Propulsion Fuel 5

Jet Propulsion Fuel 8

Jet Propulsion Fuel 8 with +100 additive

kilogram

liter

Loats Associates Inc.

milligram

milliliter

3,[4,5-dimethylthiazol-2-yl]-2,5-diphenyltetrazolium bromide sodium chloride

nicotinamide adenine dinucleotide

nicotinamide adenine dinucleotide phosphate

sodium hydroxide

North Atlantic Treaty Organization

Naval Research Laboratory

Optical Density

poly (ADP-ribose) polymerase

polycyclic aromatic hydrocarbon 
PBS

PEI

PEL

Pen

PHA

PI

PMD

ppm

ROS

rpm

S9

SCE

SCGE

SD

SDS

ssb

Strep

TBE

TLC

$\mu 1$

$\mu \mathrm{g}$

$\mu \mathrm{m}$

USAF

UV

WVU phosphate buffered saline (magnesium and calcium free) polyethyleneimine

Permissible Exposure Limit

penicillin

phytohemagglutinin

proliferation index

petroleum middle distillate

parts per million

reactive oxygen species

rotations per minute

microsomal fraction from rat liver

sister chromatid exchange

single cell gel electrophoresis

standard deviation

sodium dodecyl sulphate

single strand break

streptomycin

Tris/Borate/EDTA buffer

thin layer chromatography

microliter

microgram

micrometer

United States Airforce

ultraviolet

West Virginia University 


\section{LIST OF FIGURES}

Figure 1 Breakdown products of synthesized deicer alternatives....................11

Figure 2 Schematic of the neutral and oxidative comet assay procedure..............48

Figure 3 Schematic of the ${ }^{32} \mathrm{P}$-postlabeling technique............................. 51

Figure 4 Cytotoxicity curves for peripheral lymphocytes directly exposed to JP-8....55

Figure 5 Cytotoxicity curves for V79 cells indirectly exposed to JP-8 .............56

Figure $6 \quad$ Cytotoxicity curves for deicer alternatives.......................... 57

Figure 7 SCE formation in peripheral lymphocytes directly exposed to JP-8.........58

Figure 8 Linear regression analysis of mean SCE/cell in peripheral lymphocytes

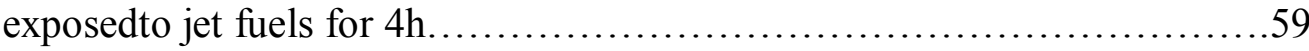

Figure 9 Selected peripheral lymphocytes from comet assay experiments with direct fuel exposure (1:150 dilution) for $4 \mathrm{~h}$.

Figure 10 Distribution of tail moment and percent DNA measures of peripheral lymphocytes directly exposed to JP-5 for $4 \mathrm{~h}$....

Figure 11 Distribution of tail moment and percent DNA measures of peripheral lymphocytes directly exposed to JP-8 for $4 \mathrm{~h}$.

Figure 12 Distribution of tail moment and percent DNA measures of peripheral lymphocytes directly exposed to JP-8+100 for $4 \mathrm{~h}$

Figure 13 Distribution of tail moment and percent DNA measures of peripheral lymphocytes directly exposed to JP-5 for $8 \mathrm{~h}$

Figure 14 Distribution of tail moment and percent DNA measures of peripheral lymphocytes directly exposed to JP-8 for $8 \mathrm{~h}$

Figure 15 Distribution of tail moment and percent DNA measures of peripheral lymphocytes directly exposed to JP- $8+100$ for $8 \mathrm{~h}$.

Figure 16 Distribution of tail moment and percent DNA measures of H411E cells directly exposed to JP-5 for $4 \mathrm{~h}$.

Figure 17 Distribution of tail moment and percent DNA measures of H411E cells directly exposed to JP-8 for $4 \mathrm{~h}$

Figure 18 Distribution of tail moment and percent DNA measures of H411E cells directly exposed to JP-8+100 for $4 \mathrm{~h}$ .70 
Figure 19 Distribution of tail moment and percent DNA measures of H411E cells

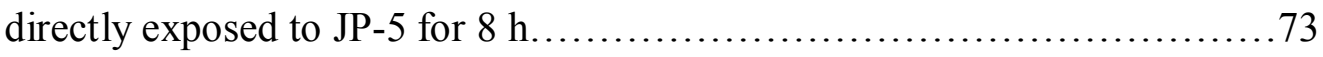

Figure 20 Distribution of tail moment and percent DNA measures of H411E cells

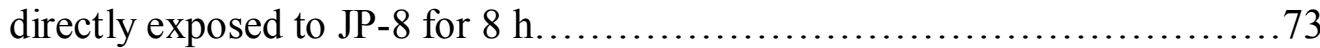

Figure 21 Distribution of tail moment and percent DNA measures of H411E cells

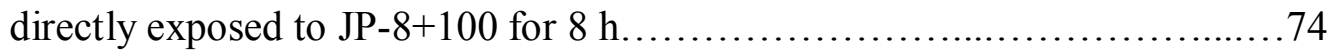

Figure 22 Effect of indirect JP-8 (0.1\% EtOH (v/v)) exposure on comet tail moment of H4IIE cells 76

Figure 23 Effect of indirect JP-8 $(0.1 \% \mathrm{EtOH}(\mathrm{v} / \mathrm{v}))$ exposure on comet tail moment of Hepa1c1c7 cells.................................................. 78

Figure 24 Effect of indirect JP-8 $(0.1 \% \mathrm{EtOH}(\mathrm{v} / \mathrm{v}))$ exposure on comet tail moment of H4IIE cells........................................................... 80

Figure 25 Tail moment measure of $\mathrm{H} 411 \mathrm{E}$ cells exposed to EtOH concentrations

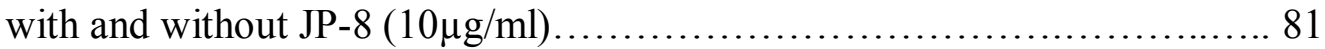

Figure 26 Effect of DNA repair inhibitors on comet formation in H411E cells indirectly exposed to JP-8 $(0.1 \% \mathrm{EtOH}(\mathrm{v} / \mathrm{v}))$

Figure 27 Comet tail moments in H4IIE cells indirectly exposed to JP-8 $(0.1 \%$ EtOH $(\mathrm{v} / \mathrm{v}))$ for $4 \mathrm{~h}$ analyzed by the FLARE assay for oxidative DNA Damage....87

Figure 28 Representative chromatographic pattern obtained from ${ }^{32} \mathrm{P}$-postlabeling analyses of DNA adducts from H411E cells indirectly exposed to JP-8

$(0.1 \% \mathrm{EtOH}(\mathrm{v} / \mathrm{v}))$ and $\mathrm{BaP}$ .89

Figure 29 Oxidative DNA damage schematic. 108 


\section{LIST OF TABLES}

Table I Characteristics of Kerosene Jet Fuels ........................................

Table II JP-8 Additive Components............................................... 10

Table III Average histidine revertant/plate \pm SD Salmonella typhimurium exposed

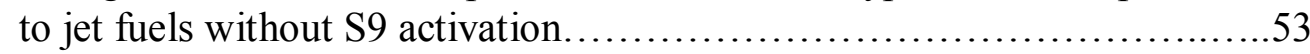

Table IV Average histidine revertant/plate \pm SD Salmonella typhimurium exposed

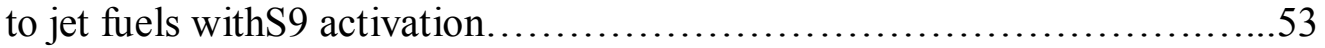

Table $\mathbf{V} \quad$ SCE frequencies and proliferation indices in peripheral lymphocytes

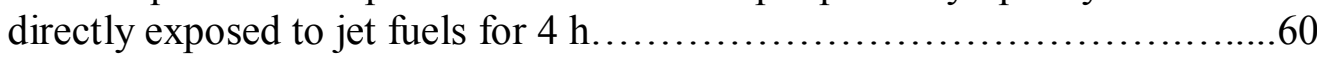

Table VI Analysis of DNA damage measures by comet assay in peripheral

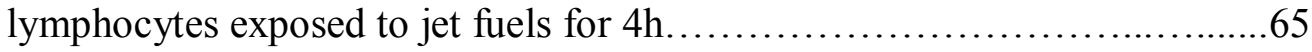

Table VII Analysis of DNA damage measures by comet assay in peripheral

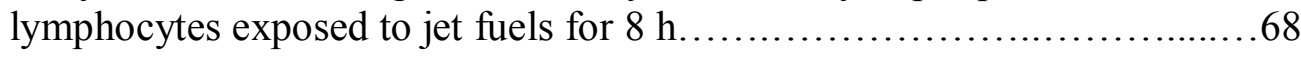

Table VIII Analysis of DNA damage measures by comet assay in H411E cells

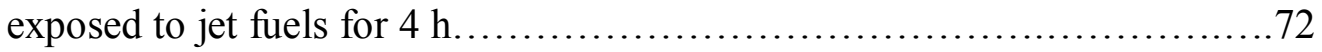

Table IX Analysis of DNA damage measures by comet assay in H411E cells

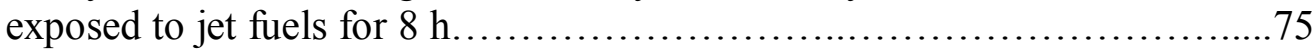

Table $\mathbf{X}$ Mean tail moment measures for H411E cells indirectly exposed to

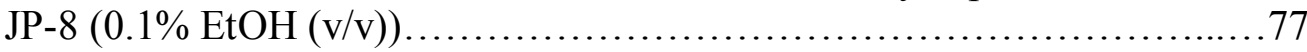

Table XI Mean tail moment measures for Hepa1c1c7 cells indirectly exposed

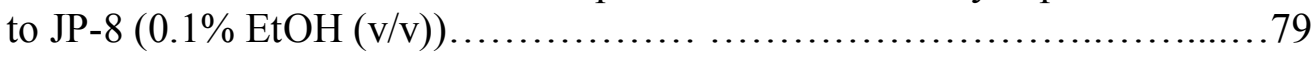

Table XII Mean tail moment measures for V79 cells indirectly exposed to JP-8

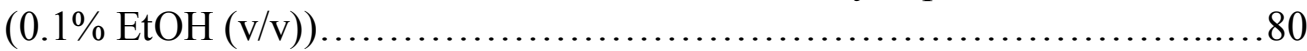

Table XIII Statistical comparisons of tail moment measures for H411E cells exposed to varying concentrations of EtOH and JP-8 ......................82

Table XIV Mean tail moments for H411E cells indirectly exposed to JP-8 (0.1\% $\mathrm{EtOH}(\mathrm{v} / \mathrm{v}))$ in the presence of DNA repair inhibitors.

Table XV Mean tail moment measures for JP-8 indirectly exposed $(0.1 \%$ EtOH $(\mathrm{v} / \mathrm{v})$ ) H4IIE cells analyzed by the FLARE ${ }^{\mathrm{TM}}$ assay for oxidative DNA damage. 


\section{INTRODUCTION}

Military and civilian aviation workers are exposed to a number of chemicals such as petroleum products, jet fuel, jet fuel vapors and aerosols during normal course of duty, operating on the flight line and through service and maintenance of aircraft. These exposures may occur acutely or chronically to raw fuel, vapor, and by dermal, respiratory inhalation, or oral ingestion, routes that commonly occur concurrently with other chemical exposures. Even though several regulatory agencies work to evaluate the effects of fuel exposure and establish safe exposure limits, workers could still be susceptible to deleterious effects since genotoxic effects have not been thoroughly investigated.

The presently used kerosene based military fuels include Jet Propulsion 5 (JP-5), Jet Propulsion 8 (JP-8) and Jet Propulsion 8+100 (JP-8+100), each contains different base components and additives. The composition of jet fuels is similar to that of diesel fuel with petroleum extracts characterized by high flash points which make them relatively safe to transport, store and handle when compared to gasoline. These fuels in general contain complex mixtures of long and short chain aliphatic, aromatic, and substituted naphthalene hydrocarbons. JP-8, in particular, is a complex mixture of more than 200 aliphatic, aromatic, and substituted naphthalene hydrocarbon components. The average aromatic content of the fuel ranges from 14.5-18.8\%, which suggests the potential for genotoxicity. Aromatic hydrocarbons have been associated with various forms of DNA damage such as DNA base adduct formation, DNA crossovers and strand breaks.

JP-5 is the primary Navy military fuel for shipboard service and some land based equipment but is not used as extensively as the JP-8 formulation. JP-8, is the primary fuel for 
military aircraft and is increasingly used in ground vehicles and equipment, making it the largest single chemical exposure in the US military (2.53 billion gallons in 2000). JP- $8+100$ is a revised fuel with increased thermal stability, which contains the additive $(+100)$ with dispersent/detergent, antioxidant and metal deactivation capabilities. The +100 additive provides the opportunity for the commercial use of lower grade fuel with the additive, which would increase fuel exposure levels.

Due to the widespread use of jet propulsion fuels and the increased contact by workers the genotoxic risks of these fuels need to be investigated. Previous investigations resulted in evidence of hepatic, renal, neurologic and pulmonary toxicity in animal models and human occupational exposures. The only genetic toxicology study on JP-8 was performed by the US Air Force (USAF) in 1978, which included the Ames Assay, mouse lymphoma, unscheduled DNA synthesis and dominant lethal assays. Due to rising technological advances and development of new assays there is an increase in the sensitivity of genotoxic analysis, thus warranting a reevaluation of the jet fuel damage.

The exposure of cells to DNA damage inducers triggers a wide range of cellular responses including alteration in gene expression, a delay in cell-cycle progression, activation of programmed cell death and stimulation of DNA repair. Damage to the genetic material of cells represents an initial event in a process that may eventually lead to manifestation of disease. Biomarkers of genetic damage can provide information concerning the critical dose that interacts with critical cellular macromolecules to produce more useful means of estimating and evaluating individual exposure. Investigations of genotoxicity are also important because eventually they will be combined with toxicology data to form an overall quantitative and qualitative evaluation of risk assessment. A comprehensive 
genotoxic investigation could aid in the risk assessment for jet fuel exposure, and perhaps identify possible problematic components of the jet fuel mixtures. Knowledge into the genotoxicity and cytotoxicity of jet fuel and molecular mechanisms responsible for DNA damage will aid in the design of efficient strategies that will prevent this damage from accumulating into mutations.

It is important to recognize the limitations of the genotoxicity assays as well as the advantages, and ultimately, a battery of tests is needed so that the strength of one test can compensate for the inadequacies of another in detecting a specific type of DNA damage. Genotoxins may affect many types of cells, and may cause more than one kind of genetic insult so many assays are needed to measure genotoxicity and detect all relevant genotoxic agents. To understand the full range of genotoxic effects of jet propulsion fuel, an evaluation will span a wide range of biological damage endpoints at the chromosome, DNA structural and at the base pair levels. With the data acquired from the assays performed, an in vitro based risk assessment for exposure to the fuel can be established and potentially constitute the need for further in vivo and human fuel exposure investigations.

Primary lymphocytes serve as an appropriate cellular model for exposure since immune system cells have been was found to be a sensitive biological indication for toxicological exposure to jet fuel. To gain insight into the extent of the JP-8 hepatic metabolic interaction an in vitro rat hepatoma model system H411E cells is additionally utilized. These cells have retained the ability to express and induce many detoxification / activation oxidases and cytochrome P450 dependent oxidases that hepatocytes express normally in vivo. General cytotoxic investigations on JP-8 and deicer additives are performed using the lysosomal acid phosphatase assay (AP) and MTT (3,[4,5- 
dimethylthiazol-2-yl]-2,5-diphenyltetrazolium bromide) assay to determine the single cell type sensitivity to the fuel. The fuels themselves are evaluated with and without metabolic activation using the standard Ames assay. Previous mutagenicity studies on petroleum middle distillates (PMDs) and JP-8have been found to have little or no activity in the Ames assay, a lack tumor initiating activity but are active skin tumor promoters. This study will be re-evaluated, specific for the three primary military jet fuels at higher concentrations not exceeding known toxicity levels. The genetic toxicological effects of military fuels and additives can be deduced in part by examining the damage induced at a chromosome level through detection of sister chromatid exchanges. The single cell gel electrophoresis assay (SCGE, comet assay) will be performed to deduce the extent of DNA damage to individual cells. DNA damage in the form of strand breaks can be visually detected and quantitatively measured in individual cells based on extracellular extrusion of DNA fragments. Additionally, the FLARETM (Fragment Length Analysis Repair Enzyme) assay is employed, which integrates repair enzymes involved in specific pathways into the comet assay, thereby demonstrating the type of DNA damage (i.e. oxidative) present. DNA damage at the base pair level will be evaluated by the detection and quantification of the formation of DNA adducts in exposed cells by the ${ }^{32} \mathrm{P}$-postlabeling method. Through these various mutagenic, cytotoxic and genotoxic investigation the overall genotoxicity of these complex jet fuel mixtures will be assessed. 


\section{REVIEW OF LITERATURE}

\section{Fuel Introduction}

Petroleum middle distillates (PMDs) are the broad classification of fuels, which include kerosene, diesel fuel, home heating oil, and jet fuel with and without additives. The exact composition of PMDs varies but all include linear and branched chain aliphatics, cycloparaffins, and aromatics in the $\mathrm{C}_{10}-\mathrm{C}_{20}$ range. Jet fuels are produced in part from the distillation of crude oil at atmospheric pressure classifying them as straight run middle distillate kerosene cuts (Nessel et al., 1999).

The adverse effects of human exposure to these fuels are of growing concern due to their extensive use throughout the military and the civilian aviation industry. PMDs have been shown to cause chronic irritation and inflammation in animals and humans, but are only slightly irritating to the eyes (Broddle et al., 1996, Upreti et al., 1989, Nessel et al., 1999). Exposures to PMDs have shown altered histology including a compromised hematologic profile, decreased organ weights as well as liver, spleen, thymus, kidney, adrenal, and lymph node lesions in mice (Broddle et al., 1996, Upreti et al., 1989). Rats exposed interperitonealy to petroleum, demonstrated hepatoxicity by an increase in liver alkaline phosphatase and increased microsomal enzyme activity and lipid peroxidation (Rao et al., 1984). Nessel et al., (1999) found that chronic dermal exposure (1yr) to various PMDs produced moderate skin irritation and a significant increase in tumor incidence in mouse. McKee et al., (1994) found PMDs to induce sub-acute inflammation and non-genotoxic tumorigenicity in mice. Certain boiling ranges of middle distillates have been concluded to act as initiators of carcinogenesis under certain exposure conditions (Broddle et al., 1996, McKee et al., 1994, Blackburn et al., 1986). 


\subsection{History of Jet Fuel}

Jet fuel has evolved to its many forms by the blending and distillation of different petroleum derivatives along with the inclusion of specific additives. Fuels are classified according to performance criteria such as flash and boiling point as seen in Table I. Jet fuel was initially introduced in 1944 as JP-1, a kerosene and gasoline mixture with a freeze point of $-61^{\circ} \mathrm{C}$. JP-2, developed in 1945 , had high viscosity and flammability characteristics rendering it unsuitable for use. JP-3, a crude oil distillate, had a sufficient vapor pressure similar to aviation gasoline but proved to be problematic at high altitudes due to tank overpressurization. JP-4 was developed in 1951 and used by the military for the next 43 years (Lemasters et al., 1999a, Bruner et al., 1993) and is presently used in Third World countries. JP-4 is a heavy naphtha-kerosene blend containing 50-60\% gasoline and is refined from either undersea crude oil deposits (petroleum derived JP-4) or shale oil (shale derived JP-4) found in rock (Ritchie et al., 2001). Despite the fuels suitable freezing point at $-77^{\circ} \mathrm{C}$, it has a low flash point (highly flammable), a high vapor pressure (increased evaporation) and large concentration of aromatic hydrocarbons.

JP-5 is the primary Navy military fuel for shipboard service but is also used for land based equipment. This fuel was developed due to fire safety concerns on naval ships and was widely used during the Vietnam War. It features a freeze point of $-51^{\circ} \mathrm{C}$ accompanied by a lower vapor pressure, higher flash point and fewer aromatic hydrocarbons than JP-4. Jet A and Jet A-1 are commercial fuels manufactured from straight run kerosenes and have a high flash point of $38^{\circ} \mathrm{C}$ for safety reasons. However, Jet A and Jet A-1 have freeze points of $40^{\circ} \mathrm{C}$ and $-47^{\circ} \mathrm{C}$ respectively, making them unsuitable for high altitude aviation. 
Supersonic aircraft necessitated the development of stable fuels that would not boil off or freeze during flight. JP-6 was developed specifically for the XB-70 and is similar to JP-5 with a lower freeze point $\left(-54^{\circ} \mathrm{C}\right)$ and improved thermal stability. The low availability of this fuel demanded the creation of JP-7 for the SR-71 with a low vapor pressure and excellent thermal stability to high altitude and Mach $3+$ operations. Virtually all aromatic fractions, sulfur, nitrogen and oxygen impurities were removed from this fuel, but it possessed poor lubricating properties. Additionally, high flying aircraft needed a fuel JP-TS, paraffinic kerosene with an extremely low freezing point and high thermal oxidative stability. While all these different fuels were optimal for the conditions of their use, it became difficult for the military to efficiently function with all the fuel variations. There was a demand for a high freezing point fuel with low flammability that could be used by all branches of the military.

Table I Characteristics of Kerosene and Jet Fuels

\begin{tabular}{|c|c|c|c|c|c|}
\hline Fuel & $\begin{array}{c}\text { Flash } \\
\text { Point }\left({ }^{\circ} \mathbf{C}\right)\end{array}$ & $\begin{array}{c}\text { Vapor } \\
\text { Pressure }\end{array}$ & $\begin{array}{c}\text { Major } \\
\text { Fractions }\end{array}$ & $\begin{array}{c}\text { Percent } \\
\text { Aromatics }\end{array}$ & $\begin{array}{c}\text { Boiling } \\
\text { Point }\left({ }^{\circ} \mathbf{C}\right)\end{array}$ \\
\hline \hline Kerosene & 52 & $1-5$ & $\mathrm{C}_{7}-\mathrm{C}_{16}$ & 3.9 & $151-300$ \\
\hline Jet A & 38 & $0.1-2$ & $\mathrm{C}_{8}-\mathrm{C}_{17}$ & $10-24$ & $149-166$ \\
\hline JP-4 & -34 & $72-380$ & $\mathrm{C}_{4}-\mathrm{C}_{16}$ & 14 & $150-246$ \\
\hline JP-5 & 63 & $0.1-2$ & $\mathrm{C}_{5}-\mathrm{C}_{14}$ & $10-25$ & $176-275$ \\
\hline JP-7 & $60-66$ & $0.1-10$ & $\mathrm{C}_{10}-\mathrm{C}_{17}$ & 2 & $150-275$ \\
\hline JP-8 & 38 & $<5$ & $\mathrm{C}_{6}-\mathrm{C}_{18}$ & $18-25$ & $141-260$ \\
\hline JP-TS & 43.3 & $0.1-10$ & $\mathrm{C}_{12}-\mathrm{C}_{15}$ & $<20$ & $250-300$ \\
\hline
\end{tabular}

*Fuels used in this study

Jet Propulsion $8($ JP-8)

Since its selection in 1972 as the main aircraft fuel for the North Atlantic Treaty Organization (NATO), JP-8 is set to be the fuel most utilized in NATO and US jet aircraft 
well into the $21^{\text {st }}$ century. The attractive properties of JP- 8 are its high freezing point, making it advantageous to high altitude flying aircraft and a low vapor pressure thereby decreasing evaporation (Mattie et al., 1991). JP-8has a lower concentration of aromatic hydrocarbons and a higher flash point $\left(4-20^{\circ} \mathrm{C}\right)$ than the pre-existing fuel JP-4, making it less volatile (i.e. decreases explosions ignited by gunfire, crashes and combustion from natural phenomena such as lightning). JP-8 is slightly more volatile and has a higher concentration of aromatic hydrocarbons than JP-5, however large quantities of JP- 8 can be formulated from existing stocks of Jet A making it readily available. It is projected that all presently used JP-5 will be converted to JP-8 use by 2009 (Ritchie et al., 2002).

The Army has recently converted to the "Single Fuel on the Battlefield" doctrine expanding the utility of JP-8 by supplying the fuel for ground vehicles (i.e. tanks, trucks and jeeps), machinery and equipment previously diesel powered. JP-8 is also used to cool aircraft systems, fuel portable tent heaters, as a herbicide and as a means of desert sand suppression (Palfeman, 1998, England et al., 1999). This extensive use of the fuel provides a convenience for military operations but also increases exposure to military personnel. Additionally, the low vapor pressure of JP-8 reduces the tendency for vapors to clear from exposed personnel, resulting in prolonged surface contact and increasing exposure times and absorption (Pleil, et al., 2000).

Exposure to petroleum and jet fuel products and by-products is one of the many possible scenarios associated with Gulf War syndrome. Relevant symptoms of Gulf War Syndrome include aching joints, headaches, dermatological problems, fatigue, loss of sensory symptoms, loss of balance, neurobehavioral (memory loss) and respiratory manifestations (Proctor et al., 1998, Jamal, 1998, Palfreman, 1998, Marafie et al., 2000). Deployed veterans 
have significantly higher prevalence to cognitive dysfunction, bronchitis and asthma compared to non deployed personnel (Jamal et al., 1998) Jet fuel was used as a thermal spray and burned in un-vented heaters in the Gulf War (Palfreman, 1998). Self reported exposures to oil fire smoke, vehicle exhaust and smoke from tent heaters have been related to veterans experiencing these symptoms (Proctor et al., 1998, Marafie et al., 2000). Additionally, soldiers serving in Kuwait exposed to burning oil fires were evaluated for genotoxic insult (Jacobson-Kram et al., 1993) and found to have highly significant increases in mean SCEs, (McDiarmid et al., 1995) with no evidence of PAH adducts in lymphocytes or human placentas (Marafie et al., 2000).

\subsection{JP-8 Additives}

Investigation of the toxicity of existing and newly developed fuel additives is critically important to human risk assessment for repeated jet fuel exposure. JP-8 is differentiated from Jet A with the addition of a corrosion inhibitor, DC1-4A, an antistatic component, Stadis 450, and an icing inhibitor, diethylene glycol monomethyl ether (diEGME) (Cooper and Mattie, 1996, Riviere et al., 1999) (Table II). Stadis450 and DC1-4A are proprietary compositions, which make it difficult to evaluate them individually or to predict their individual dermal absorption effects (Baynes et al., 2001). DC1-4A is a linoleic acid derivative, which has previously been identified as a skin penetration enhancer for topically applied drugs (Committee on Toxicology, 1996). These additives have been found to be skin irritants and are capable of having synergistic or antagonistic effects on dermal penetration and retention of jet fuel components on the surface of porcine skin flaps (Baynes et al., 2001). 
Table II JP-8 Additive Components

\begin{tabular}{|c|c|c|c|c|}
\hline Additive & $\mathrm{mg} / \mathrm{L}$ & Component & $\begin{array}{l}\text { Percent of } \\
\text { additive }\end{array}$ & $\begin{array}{l}\text { Final } \\
\text { mg/L }\end{array}$ \\
\hline DCI4A $^{1}$ & 20 & $\begin{array}{l}\text { Xylene } \\
\text { Ethylbenzene } \\
\text { Benzene }\end{array}$ & $\begin{array}{l}30 \% \\
5.00 \% \\
0.03 \%\end{array}$ & $\begin{array}{l}6 \\
1 \\
0.005\end{array}$ \\
\hline FSII $^{2}$ & 1.5 & $\begin{array}{l}\text { Diethylene glycol } \\
\text { monomethyl ether }\end{array}$ & $100 \%$ & 1.5 \\
\hline Stadis $450^{3}$ & 2 & $\begin{array}{l}\text { Toluene } \\
\text { Trade Secret 5037-P } \\
\text { Aromatic } 150 \\
\text { Dinonylnaphthylsulfonic } \\
\\
\text { Trade Secret 5457-P } \\
\text { Mixed aromatics C9-C16 } \\
\text { Isopropanol } \\
\text { Naphthalene } \\
\text { Benzene }\end{array}$ & $\begin{array}{l}65 \% \\
20 \% \\
15 \% \\
15 \% \\
\\
10 \% \\
10 \% \\
5 \% \\
2 \% \\
0.06 \%\end{array}$ & $\begin{array}{l}1.3 \\
0.4 \\
0.3 \\
0.3 \\
\\
0.2 \\
0.2 \\
0.1 \\
0.04 \\
0.00118\end{array}$ \\
\hline
\end{tabular}

${ }^{1}$ Corrosion Inhibitor, ${ }^{2}$ Icing Inhibitor, ${ }^{3}$ Static Dissipater

\section{$\underline{\text { Deicers }}$}

Diethylene glycol monomethyl ether $\left(\mathrm{CH}_{3} \mathrm{O}\left(\mathrm{CH}_{2}\right) \mathrm{O}\left(\mathrm{CH}_{2}\right)_{2} \mathrm{OH}\right)$ is the present the antiicing additive in military jet fuels with good solubility properties but highly flammability. The military requirements for deicing additive concentrations are $0.03 \mathrm{vol} \%$ for the Navy and 0.07 vol \% for the Army, USAF and NATO (Mushrush et al., 1999). However, the agent is normally added to the fuel at $0.15 \mathrm{vol} \%$ to insure complete deicing of turbines and to avoid engine failure at high altitude. Exposure to diEGME has demonstrated long-term toxicity effects on the central nervous system, skin, eyes and kidneys (Hardin et al., 1986) in addition to decreased thymus and pituitary gland weights, white and red blood cell counts and hemoglobin concentrations (Yamano et al., 1993). This deicing agent is mildly irritating but is rapidly absorbed by the skin (McDougal et al., 2000). 
The potential deleterious effects of exposure to this deicer increase the demand to develop efficient operational compounds that are less toxic and still exhibit the optimal performance characteristics (Mushrush et al., 1999). George Mushrush and colleagues at George Mason University and Naval Research Laboratories developed three potential deicing biodegradable replacements synthesized from mannose sugars (Figure 1). 2-methyl-[1,3]dioxolane-4-methanol and 2,2-dimethyl-[1,3]-dioxolane-4-methanol break down into glycerol and acetaldehyde and glycerol and acetone respectively. [1,3]-dioxolane-4-methanol breaks down into glycerol and formaldehyde. These compounds exhibit the appropriate deicer properties by achieving the required temperature $-37^{\circ} \mathrm{C}$ and mimic the behavior of diEGME (Mushrush et al., 1999).

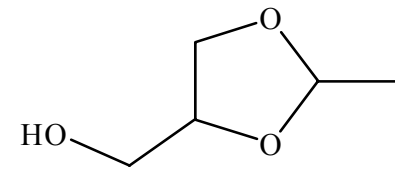

2-methyl-1,3-dioxolane-4-methanol

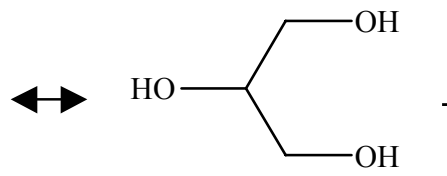

Glycerol

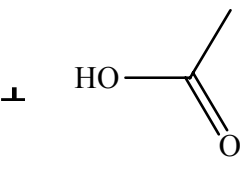

Acetic Acid

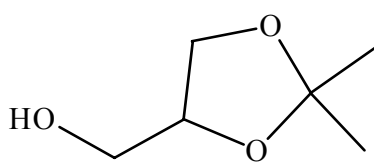

2,2-dimethyl-1,3-dioxolane-4-methanol

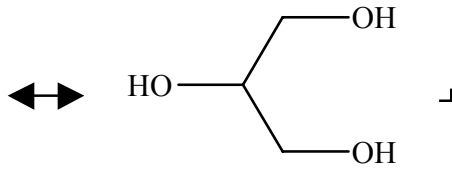

Glycerol

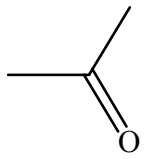

Acetone

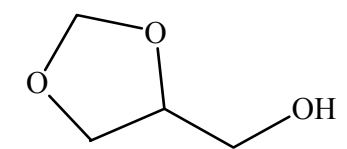

1,3-dioxolane-4-methanol

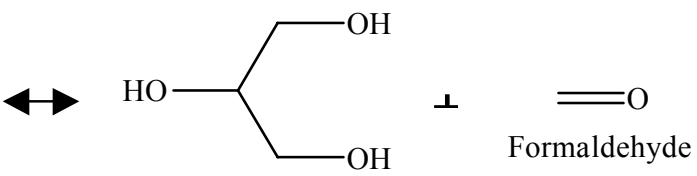

Glycerol

Figure 1 Breakdown products of synthesized deicers as possible alternatives to diEGME 
+100 Additive

The +100 additive results in JP- $8+100$, the next generation of JP- 8 was created to reduce afterburner (reheat) malfunctions that place pilots and their equipment at risk. Failures to ignite result in engine bangs and can cause mechanical difficulties, which is dangerous especially in combat situations. JP-8+100 exhibits increased thermal stability $\left(325^{\circ} \mathrm{C}\right.$ to $\left.425^{\circ} \mathrm{C}\right)$ and an extended heat capacity, due to the addition of the additive $(+100)$. The additive extends the fuel's ability to cool the engine subsystems and increases engine life and performance by cleaning fuel lines. The additive package consists of 25 parts per million (ppm) BHT (antioxidant), 70 ppm 8Q405 (dispersant/ detergent), 3 ppm MDA (metal deactivator) and $158 \mathrm{ppm}$ solvent oil. The dispersant and detergent contains polybutyenyl succinimide which helps prevent carbon/coke deposits from accumulating and clogging fuel systems in aircraft engines, thereby reducing hazardous waste disposal associated with cleaning aircraft parts. BHT (2,6-di-tertiary-butly-4-methyl-phenol) is a synthetic antioxidant that is widely used to stop the formation of gums. The metal deactivator and chelator (N, N'disalicylal-1, 2 propane diamine) prevents trace metals from depositing.

The +100 additive is applied to JP- 8 during the vehicle refueling operation at a dose rate of $256 \mathrm{ppm}(\mathrm{mg} / \mathrm{L})$ (1:4000 dilution) using a hydrant line injector system, which increases exposure to workers to the additive and the fuel. An additional problem with the +100 additive is it permanently disables water separators in vehicle fuel filters resulting in corrosion and seizure of fuel injectors and the proliferation of microbial growth. 


\subsection{Jet Fuel Compositions}

Jet fuel contains varying percentages of saturated hydrocarbons, aliphatic hydrocarbons (straight-chain alkanes (paraffins), branched-chain isoalkanes, isoparaffins, alicyclic hydrocarbons (cycloalkanes, naphthalene and cycloparaffins), unsaturated hydrocarbons (straight -chain alkenes (olefins), branched-chain alkenes), benzenes, polynuclear aromatics (i.e., anthracene) and nonhydrocarbon compound contaminants (sulfur-, nitrogen-, and oxygen-containing compound, organometallics and inorganic salts) (Mattie et al., 1991, Ritchie et al., 2001). Since fuel is performance based not constituent based, the chemical compositions can vary based on fuel type, source of crude oil, refining methods, lot, blending agents, fuel aging and additive performance packages.

JP-8 is comprised of some 228 hydrocarbon components $\left(\mathrm{C}_{6}-\mathrm{C}_{14}\right)$ that distill between $170^{\circ} \mathrm{C}$ and $325^{\circ} \mathrm{C}$ (Riviere et al., 1999, Rossi et al., 2001), $>80 \%$ are aliphatic hydrocarbons $\mathrm{C}_{8}-\mathrm{C}_{16}\left(9 \% \mathrm{C}_{8-9}, 65 \% \mathrm{C}_{10-14}\right.$, and $\left.7 \% \mathrm{C}_{15-17}\right)$, approximately $18 \%$ aromatic hydrocarbons, and $<2 \%$ are additives (Committee on Toxicology, 1996, IARC, 1989, Kannikkannan et al., 2001a, Zeiger and Smith, 1998, McDougal et al., 2000). The amounts of aromatics are limited due to their combustion performance for example when the hydrocarbon concentration increases in JP-5 it begins to gel at cold temperatures. JP-5 consists of $52.8 \%$ cycloalkanes, $30.8 \%$ paraffin, $15.9 \%$ aromatics and $0.5 \%$ olefins (IARC, 1989) and distills between $176^{\circ} \mathrm{C}$ and $204^{\circ} \mathrm{C}$. (Appendix B). The Total Petroleum Working Group characterized symptoms of specific hydrocarbon exposure based in previous in vivo animal investigations. The $\mathrm{C}_{7}-\mathrm{C}_{8}$ aromatic fraction have been associated with nephrotoxcity, the $\mathrm{C}_{8}-\mathrm{C}_{16}$ aliphatic fraction contributes to hypertrophy and hepatic toxicity, and the $\mathrm{C}_{9}-\mathrm{C}_{16}$ 
aromatics demonstrate decrease body weight from exposure (IARC, 1989, reviewed by Ritchie et al., 2001).

Data on breath exposure levels of jet fuel exposed workers found the presence of benzene, toluene, ethyl benzene, nonane, decane and undecane and xylenes (England et al., 1999, Pleil et al., 2000, Lemasters et al., 1999a). Benzene and naphthalene are also contained in substances such as gas vapors, vehicle exhaust and tobacco smoke (Egeghy et al., 2000, Carlton and Smith, 2000). It may take up to two days for these organic compounds to reach their half lives, which elevates the potential damage from repeated exposures to the fuels.

Most environmental benzene exposure comes from the use of petroleum products and exhausts of engines operating on gasoline and is considered to be a possible route of carcinogenic activity in humans (IARC, 1989, Carlton and Smith, 2000). Much of the inhaled benzene is exhaled in the unmodified form or stored temporarily in fat while the rest is rapidly absorbed into the blood and distributed throughout the body (Egeghy et al., 2000). Chronic exposure is associated with blood disorders, such as bone marrow depression, aplastic anemia and leukeamogenicity (Snyder et al., 1996). The occurrence of genotoxic effects, mainly cytogenetic damage, from in vivo and in vitro exposure to benzene and its metabolites is well established (Anderson et al., 1995, 1996, Bukvic et al., 1998, Carere et al., 1995a,b, 1998, Major et al., 1994, Andreoli et al., 1997).

Toluene and the xylenes are the alkyl benzenes found in the highest percentages in military fuels. The acute toxicity of inhaled alkyl benzenes leads to depression of the central nervous system (Ritchie et al., 2001, Committee on Toxicology, 1996). Toluene does not have clastogenic properties and is not considered a carcinogen even though cell mortality increases with exposure. The general consensus on toluene exposure is that it does not induce 
significant cytogenetic or genotoxic effects through in vitro or in vivo investigations (McGregor, 1994). However, in combination with benzene exposure, toluene exposure has been shown to significantly increase the frequency of observed chromosome aberrations (Pitarque et al., 1999b, Bauchinger et al., 1982, Popp et al., 1993).

\subsection{Exposure Scenarios}

The USAF Office of Safety and Health, US Navy Office of Safety and Health and the US Occupational Safety and Health Administration have set the permissible exposure levels (PELs) for these petroleum distillates at $350 \mathrm{mg} / \mathrm{m}^{3}$ for $8 \mathrm{~h}$ exposures and $1000 \mathrm{mg} / \mathrm{m}^{3}$ for short-term exposure to vapors (Committee of Toxicology, 1996). Even though most exposures occur below the PELs, it is possible that additive and synergistic interactions occur compounding the potential deleterious effects of jet fuel. Documented worst-case exposures of fuel personnel can achieve a reported 15,000 $\mathrm{mg} / \mathrm{m}^{3}$ (Carlton and Smith, 2000, Ritchie et al., 2001, Witzmann et al., 1999).

Exposure to fuels can occur acutely or chronically by respiratory inhalation and percutaneous exposure of aerosol, vapor and liquid form. Most exposure to jet fuel occurs in combination with other chemicals and stressors, such as harsh work conditions, which further complicates the exposure scenarios. The USAF community (i.e. office workers) is a low risk group because they are not in direct contact with the fuel but have still been shown to have slight increased breath levels especially of benzene (Pleil et al., 2000, Lemasters et al., 1999a). The jet fuel handlers whose duties include fuel refining, fuel transportation and storage, aircraft fueling, filling field and supply tanks, defueling and draining tanks, aircraft 
maintenance and engine manufacturing are at the greatest risk for both dermal and vapor exposures.

Incomplete combustion of the fuel, which results from engine starts especially at low temperatures, creates the aerosolized form of the jet fuel (Zeiger and Smith 1998). This exposure involves a plume of JP-8 from the turbines passing over the flight line personnel especially the crew chief (15-20ft from the wing) 3-4 times/d. Army troops are vulnerable to aerosol exposure from the generators in the field. JP-8 aerosols are primarily an inhalation hazard affecting the mucus membrane however, the ability for the fuel to penetrate clothing and generate a prolonged dermal exposure of the ground personnel must be considered.

Potential dermal exposure to the liquid form of fuel arises from, pipeline burst, splashing during refueling, contact with engine turbines and parts covered in fuel, contact with sides of fuel tanks during maintenance procedures and from exposure to fuel leaks on the airplane or flight decks (McDougal et al., 2000). A biomonitoring study of Swedish civilian aircraft personnel found low long-term exposure to fuel with peak exposures in the range of $100-1000 \mathrm{mg} / \mathrm{m}^{3}$ in assignments such as dismantling of fuel systems, cleaning of fuel supply tanks and removing engines (Holm et al., 1987).

The aircraft fuel cell maintainers actually enter the aircraft fuselage during maintenance operations and inspections, which involves being doused with approximately a gallon of fuel upon opening the wing tanks. In addition, some fuel tanks contain reticulated polyurethane foam to reduce risk of explosions that may be caused by electrical arcing, lightning strikes, static electricity or from impact. This foam needs to be removed regularly creating a low-medium inhalation exposure and a high dermal exposure even though the workers are equipped with breathing devices and suits. A significantly higher exposure to jet 
fuels was seen in operations involving foamed fuel tanks versus non-foamed (Carlton and Smith, 2000). Due to the static that can occur in engine turbines during maintenance, all protective suits must be made of non conducting cotton, however this increases exposure due to a wicking effect of the material resulting in long-term exposure to the skin during the $8 \mathrm{~h}$ work period.

Ventilation in the wing tanks is a confounding problem as they are closed systems. Some workers choose not to or cannot wear the breathing devices due to space constrictions in the fuel tanks (Witzmann et al., 1999). In addition these respirators are rarely properly monitored or maintained. Additionally a pneumatic vacuum is used when cleaning the tanks, which adds to ventilation problems, creating aerosols and promoting the spread of bacterial growth found in some tanks of larger aircraft. Workshop service personnel mainly work indoors especially when dismantling jet engines, which decreases ventilation adding the vapor effects to the already known dermal exposure.

Jet fuel can then be absorbed into the general circulation at sites of direct contact, such as skin and respiratory system, potentially resulting in systemic toxicity. In the field and on the flight line it is standard procedure to be aware of dermatitis, skin inflammation and inhalation burns. Exposure to the liquid form of the fuel results in an increased dermal exposure, however an occasional accidental ingestion does occur. Another consideration of exposure to personnel is the potential off-gassing and exposure of dependents of the workers. Another nonoccupational exposure concern near fuel manufacturing plants or abandoned military bases is heavily polluted soil and groundwater contamination (Krichevskaya et al., 2001). Water contamination by fuels stored in leaking underground tanks and pipelines has become a serious environmental problem and might be linked to a childhood leukemia 
cluster recently identified in Nevada (Furlow, 2001). This problem is compounded by the release of several million gallons of hydrocarbon fuels, accidentally and through jettison, into the atmosphere, ground, and water supplies on an annual basis (Ritchie et al., 2001).

\subsection{Previous Investigations of Jet Fuel}

Investigation into the health effects of fuel was initiated after the switch from JP-4 to JP-8, when workers complained of nausea, tasting and burping fuel, headaches, fatigue, blocked nasal passages and skin irritation. For example, Porter (1990) reported acute symptomatic effects from two Navy aviators exposed to a severe jet fuel leak to include burning eyes, nausea, impairment of eye and hand coordination, euphoria and laughing, fatigue and memory loss. In recognition of the potential hazard of exposure to the jet fuels, investigations have been conducted to characterize the acute, subchronic and chronic toxicity of fuel in neat, vapor and aerosolized forms. A series of studies have been performed on vapor, aerosol and liquid forms of JP-8 and similar fuels both in vitro using cell lines and in vivo with animal models. These studies encompass renal, hepatic, pulmonary, neurological, developmental, dermal, immunological and genotoxicity (Appendix A). The fuels' chemical complexity and variable routes of exposure most likely explain the broad and variable effects of jet fuel exposure reviewed here. Profound changes have been noted in pulmonary and immune function by a variety of exposure routes.

\subsubsection{USAF JP-8 Acute Exposure Study}

Evaluating total human risk to jet fuels is very involved due to the large number of interacting intrinsic and extrinsic factors that influence the toxic consequences. These factors 
include routes of exposure, forms of fuel (i.e. raw fuel, vapor, aerosol), exposure frequency times, mean concentrations of exposures, solubility/lipophilic/protein charge of absorbed fuel constituents, individual susceptibility (genotype, metabolic mechanisms) chemical and drug exposure history, chemical co-exposures and tobacco use. Recently the Air force Institute for Environment, Safety and Occupational Health Risk Analysis (AFIERA) coordinated a study evaluating the acute effects of JP-8 on the USAF community concentrating on high risk military personnel with aircraft maintenance duties. Previous studies by the AFIERA showed that fuel workers were exposed to high levels of JP-8 (up to $10,295 \mathrm{mg} / \mathrm{m}^{3}$ for tank entrants) and had 100 times greater risk of fuel exposure compared to a non-USAF group. These studies were performed to evaluate the impact of JP-8 on human health and performance and establish potential biomarkers of exposure such as cytoplasmic enzymes, urinary glycol ether metabolites, and glutothione S-transferase (GST) activation. Measurement of JP-8 exposed workers showed higher levels of benzene, naphthalene, naphthaquinones and total JP- 8 in the blood and an increase in total JP-8 on the skin. Once these chemicals are absorbed in the blood, the liver metabolizes the majority and the rest are eliminated in the breath and urine. Evaluation of the urine showed the presence of benzene, naphthalene, 1 and 2hydroxynapthalene, and some naphthalene mercapturic acid and PAH-1hydroxypryene. The highly exposed individuals reported more health symptoms and pain than controls and rated their own health lower.

\subsubsection{General Toxicity, Pathology and Reproductive Studies}

Long-term toxicity testing with JP-8 vapor and aerosol in rats $\left(0-1000 \mathrm{mg} / \mathrm{m}^{3}\right.$ for 90 d) indicated limited toxicity and no tumor formation (Mattie et al., 1991, 1995). Oral dosing 
of rats with JP-8 (0-3000 mg/kg/d) resulted in no mortality, but did result in decreased body weights, nephropathy, increased serum liver enzyme levels, irritation to the squamous epithelium of the stomach (gastritis) and perianal dermatitis (Mattie et al 1995). Additionally, gastric gavage at high doses, resulted in a dose dependent decrease in lymphocyte number and a non-dose dependent increase in nuetrophils and platelets. (Mattie et. al., 1995). Mice dermally exposed to JP-5 (250-500 mg/kg) for 103 weeks resulted in death due to nonneoplastic lesions and incidence of malignant lymphomas (Committee on Toxicology, 1986).

Developmental toxicity study of rats exposed by oral gavage to JP-8 demonstrated no evidence of teratogenic behavior in rat, nor did the ingestion of JP-8 induce fetal malformation (Cooper and Mattie, 1996). In male reproductive studies performed by Mattie et al., (1995) there was a decrease in body weight accompanied by a decrease in urine $\mathrm{pH}$ of rats at the highest does of JP-8 exposure. This result of no maternal, reproductive, or developmental toxicity was confirmed in a dermal hydrodesulfurized kerosene study (Schreiner et al., 1997). A biomonitoring study on jet fuel maintenance personnel also revealed no apparent effect on semen quality from exposure (Lemasters et al., 1999b).

\subsubsection{Inhalation Studies and Pulmonary Effects}

The pathological changes in the lung due to JP-8 plume exposure is typical of that observed in acute exposure to smoke, including an increase in lamilar bodies, alteration of the endoplasmic reticulum and edema produced in the endothelium (Witten, personal communication). Experimental exposure of Fisher 344 rats to a combination of JP-8 aerosol and vapor, resulted in decrease in pulmonary epithelial barrier function, disruption of the 
integrity of the epithelial lining, subendothlial edema, increased dynamic lung compliance and pulmonary resistance, accumulation of inflammatory cells and the appearance of lesions (Pfaff et al., 1995, 1996). This shedding of the epithelium lining enables exposure to extend to nerve fibers and further induce neurotoxic effects. Aerosolized JP-8 exposed mice (200 $\mathrm{mg} / \mathrm{m}^{3} / \mathrm{h}$ for $7 \mathrm{~d}$ ) demonstrated leukocytic infiltration and morphological alterations in the distal lung and symptoms normally found in emphysema (Hays et al., 1995).

Exposures of rat lung to JP-8 aerosol/vapor demonstrated a dose and duration of exposure dependent decrease in pulmonary function (Pfaff et al., 1996). The compromising of the lung barrier and decrease in pulmonary resistance observed is important due to the fact that it leaves the subject more susceptible to allergens and inflammatory reactions. These effects can be ablated by administration of aerosolized neuropeptide substance $\mathrm{P}$, a neuropeptide that aids in tissue protection from noxious agents (Pfaff et al., 1996). This protection at concentrations as low as $1 \mathrm{nM}$ was effective in protecting and ameliorating the immunotoxicity effects of aerosolized JP-8 (Harris et al., 1997c, 2001b) and protecting against previously observed decrease in spleen and thymus weights (Harris et al., 2001).

Results of acute JP-8 aerosolized exposure studies that remained below the PELs (50 $\mathrm{mg} / \mathrm{m}^{3}$ ) in mice showed moderate pulmonary toxicity, characterized by bronchiolar epithelium damage including vacuolization of smooth endoplasmic reticulum, pulmonary alveolar macrophages, degranulation of the nonciliated airway epithelial (Clara) cells (Robledo and Witten, 1998, Robledo et al., 1998, 1999,). These effects lead to increased respiratory permeability, peribronchiolar edema, increases glycosidase activity and cellular necrosis (Robledo et al., 2000). In the lung, the Clara cells develop apises when exposed to fuel, implying that the injury endured is mediated through these cells' metabolic activity 
(Robledo and Witten 1998). A proteonomic study of the lung showed numerous altered enzyme levels including the proteins involved in processing/vesicular machinery (e.g., thio ester S-methytransferase), toxic/ metabolic stress and detoxification systems (e.g., hsc 70, hsc70/hsc90, GST, hsp 84), and post translational modifications were increased with JP-8 exposure (Witzmann et al., 1999).

\subsubsection{Immunotoxicological Effects}

Studies involving respiratory exposure to JP-8 were the first to demonstrate the immune suppression and dysfunction effects of this fuel. Aerosolized JP-8 exposures (100$2500 \mathrm{mg} / \mathrm{m}^{3}$ ) in mice demonstrated suppression of the immune function accompanied by decreased spleen and thymus organ weights, decrease in viable immune cells and changes in lymphocytic subpopulations (Harris et al., 1997a). Significantly these detrimental effects on the immune system occur even at short-term low concentration exposures and persist after exposure has ended, implying severe long-term consequences for immune system functionality (Harris et al., 1997b, 2001a). This immunotoxicity of JP-8 exposure has more recently been confirmed in mice (oral 1000 or $2000 \mathrm{mg} / \mathrm{kg} / \mathrm{d}$ for $7 \mathrm{~d}$ ) as reductions in thymic mass, an increase in liver mass and suppression of antibody responses were observed (Dudley et al., 2001). In experiments performed on mice with a lung melanoma found that tumor growth and metastasis to the liver were increased when given aerosolized JP-8 (Harris, personal communication).

When JP-8 was topically applied, decreased immune organ weight and a decrease in viable immune cells were seen along with an increase in inflammatory response inhibitors. (Ullrich, 1999, Ullrich and Lyons, 2000). Additionally, Ullrich (1999) found that exposure to 
JP-8 (50 $\mu 1 / \mathrm{d}$ for $5 \mathrm{~d}$ or 250-300 $\mu 1$ single exposure) suppressed T-cell blastogenesis and impaired contact hypersensitivity. Global immune suppression has not been observed as there is no known effect on the antibody response to JP-8 exposure, however there is a secondary response on the immune system implying a selective effect on the immune response possibly driven by cytokine production (Ullrich and Lyons, 2000). Long-term exposure to JP-8 could immunocomprimise individuals making them more susceptible to infectious disease from depressed vaccine efficacy, as well as increasing risks of developing and or progressing a malignancy or an autoimmune disorder (Harris et al., 2000, 2001a, Ullrich, personal communication). Since low level aerosol exposure to JP-8 significantly impaired natural killer, helper $\mathrm{T}$ cell and lymphokine activated killer activity in mice it is possible that individuals with this impaired immune function could be at higher risk for infections and an increase in autoimmune disease incidence (Harris et al., 2000).

\subsubsection{Dermatotoxicologic Investigations}

In order to determine the local and systemic effect of jet fuel exposure to the skin, researchers attempted to determine the percutaneous absorption and skin irritation of fuel. Marker components must be used for assessment of absorption of this volatile mixture due to the jet fuels' chemical complexity and the selective barrier properties of the skin. Dermal toxicity studies with rats, rabbits and guinea pigs found skin to be weakly sensitive to JP-8 while the eyes showed no irritation. (Cooper and Mattie, 1996, Kinkead et al., 1992). The murine local lymph node assay confirmed JP-8 as a mild skin sensitizer and showed Jet A and JP-8+100 not to be irritating (Kanikkannan et al., 2000). These results are consistent with histopathological observations of granulocyte infiltration into the skin and separation of the 
basement membrane (Kabbur et al., 2001). JP-8 application resulted in a much more significant skin irritation compared to an application of toluene alone (Kanikkannan et al., 2001a), suggesting many components of the fuel contribute to the skin's sensitivity.

The capacity for the jet fuel hydrocarbon components to traverse the stratum corneum skin barrier have thoroughly been investigated (Riviere et al., 1999, Ulrich et al., 1999, McDougal et al., 2000, Kanikkannan et al., 2001 a,b). Generally the aliphatic hydrocarbons of the fuel were found to be sequestered in the skin epidermis while the aromatic traverse or volatilize. In a non-occluded isolated perfused porcine skin flap (IPPSF) study for $5 \mathrm{~h}$, the rank order absorption for marked components was naphthalene $(1.2 \%)$, dodecane $(0.6 \%)$ and hexadecane (0.2\%) (Riviere et al., 1999). For JP-8+100 the permeation of dodecane was significantly less than that found in JP-8, while the percutaneous absorption of naphthalene was higher.

Studies with JP-8 on excised rat skin cells have demonstrated that the aliphatic components are absorbed by and remain in the skin while the aromatics rapidly penetrate the blood stream based on permeability coefficients (McDougal et al., 2000). The penetration for decane was the highest followed by nonane, undecane, tridecane and dodecane at two orders of magnitude less than the aromatics. Based on this steady state flux of hydrocarbon penetration it can be estimated that 2 human hands absorb $17.1 \mathrm{mg} / \mathrm{h}$ and it takes 22.4 minutes for enough JP-8 to penetrate the human skin to cause deleterious effects (McDougal et al., 2000).

Significant skin absorption of fuel components of JP-8 and JP-8+100 such as tridecane, naphthalene, nonane and toluene was reported using excised pig ear skin and human cadaver skin (Kanikkannan et al., 2001a,b). In JP-8 permeation of tridecane was 
found to be the highest followed by nonane, naphthalene and toluene, while in JP- $8+100$ the tridecane was followed by naphthalene, nonane and toluene. These data coincide with Riviere et al., (1999) and McDougal et al., (2000) in that the absorption profiles and permeability coefficients of aromatics were greater than the aliphatic compounds. Exposure of Yucatan minipigs to JP- 8 and JP-8+100 for $24 \mathrm{~h}$, indicate disruption of the skin barrier function and possible alteration to the skin lipid matrix, which could increase the permeation of other chemicals incident on the skin. When compared overall to JP-8 chemical permeation, the JP-8+100 fuel permeation was significantly lower (Kanikkannan et al., 2000, 2001b).

Keratinocytes are a primary target of JP- 8 because individual jet fuel components cross the skin barrier and become sequestered in the epidermis at varying rates increasing cell exposure (Riviere, et al., 1999, McDougal, et al., 2000, Baynes et al., 2001, Rosenthal, et al., 2001). Normal human epidermal keratinocytes release cytokines in response to dermal exposure to Jet A, JP- 8 and JP- $8+100$ and could act as biomarker of the jet fuel induced inflammation (Allen et al., 2000). This group later demonstrated that specific aliphatic hydrocarbon components (undecane, dodecane, tridecane, and hexadecane) are capable of induction of the cytokine cascade themselves (Allen et al., $2001 \mathrm{a}, \mathrm{b}$ ). This release of proinflammatory cytokines and chemokines potentates chronic inflammation, edema, erythema and cellular damage to the skin, which can contribute to the development and progression of skin diseases (Kabbur et al., 2001). Based on the absorption studies (Riviere et al., 1999, McDougal et al., 2000, Baynes et al., 2001) and proinflammatory cytokine release (Allen et al., 2000, 2001 a,b, Ullrich, et al., 1999) it is apparent that the aliphatic hydrocarbons are directly related to skin irritation of JP-8. 


\subsubsection{Neurological Effects}

The central nervous system has been noted as the primary target of toxicity after acute inhalation of jet fuel through a battery of neurological and psychological tests performed on aircraft maintenance workers highly exposed to JP-8 (Smith et al., 1997). Studies have demonstrated that long-term exposure of workers to jet fuel can result in deficits in central nervous system function, fatigue, nausea, neurasthenia (psychiatric symptoms, anxiety, mood disorders), loss of attention and altered memory function and sensorimotor speed. (Knave et. al., 1976, 1978, 1979, Struwe et al., 1983). No change in cognitive function was observed in chronically exposed rats to JP-8 but it did increase arousal levels and locomotor activity (Baldwin et al., 2001). A subtle effect on neurological function (significant reduction of proprioception functionality) was demonstrated in a posturagraphy study on airport personnel that were exposed to fuel for at least 9 months (Smith et al., 1997). A comparison of low and high exposure subjects suggests a cumulative effect, which could increase risk of degradation of specific neurological functions (Smith et al., 1997).

Repeated exposure of rats to jet fuel vapor $\left(2000 \mathrm{mg} / \mathrm{m}^{3}\right)$ resulted in persisting changes in performance capacity and significant long-term changes in serum and regional brain levels of several neurotransmitters (Nordholm et al., 1999). JP-5 and JP-8 exposure significantly modulated concentrations of some major neurotransmitters and metabolites in rat brains (Rossi et al., 2001). A measure of learning response in JP-8 exposed humans showed hypersensitivity and significant slower responses in learning. These results have lead researchers to believe that the effects of JP-8 exposure are in the lower brain areas, affecting learning and memory and not motivation or motor skills especially at low doses (Ritchie et al., 2001). 


\subsubsection{Hepatic and Renal Effects}

In a biomonitoring study on fuel attendants in Scandinavia, there was induction of microsomal enzyme activity in workers directly in contact with the fuel (Dössing et al., 1985). Mattie et al., (1995) showed no increase in liver weight or pathological changes but found an increase in liver enzyme activity. An increase in mean liver weights was detected in rats exposed to aerosolized JP-8 (500 mg/m³, $1 \mathrm{~h} / 7 \mathrm{~d})$ (Parton et. al. 1993). Conversely, other studies on jet fuel vapor found no significant increase in liver enzyme activity but were concurrent with the finding of no liver pathology (Gaworski et al., 1984, Mattie et al., 1991, Parton et al., 1993). Proteonomic evaluation of liver protein alterations from JP-8 exposure demonstrated a post-transcriptional modification in membrane protein lamin A that could influence continued hepatic insult and generate liver disease (Witzmann et al., 2000b).

The renal effects of exposure to jet fuel include significant changes in kidney weights and development of progressive nephrosis (Mattie, 1991, 1995, Bruner et al., 1993, Kinkead 1995, Gaworski et al., 1984). Proteonomic analysis of kidneys of mice exposed to aerosolized JP-8 demonstrated the first molecular evidence of JP-8 nephrotoxicity from protein expression alterations in protein synthesis and metabolic processes (Witzmann et al., 2000a,b). Specifically, these alterations show a decrease in aminopeptidase abundance, which suggests reduced growth and viability and a possible decrease in glycolytic capacity (Witzmann et al., 2000a).

\subsubsection{Cytotoxicity and Genotoxicity Investigations}

Preliminary in vitro investigations on a number of cell lines exposed to JP-8 showed that the cell types demonstrated differential sensitivity to the fuel both in their ability to 
survive exposure and their electrophysical response (Grant et al., 1999, Stoica et al., 2000, Rosenthal et al., 2000). Rat liver cells exposed to JP-8 in vitro showed a dose dependent cytotoxicity by demonstrating an $\mathrm{IC}_{50}$ of $12.6 \pm 0.4 \mu \mathrm{g} / \mathrm{ml}$ for H4IIEs exposed to JP-8 (at a final EtOH concentration of 0.5\%) over 72h (Grant et al., 1999).

The molecular mechanism responsible for morphological and biochemical changes and JP-8 toxicity were investigated employing numerous in vitro cellular models and the fuel has been shown to interfere at multiple levels with the cellular machinery (Stoica et al., 2001, Rosenthal et al., 2001, Dudley et al., 2001). Dudley et al., (2001) showed the Hepalc1c7 cell line to be a reliable model for investigating JP-8 exposure by demonstrating jet fuel induced changes in cellular architecture and a reduction in total cellular protein and by positively correlating the result with JP-8 effects in vivo. The release of cytochrome c into the cytoplasm due to JP-8 exposure was demonstrated in a rat lung epithelial cell line (Stoica et al., 2001). The onset of the caspase cascade, positive DNA fragmentation and the cleavage of poly (ADP-ribose) polymerase (PARP) suggests apoptosis as the primary mode of cellular death and may be resultant from a form of mitochondrial damage (Stoica et al., 2001). Apoptotic cell death was shown in lung and immune cell lines to be partially responsible for cytotoxic effects of JP- 8 by caspase- 3 activation, PARP cleavage, chromatin condensation, membrane blebbing, cytochrome c release and genomic DNA cleavage (Stoica et al., 2001). Conversely, Rosenthal et al., (2001) found necrosis to be the primary mode of cell death for skin fibroblasts and keratinocytes exposed to EtOH solubolized JP-8 once the cytotoxicity level of $80 \mu \mathrm{g} / \mathrm{ml}$ was exceeded.

A genotoxicity studies on JP-8 which included Ames assay, mouse lymphoma, unscheduled DNA synthesis and dominant lethal assay, showed no significant and concurrent 
evidence for mutagenicity or genetic risk associated with the JP-8 jet fuel (Brusick and Materson, 1978). A moderate increase in unscheduled DNA synthesis in an in vitro cell system WI-38 exposed to JP-8 $(1-5 \mu \mathrm{l} / \mathrm{ml})$ suggests the potential production of nonspecific DNA lesions from the fuel's interaction with the DNA (Brusick and Materson, 1978). This result was not viewed as a clear marker of genotoxicity because the significance was moderate and was not dose related.

Many studies have shown a small but insignificant increase in SCEs in peripheral lymphocytes in aircraft personnel exposed to fuel with no consistent increase in micronuclei (Lemasters et al., 1997, 1999a, Pitarque et al., 1999a, Anderson et al., 1996). In contrast Carere et al., (1995b) found in a cytogenetic survey of gasoline station attendants a borderline but significant increase in SCE formation. Another biomonitoring study on fuel plant workers showed that the group exposed to petroleum emissions had statistically significant increase in the comet assay and in the percentage of aberrant cells (Anderson et al., 1996). An excess of DNA damage in peripheral lymphocytes as measured in a human biomonitoring study has been related to occupational exposure to petroleum fuels (Andreoli et al., 1997). More recent investigations of genotoxicity of jet fuels employing the more sensitive comet assay have shown positive results for genetic damage possibly due to the hydrocarbon content of these fuels (Pitarque et al., 1999). Investigations of peripheral blood samples taken from ground crew and fuel line employees by Pitarque et al., (1999) found subtle changes in DNA damage as detected by the alkaline comet assay, indicating possible genetic aberrations due to exposure in the routine occupational environment. 


\section{SPECIFIC RESEARCH AIMS}

The objective of this study is to determine the magnitude of genotoxic insult to cellular models exposed to jet propulsion fuels particularly JP-8 through the evaluation of mutagenicity, cytotoxicity and measurement of specific biological endpoints of DNA damage.

- Determine if JP-5, JP-8 and JP-8+100 cause mutagenesis by measuring revertants in the Salmonella microsomal mutagenesis assay (Ames Assay) with and without metabolic activation.

- Detect the DNA damage at the chromosome level through the examination sister chromatid exchange frequency in peripheral lymphocytes directly exposed to JP-8, JP-5 and JP-8+100 exposures.

- Detect the DNA damage at the strand break level through the comet assay measures of peripheral lymphocytes and H411E cells directly exposed to JP-5, JP-8, and JP-8+100.

- Determine the role of metabolism and repair from JP-8 indirect exposure through comet measures in H411E, Hepa1c1c7 and V79 cells.

- Characterize the type of DNA damage occurring (i.e. oxidative ) in H411E cells indirectly exposed to JP-8.

- Detect the DNA damage at the base pair level by sensitively detecting DNA adduct formation in H411E cells indirectly exposed to JP-8. 


\section{MATERIALS AND METHODS}

Refer to Appendix A for recipes and a chart of experiments performed detailing exposure types and cells employed. All chemicals were purchased from Sigma Chemical Co., St.

Louis, MO unless otherwise noted.

Fuels: Jet propulsion fuels JP-5, JP-8, and JP-8+100 for direct exposures (lymphocyte and H411E comet studies and SCE studies), were donated by the Mobility Fuels Section Code 6120, Chemistry Division Naval Research Laboratory (NRL) (Washington D.C. 20375). All other experiments used a standard mixture of JP-8 for experimental use obtained from Wright Patterson Airforce Base.

\subsection{Ames Protocol}

The Ames Salmonella / microsome mutagenicity assay (Ames assay) is a short-term bacterial reverse mutation assay developed by Bruce Ames as an initial screen to determine the mutagenic potential of a wide variety of chemicals (Maron and Ames, 1983, Ames et al., 1975, Zeiger et al., 1992). The Ames assay using the plate incorporation method with and without the presence the S9 fraction were performed as described by Ames et al., (1975) and Maron and Ames, (1983) including modifications developed by Blackburn and coworkers $(1984,1986)$ for petroleum mixtures. Strain TA98 was obtained from B. Ames, University of California at Berkley, CA, USA and stored at $-80^{\circ} \mathrm{C}$. The TA98 with his D3052 operon is sensitive to frameshifts with a C-G-C-G-C-G-C-G DNA target sequence and contains the plasmid pKM101 which further enhances chemical mutagenesis (Mortelmans and Zeiger et al., 2000, Ames et al., 1975). To make the bacterial strains more sensitive chemical mutagens, additional genetic alterations exist such as an uvrD deletion to eliminate repair and 
a rfa mutation affecting the liposaccaride layer to make the bacteria more permeable to bulky chemicals (Maron and Ames, 1983). Bacterial strains were purified upon arrival and routinely checked for the presence of known characteristics.

The fuels (JP-8, JP-5, and JP-8+100) were extracted with dimethyl sulfoxide (DMSO) to provide an aqueous compatible subfraction. Each fuel was tested in a preliminary toxic dose range experiment with eight concentrations spaced in half long intervals with the high dose limited by solubility. The test samples were prepared by one $\mathrm{ml}$ of each fuel directly extracted with $5 \mathrm{ml}$ of DMSO. The final dose range for the fuel exposure was chosen to minimize toxicity and optimally estimate mutagenic potency. Each sample was tested on triplicate plates using 5-60 $\mu 1$ of the fuel DMSO extract. Based on the density of the jet fuels $(\sim 0.8 \mathrm{~kg} / \mathrm{L}), 5-60 \mu 1$ represents $\sim 0.8-9.6 \mathrm{mg}$ (McKee et al., 1994).

Over night cultures (12h) were grown from $1.0 \mathrm{ml}$ aliquots of the frozen culture in 15 $\mathrm{ml}$ of Oxiod nutrient broth No. 2 at $37^{\circ} \mathrm{C}$ at $210 \mathrm{rpm}$. The incubation was performed in a culture flask 3 times the volume of the culture medium to ensure adequate aeration and covered with foil due to light sensitivity. A master plate was additionally streaked from the frozen culture and incubated at $37^{\circ} \mathrm{C}$ for $48 \mathrm{~h}$ to create a stock and control for contamination.

In each experiment the test strain was analyzed for its genetic integrity. The histidine dependence was examined by streaking the culture on a minimal agar plate supplemented with biotin. Streaking a minimal agar plate rich in histidine tested biotin deficiency. The presence of the rfa marker is insured on nutrient agar plated with bacteria in the top agar with a sterile filter disc saturated in $10 \mu 1$ of sterile $0.1 \%$ crystal violet solution. After the $48 \mathrm{~h}$ incubation at $37^{\circ} \mathrm{C}$ there should be a zone of growth inhibition surrounding the disk. The uvr B deletion makes the bacteria sensitive to UV light so half a nutrient agar plate streaked with 
the bacteria culture was exposed to UV light for 8 seconds. The presence of plasmid pKM101 was detected by ampicillan resistance on a nutrient/amp plate. The negative controls or the spontaneous reversion plates included DMSO, culture and top agar and were performed in triplicate. A minimal agar plate and a top agar plate were incubated to control for agar contamination. Benzo [a] pyrene $(\mathrm{BaP})$ was used as a positive control at a concentration of $5 \mu \mathrm{g} /$ plate.

The top agar is melted in a boiling water bath and cooled to $45^{\circ} \mathrm{C}$ at which point 10 $\mathrm{ml}$ of histidine biotin solution is added. Initially the assay requires a growth limiting concentration of histidine to support a few rounds (6-8) of DNA replication and permit a few generations of growth for the formation of a background bacterial lawn. Appropriate concentrations of fuels were mixed with $100 \mu \mathrm{l}$ of bacterial suspension and $2 \mathrm{ml}$ of $45^{\circ} \mathrm{C}$ of warm top agar ( $0.6 \%$ agar, $0.5 \% \mathrm{NaCl}, 50 \mu \mathrm{M}$ biotin, $50 \mu \mathrm{M}$ histidine) in a sterile glass tube. The vortexed mixture was plated onto a plate containing $\sim 25 \mathrm{ml}$ minimal agar (1.5\% agar, $4 \%$ Vogel-Bonner medium, $2 \%$ glucose). Care was taken to evenly distribute the top agar mixture throughout the plate. Plates were allowed to incubate inverted for $48 \mathrm{~h}$ at $37^{\circ} \mathrm{C}$. Cytotoxicity on the Ames plates was checked by analysis of the background lawn in a microscope (100X) and by comparison of background colonies. Cytotoxicity was indicated if the number of background colonies on the sample plate was less than that on the spontaneous revertant plate. Only revertants that have mutationally regained the ability to synthesize histidine will grow since initially Salmonella typhimurium are histidine auxotrophs. The revertant colonies were hand counted and the revertant frequency calculated [ (number of mutants per treated plate) - (number of mutants per control plate)/ number of 
viable cells per treated plate]. The sample was deemed to be non-mutagenic if the revertant level at all doses were less than twice the control values.

\section{Pre-incubation Procedure}

An exogenous metabolic activation system, S9 liver microsomal fraction, is often incorporated in the test system to aid in oxidation and metabolism of test compound (Maron and Ames, 1983, Ames et al., 1975). When the S9 homogenate from liver preparations of Aroclor 1254 treated Spague Dawley rats (Moltox Inc., Boone, NC) was included to simulate metabolism an additional preincubation assay was employed (Zeiger et al., 1992) with the S9 fraction concentration at four times the standard amount (Blackburn et al, 1986). In sequential order $70 \mu 1$ of DMSO extract, $400 \mu 1 \mathrm{~S} 9$ mixture (1.2 $\mathrm{ml} \mathrm{S} 9$ fraction, $8 \mathrm{mM} \mathrm{MgCl}_{2}$, $33 \mathrm{mM} \mathrm{KCl}, 5 \mathrm{mM}$ glucose 6-phosphate, 4mM NADP, and $100 \mathrm{mM}$ sodium phosphate (pH7.4) per $\mathrm{ml}$ ), and $0.1 \mathrm{ml}$ S. typhimurium was mixed. The mixture was incubated for 20 min at $37^{\circ} \mathrm{C}$. The procedure of plate pouring, incubation and counting of revertants was the same as previously described.

\subsection{Cell culture Techniques}

All cell culture procedure was performed with sterile equipment and supplies in a sterile laminar flow hood routinely wiped with $70 \%$ ethanol. All cells and exposures were incubated and maintained at $37^{\circ} \mathrm{C}$ in a $5 \% \mathrm{CO}_{2}$ buffered and humidified incubator. Cells were counted in a hemocytometer under a light microscope. 


\section{Lymphocyte Isolation}

Primary human peripheral blood was obtained from healthy, non-smoking donors aged 23-33 years by venipuncture into heparin-containing vacutainers (Becton-Dickinson, Rutherford, NJ). Lymphocytes and monocytes were isolated from whole peripheral blood by layering over a density gradient (Histopaque 1077) and centrifuging at $800 \mathrm{~g}$ for $15 \mathrm{~min}$. The interface layer consisting of mononuclear cells was collected and washed three times in phosphate buffered saline (PBS) (pH 7.4, Invitrogen, Gaithersburg, MD). Cells were resuspended in a tissue culture medium (Karyomax, Invitrogen) at a concentration of $1-1.5 \times 10^{6}$ per ml once viability was assessed by trypan blue exclusion (Section 3.3). After supplementation with the test compound, cell division was stimulated by the addition of phytohemagglutinin (PHA, $0.5 \mathrm{mg} / \mathrm{ml}$; Invitrogen).

\section{Cultured Cell Lines}

Rat hepatoma H411E cells, mouse hepatoma Hepa1c1c7 cells and hamster fibroblast V79 cells were obtained from American Type Culture Collection (Rockville, MD). The rat hepatoma cell line H4IIE developed by Bradlaw and Casterline (1979) from Reuber H-35 hepatoma have retained the ability to express and induce many detoxification / activation enzymes (Yu et al., 1996). The Hepa1c1c7 a derivative of the BW7756 mouse hepatoma that arose in a c57/L mouse and are highly inducible for cytochrome P4501A1 (Dudley et al., 2001). Ford and Yerganian developed the V79 cell line in 1958 from lung tissue of a young male Chinese hamster and are convenient to use for mutagenesis studies since it has a rapid growth rate and low metabolic processes to act as a metabolic negative control. H411E cells and V79 cells were maintained in Dulbecco's Minimum Essential 
Media (DMEM, Invitrogen)(5\% fetal bovine serum (FBS), 1\% Penicillin (Pen)/Streptomycin (Strep), Hepa1c1 cells were maintained in alpha-DMEM (Invitrogen)(5\% FBS, 1\% Pen/Strep).

Routine maintenance of cell cultures included feeding, sub-culturing, freezing and thawing. To feed the adherent cells, the previous waste media was removed by decanting and the appropriate fresh media was added to the flasks. Subculturing of cell lines was normally performed in $25 \mathrm{~cm}^{2}$ flasks however occasionally $75 \mathrm{~cm}^{2}$ and $125 \mathrm{~cm}^{2}$ flasks were used depending on the volume of cells needed. Waste media was removed by decanting and a small volume of trypsin was added to wash flask and remove the remaining media. The adherent cells were overlaid with trypsin and incubated at $37^{\circ} \mathrm{C}$ for $5 \mathrm{~min}$ or until cells have detached from the flask. Media was added to the trypsin cell suspension and total volume was removed and cells pelleted at $1000 \mathrm{rpm}$ for $10 \mathrm{~min}$. The supernatant was decanted and the pellet resuspended in complete medium. A fresh flask was re-seeded with an appropriate dilution of the cell population, supplemented with additional media.

Frozen cell culture stocks were made to maintain the cell line for extended laboratory use. Once confluent, a $75 \mathrm{~cm}^{2}$ flask is trypsinized and the cells resuspended in appropriate media containing 5\% DMSO. Cultures were placed in coded cryogenic tubes and frozen overnight at $-80^{\circ} \mathrm{C}$ and then place in liquid nitrogen. When a fresh passage of cells was needed one frozen culture vial was thawed slowly at room temperature and checked for viability by trypan blue exclusion (Section 3.3 ) and replated into a $75 \mathrm{~cm}^{2}$ culture flasks.

Pretreatment of cells before exposures was required to ensure log phase of growth at time of experimentation. Cells were seeded to tissue culture treated flasks $\left(1 \times 10^{5} / 25 \mathrm{~cm}^{2}\right)$ $4 \mathrm{~d}$ prior to experimentation. This density was chosen as it had previously resulted in cultures 
that were at the required $70-80 \%$ confluence. One day prior to exposure the media was replaced with fresh medium.

\subsection{Cell proliferation assays / Cytotoxicity}

Cell survival is determined in respect to the biological significance of test results, since genotoxicity is only relevant if it occurs in cells capable of surviving the damage. It is critical that the highest dose tested does not induce excessive cytotoxicity and that cytotoxicity is evaluated concurrently within each experiment. For each cell type the linear relationship between cell number and type of signal produced is established thus allowing an accurate quantitation of changes in the rate of cell proliferation.

\section{$\underline{\text { Trypan Blue Exclusion }}$}

The trypan blue exclusion assay allows for visual differentiation under a light microscope between live and dead cells by the permeation of the dye through the cell membrane of the dead cell. An aliquot of the cell suspension was mixed with trypan blue exclusion stain (Invitrogen, $0.2 \%$ in $0.85 \%$ saline) at a $1: 1$ ratio and incubated at room temperature for $3 \mathrm{~min}$. The trypan blue excluding (live) cells were counted in a hemocytometer under a light microscope. Counts were made in two randomly selected quadrants and averaged. Cell viability was calculated as: Cell viability $(\%)=($ Number of viable cells (unstained cells) X 100) / Total number of cells. 
Acid Phosphatase enzyme assay for cell growth

For jet fuel and deicer toxicity testing, H411E, Hepa1c1c7, V79 cells were trypsinized and seeded in 96 well tissue culture plates at a density of $1 \times 10^{3}$ cells/ $100 \mu \mathrm{l} /$ well and allowed to attach to the flasks overnight at $37^{\circ} \mathrm{C}, 5 \% \mathrm{CO}_{2}$. At this concentration the control cell population does not reach confluence by the end of the assay (72h). Cytotoxicity was assessed by the AP assay for determination of cell growth based on quantification of cytosolic acid phosphatase activity. This assay is based on the conversion of $p$-nitrophenyl phosphate (pNPP, $\mathrm{C}_{6} \mathrm{H}_{4} \mathrm{NO}_{6} \mathrm{PNa}_{2} \cdot 6 \mathrm{H}_{2} \mathrm{O}$ ) to $p$-nitrophenol by cytosolic acid phosphatase (Yang et al., 1996). Following exposure to a compound, the media was removed from the 96 well plate and the wells washed with PBS twice. To each well $100 \mu 1$ of $10 \mathrm{mM}$ paranitrophenolphosphate in cytotoxicity buffer $(0.1 \mathrm{M}$ sodium acetate: $0.1 \%$ Triton X-100, $\mathrm{pH}$ 5.5) was added. The plates were then incubated in the dark at $37^{\circ} \mathrm{C}$ for $2 \mathrm{~h}$. The reaction was terminated with the addition of $100 \mu 1$ of $0.5 \mathrm{M} \mathrm{NaOH}$ to each well and microplates were incubated at room temperature for color development. Growth was determined by the absorbence at 410 and 590 on a dual wavelength plate reader (Dynex Technologies Inc., Chantiliy, VA).

\section{MTT Assay}

Primary lymphocytes exposed to various concentrations of JP-8 ( 1 X $10^{5}$ cells $/ \mathrm{ml}$, $>98 \%$ viable) were cultured in $100 \mu 1$ of tissue culture medium (Karyomax) in 96-well flat bottomed tissue culture and incubated for $8 \mathrm{~h}$ for repair. Triplicate wells of cells at approximately $50 \%$ confluency were assayed for cell death using a MTT Cell Proliferation Assay kit (Trevigen Inc., Gaithersburg, MD). The MTT assay functions based upon the 
reduction of the tetrazolium salt 3,[4,5-dimethylthiazol-2-yl]-2,5-diphenyltetrazolium bromide $\left(\mathrm{C}_{18} \mathrm{H}_{16} \mathrm{~N}_{5} \mathrm{SBr}, \mathrm{MTT}\right)$ (Yang et al., 1996) via mitrochondrial enzyme succinate dehydrogenases activity. A total of $10 \mu 1$ of MTT solution was added to each well and mixture incubated for $3 \mathrm{~h}$ at $37^{\circ} \mathrm{C}, 5 \% \mathrm{CO}_{2}$. The formazan crystals were dissolved in a sodium dodecyl sulfate (SDS) based detergent solution and plates were developed without shaking overnight in the dark at room temperature. The color change was measured spectrophotometrically at an absorbence of $590 \mathrm{~nm}$ on the microplate reader.

\section{Cytotoxicity Data}

The average values from triplicate readings were taken for each plate. The concentration resulting in $50 \%$ inhibition of the cell growth $\left(\mathrm{IC}_{50}\right)$ was determined by assigning $100 \%$ to the mean value for the optical density (OD) of the control wells after subtraction of the mean blank value. The OD was determined and expressed as a percentage of that observed in control cells. Results for triplicate plates were averaged and were recorded as percent cell growth as compared to control values. Dose-response curves were obtained by measuring in triplicate the percent of cell survival in the presence of the test compound with respect to control cultures.

\subsection{Cell Exposures}

\section{Direct exposure of fuel}

JP-8, JP-5, and JP-8+100 at diluted concentrations (1:500, 1:300, 1:150, 1:100, and 1:75)

were added directly to media of $\mathrm{H} 411 \mathrm{E}$ cell populations $\left(1 \mathrm{X} 10^{6}\right)$ and isolated primary lymphocytes $\left(3 \times 10^{6}\right)$. Exposures were chosen based on the results of the MTT assay and AP 
assay for cell proliferation. Cell survival was additionally monitored by trypan blue exclusion. Cells were incubated with slow rotation for 4 or $8 \mathrm{~h}$ at $37^{\circ} \mathrm{C}, 5 \% \mathrm{CO}_{2}$. Duration of exposure was chosen to correlate to occupational exposure times. Cells were then washed twice in appropriate media to remove all fuel and replated to undergo repair at $37^{\circ} \mathrm{C}, 5 \% \mathrm{CO}_{2}$ for $8 \mathrm{~h}$ to determine the overall insult of the cell population by the fuels.

\section{Indirect Exposure of fuel}

JP-8 was solubilized in EtOH such that the final EtOH concentration was $0.1 \%$, $0.25 \%$ or $0.5 \%(\mathrm{v} / \mathrm{v})$, which was previously determined to be non-toxic to the cells based of the results of cytotoxic analysis. H411E, Hepa1c1c7 and V79 cells were exposed to solubilized JP-8 in the range of $1-20 \mu \mathrm{g} / \mathrm{ml}$ for $4 \mathrm{~h}$ at $37^{\circ} \mathrm{C}, 5 \% \mathrm{CO}_{2}$.

\section{Repair Exposures}

Cytosine arabinoside (Ara-C), is a potent inhibitor of DNA polymerases associated with DNA repair by reducing the nucleotide pool and inhibiting polymerization by competing with dCTP (Gedik and Collins, 1991, Mirzayans et al., 1993). Hydroxyurea (HU) is a ribonucleotide reductase, which specifically is responsible for the conversion of ribonucleotides to deoxyribonucleotides rendering them useless in the repair process (Martin et al., 1999). HU and Ara-C were dissolved in DMEM and passed through a $0.2 \mu \mathrm{m}$ filter before use. H4IIE cells were exposed to JP-8 $(3,5,10,20 \mu \mathrm{g} / \mathrm{ml})$ and a combination of repair chemicals $2 \mathrm{mM}$ HU: $20 \mu \mathrm{M}$ Ara-C or $4 \mathrm{mM}$ HU: $40 \mu \mathrm{M}$ Ara-C DNA for $4 \mathrm{~h}$ at $37^{\circ} \mathrm{C}$. 


\section{Deicer Exposures}

All deicers were synthesized and provided by Dr. George Mushrush, George Mason University, Fairfax, VA. The cells were exposed to deicers 2,2-dimethyl-1,3-dioxolane-4methanol, 1,3-dioxolane-4-methanol, and 2-methyl-1,3-dioxolane-4-methanol each for 72h at $37^{\circ} \mathrm{C}$ (Figure 1). The percent concentrations range from $0.125 \%$ to $1.25 \%, 0.125 \%$ to $2.5 \%$ and $0.04 \%$ to $1.25 \%$ respectively as determined experimentally.

\section{5 Sister Chromatid Exchange Assay (SCE)}

The SCE technique is advantageous for detection of chemically induced chromosomal damage due to its simplicity, its direct scorable endpoint and sensitivity to genotoxicants (Tucker et al., 1993, Albertini et al., 2000). Peripheral lymphocyte cell suspensions (Section 3.2) (1 X 10 ${ }^{6}$ ) were supplemented directly with JP-5, JP-8 and JP$8+100$ at appropriate dilutions $(1: 3000,1: 1500,1: 750,1: 500,1: 300)$. Exposures are tested at the limits of toxicity indicated by $50 \%$ cell killing, $50 \%$ reduction in the mitotic index, $50 \%$ reduction in the \# of second division cells and 50\% inhibition of growth (Latt et al., 1981, Tucker et al., 1993, Albertini et al., 2000).

\section{Cell Culture, Harvest and Slide Preparation}

Following exposures, lymphocytes were washed three times in RMPI-1649 medium (Invitrogen) supplemented with 5\% FBS, 1\% Pen/Strep and stimulated to grow by the addition PHA in the presence of bromodeoxyuridine (BrdU) $(10 \mu \mathrm{g} / \mathrm{ml})$ in the dark for $72 \mathrm{~h}$ at $37^{\circ} \mathrm{C}$ for two cell cycles. Colcemid (Invitrogen) was present during the final $4 \mathrm{~h}$ to stop cell cycle progression. Cells were harvested by the standard procedure of centrifugation at $1500 \mathrm{x}$ $\mathrm{g}$ for $5 \mathrm{~min}$. Cells were subjected to hypotonic swelling in a $1 \%$ sodium-citrate solution for 
$1 \mathrm{~h}$ at $37^{\circ} \mathrm{C}$ and then centrifuged for $5 \mathrm{~min}$ at $1500 \mathrm{xg}$ and resuspended in a fixative of 1:3 glacial acetic acid: methanol three times. Metaphase spreads were prepared on acid- cleaned glass slides according to standard dropping procedures.

\section{$\underline{\text { Slide Staining }}$}

Standard fluorescence plus Giemsa staining protocol (Perry and Wolff, 1974) with modifications as described by Krishna et al. (1986) was used to stain slides. The slides were immersed in Hoechst $33258(5 \mu \mathrm{g} / \mathrm{ml})$ for 30 min rinsed in Sorenson's buffer (pH 6.8) for 15-20 min at $\sim 56^{\circ} \mathrm{C}$. Slides were exposed in Sorenson's buffer to a black light (360 nm) for $30 \mathrm{~min}$, rinsed and counter-stained with 5\% Giemsa (Invitrogen) in Sorenson's buffer. The slides were rinsed in distilled water, air dried and coded before analysis.

\section{$\underline{\text { Scoring and Data Analysis }}$}

SCE analysis was performed without knowledge of exposed or control status. Only second division metaphases containing 46 centromeres are analyzed based on the differential staining of sister chromatids by the incorporation of the BrdU. SCEs were visualized as harlequin stained chromosomes and scored on a light microscope in 50 cells per sample for independent trials. SCEs data analysis can be facilitated with high capacity and automated analysis employing a robotic metaphase finder to acquire images of spreads and analysis software to help discriminate, classify and count the number of SCEs (Knudson et al., 1998). SCE analysis was enhanced using Loats Associates Inc. (LAI, Westminster, MD) software. This system consists of a microscope equipped with a 16-slide capacity site and motorized x, y-, and z-axis computer controlled positioning with autofocus capabilities. The criteria for a 
scorable metaphase included clearly differentiated sister chromatids. Metaphase spreads were automatically located with a 10X objective lens and images were acquired with a color video camera. Selected metaphase spreads were revisited with a 100X lens and the numbers of SCEs were counted employing digital annotated SCE analysis software. Proliferation of the lymphocytes was evaluated in 100 metaphases, determining the portion of the first (M1), second (M2), and the third (M3) mitotic divisions. In additions to the measures of SCEs the relative frequency (proliferation index (PI)) of first division, second division and subsequent division metaphase cells are recorded to evaluate cell proliferation kinetics (Palma et al., 1993). The PI was calculated according to the formula: $\mathrm{PI}=[(\mathrm{M} 1+2) \mathrm{X}(\mathrm{M} 2+3) \mathrm{X}(\mathrm{M} 3)]$ / 100 (Latt et al. 1981). Categorizations of test agents employing SCE detection include negative, statistically significant increase and doubling of the SCE frequency above the negative control (Tucker, et al., 1993, Albertini et al., 2000). All cytogenetic data were tested for normality and homogeneity of variance prior to analysis to insure no transformation of data was necessary. Linear regression (significance of slope) was used for statistical analysis.

\subsection{Comet Assay}

Reviews of the SCGE assay have been published by McKelvey-Martin et al., 1993, Fairbairn et al., 1995, Tice et al. 1995, 2000, Olive, 1999, Albertini et al., 2000, Anderson et al., 1998, Rojas et al., 1999, Collins et al., 1997, Møller et al., 2000; detailing the methodology, applications, limitations and standardization of the assay. The general principle of the comet assay involves cells suspended in agarose layered onto a microscope slide, which is lysed by detergents and the DNA is allowed to unwind by an alkaline treatment and cells are electrophoresesed to reveal DNA fragmentation by DNA migration towards the 
anode (Figure 2). Essentially the ability of DNA to migrate is a function of size of DNA and correlated to number of strand breaks.

Comet assays were performed employing alkaline unwinding of DNA and neutral electrophoresis following the manufacturer's instructions for rapid detection of DNA damage from the CometAssay ${ }^{\mathrm{TM}}$ kit, (Trevigen). This kit utilizes a proprietary technology to precoat the glass slide, which allows direct application of agarose sample without any additional slide treatment. Hydrogen peroxide treatment was used as the positive control. A mixture of the exposed cell suspensions $\left(1.5 \times 10^{5} / \mathrm{ml}\right)$ and $0.5 \%$ low melting agarose, kept at $42^{\circ} \mathrm{C}$, was applied directly onto an area of the CometSlide ${ }^{\mathrm{TM}}$. The slides were then placed at $4^{\circ} \mathrm{C}$ for at least $10 \mathrm{~min}$ to accelerate gelling of the agarose disc (30 min under humid conditions) followed by careful immersion in a freshly prepared ice cold lysing solution $(2.5 \mathrm{M} \mathrm{NaCl}$, $100 \mathrm{mM}$ EDTA, $10 \mathrm{mM}$ Tris base, 1\% (v/vol) SDS, 0.01\% (vol/vol) Triton® X-100, pH 8) for $30 \mathrm{~min}$ at $4{ }^{\circ} \mathrm{C}$ in the dark (Note: $10 \%$ DMSO is added to the lysing solution for primary lymphocyte cultures). Following lysis, a denaturation step was performed by placing the slides in an alkali buffer ( $300 \mathrm{mM} \mathrm{NaOH}, 1 \mathrm{mM}$ EDTA, $\mathrm{pH}>13)$ for $45 \mathrm{~min}$ at room temperature in the dark to unwind the DNA. Slides were neutralized and washed twice in $1 \mathrm{X}$ Tris $100 \mathrm{mM}$, Borate $90 \mathrm{mM}$, EDTA $1.0 \mathrm{mM} \mathrm{pH} 8.3$ (TBE) buffer for $5 \mathrm{~min}$.

Electrophoresis was conducted at room temperature in a horizontal electrophoresis chamber in $1 \mathrm{X}$ TBE for $10 \mathrm{~min}$ at $28 \mathrm{~V}(20 \mathrm{~mA}, 1 \mathrm{~V} / \mathrm{cm})$. Under alkaline unwinding and neutral electrophoresis conditions $\mathrm{pH}$ 7-8 comet formation is predominantly double strand breaks (dsbs). Slides were fixed after electrophoresis, in ice-cold methanol for 5 min followed by 5 min in ice cold EtOH and then allowed to air dry. The slides were stored at room temperature with desiccant until scored. 


\subsubsection{Oxidative Damage Comet Assay}

The FLARETM assay for oxidative damage, is based on the fact that specific oxidative repair bifunctional DNA glycosylases/AP leases convert oxidized pyrimidine and/or purine bases into strand breaks (Collins et al. 1993), which can be accurately measured through increased DNA fragmentation. The formamidopyrimidine (FPG) protein that removes the 8-hydroxyguanine lesion, the imidazole ring-opened forms of 7 methyguanine including 2,6-diamino-4-hydroxy-5-N-methylformamidopyrimidine (FapyGua) and 4,6-diamino-5-formamidopyrimidine (Fapy-Ade). FPG also catalyzes the repair of 5-hydroxycytosine, 5-hydroxyuracil, aflatoxin-bound imidazole-ring-opened guanine and imidazole ring opened N-2-aminofluorene-C8-guanine. The FPG FLARE ${ }^{\mathrm{TM}}$ adaptation to the comet assay (Trevigen) was incorporated to H411E cells exposed indirectly to 10 and 20 $\mu \mathrm{g} / \mathrm{ml} \mathrm{JP}-8$ in $0.1 \%$ EtOH (Figure 2). The previously described comet procedure was followed except for an additional incubation for $1 \mathrm{~h}$ at $37^{\circ} \mathrm{C}$ with the FPG enzyme and alkaline electrophoresis $\mathrm{pH}>12.1$. Incubation of cells with FPG cuts DNA at the sites where oxidative lesions occur, resulting in fragmentation of the DNA without ligation and increased comet tail moments. It is thought to function by a common reaction mechanism where a nucleophilic attack of the enzyme leads to a Schiff base reaction intermediate that is converted to a stable enzyme-substrate complex by reduction (Collins et al., 1997). Following lysis the slides were washed 3 times for 5 min each in 1 X FLARETM buffer and drained. The aragose was then covered with optimized working dilutions of FPG enzyme $(1: 100$ or $1: 500)$ in reaction buffer and incubated for $30 \mathrm{~min}$ at $37^{\circ} \mathrm{C}$. Alkaline treatment was performed as described above. Electrophoresis of the slides was performed in alkaline 
solution $(\mathrm{NaOH}, 1 \mathrm{mM}$ EDTA, $\mathrm{pH} 12.5)$ at $28 \mathrm{~V}, 18 \mathrm{~mA}$ for $10 \mathrm{~min}$ at $4^{\circ} \mathrm{C}$ to reveal the apurinic/ apyrimidinic sites (AP sites) and single strand breaks (ssbs).

\subsubsection{Comet Analysis}

The comet assay fragments can be visualized by epifluoresence employing a fluorescent DNA intercalating dye usually SYBR Green, which emits green light when excited at $425-500 \mathrm{~nm}$. The amount of DNA at specific location is proportional to fluorescent intensity at that location in the two dimensional planar image. The dried microscope slides were stained with SYBR Green (diluted 1:10000 in $10 \mathrm{mM}$ Tris-HCl, $\mathrm{pH} 7.5,1 \mathrm{mM}$ EDTA, $50 \mu \mathrm{l} / \mathrm{slide})$ and the signal maintained by an antifade $(10 \mathrm{mg} / \mathrm{ml}$ phenylenediamide dihydrochloride in PBS, 90\% glycerol, $\mathrm{pH}$ 8). The DNA damage was visualized with a Leitz Dialux fluorescence microscope equipped with an excitation filter $(515-560 \mathrm{~nm})$ and barrier filter $(590 \mathrm{~nm})$ at $100 \mathrm{X}$ magnification. A Diage cooled gated charge-coupled device (CCD) camera enhances the signal during image acquisition by the computer-based analysis system LAI Automated comet assay. Digital specialized analysis systems acquire images, compute the integrated intensity profile for each cell, estimate the comet cell components (head and tail) and calculates a range of derived parameters after intensities are correction for background illumination. The optimal number of cells for image analysis is no more that a few per visual field to avoid overlapping comets. For each exposure, $\sim 50$ non-overlapping comets per 2 slides were randomly captured, avoiding edges and damaged gel regions.

If the DNA damage effect is cytotoxic, it is artifactual and could confound the interpretation of the comet assay results and interfere with the ability of the comet assay to 
distinguish between genotoxicity and cytotoxicity (Hartmann et al., 2001, Roser et al., 2001, Hartmann and Speit, 1997, Tice al., 2000, Olive, 1999, Olive and Banath, 1995). Appropriate measures, such as defining cytotoxicity limits, must be taken to avoid experimental conditions that would lead to false interpretations of DNA damage not accurately reflecting genotoxicity since cell death processes are induced by the formation of dsbs. To avoid false positives suspected apoptotic cells are excluded from evaluation of genotoxic effects with the comet assay under the principle that these cells represent dead cells.

The degree of DNA damage in the comets can be presented in multiple measures; tail length, moment, moment of inertia, percent DNA and total cellular DNA fragmentation. Tail length is determined by the length of the loops, which initially increases with damage but reaches a maximum that is defined by the electrophoresis conditions (McKelvey-Martin et al., 1993). Once an image is acquired, the DNA content of total comet intensity $\left(\int P_{c}(x) d x=\iint\right.$ $C(x, y) d y d x)$ is calculated and the pixel values represent the mass (Nelms et al., 1997). The intensity integrals for each column of pixel data are weighted by multiplying by their horizontal distance (in pixels) from the center of the comet head. The individual integrals are then summed for the entire tail and the values are normalized to the total comet intensity to give the measurement of tail moment $\left(\int(x-c) \mathrm{P}_{\underline{T}}(x) d x / \int P C(x) d x\right)(N e l m s$ et al., 1997). The concept of tail moment introduced by Olive et al., 1990, expresses damage as the product of DNA in the tail and the mean distance of migration in the tail. This measurement factors in the amount of DNA that migrates into the tail and the distance it migrates. The percentage of migrated DNA in the tail $\left(\int \mathrm{P}_{\underline{\mathrm{T}}}(\mathrm{x}) \mathrm{dx} / \int \mathrm{P}_{\mathrm{C}}(\mathrm{x}) \mathrm{dx}\right)($ Nelms et al., 1997) is the fraction of DNA in the tail as compared to the whole image (Albertini et al., 2000). The parameters of tail moment and percent DNA in tail were used as indicators of the severity of DNA damage. 


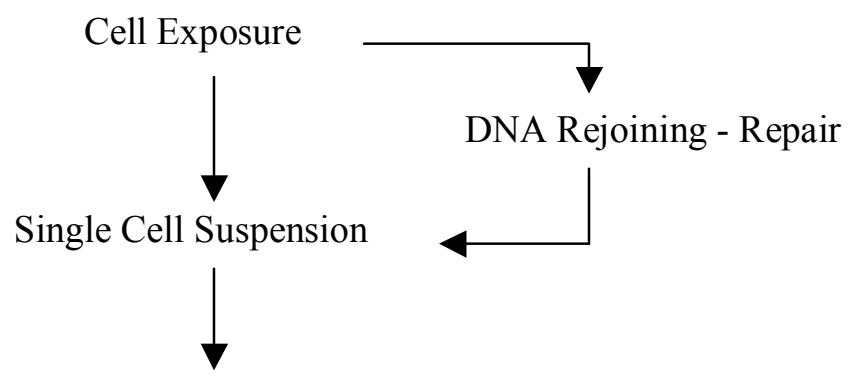

Preparation of Slides

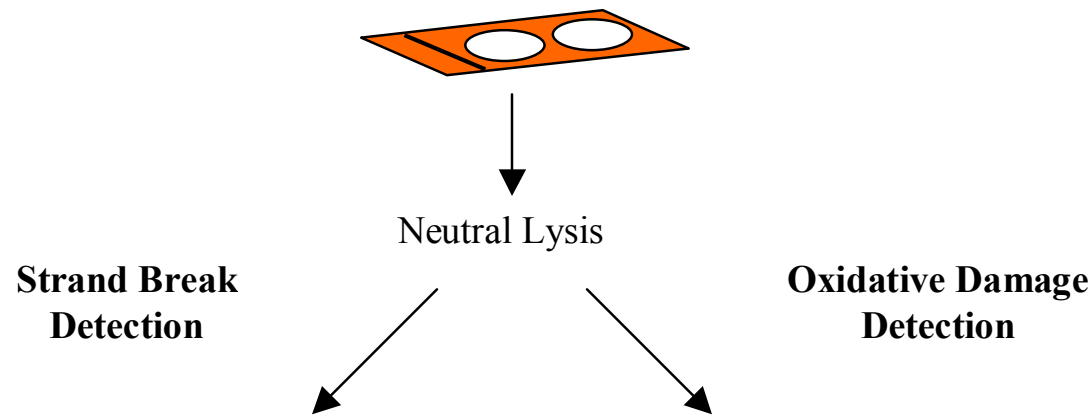

Alkaline Unwinding

Endonuclease Incubation

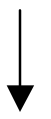

Neutral Wash

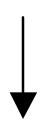

Neutral Electrophoresis

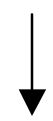

Alkaline Unwinding

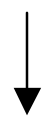

Alkaline Electrophoresis
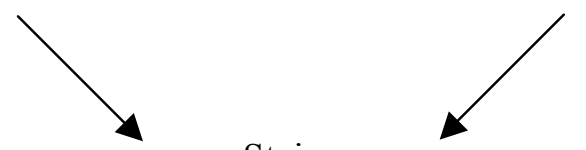

Stain
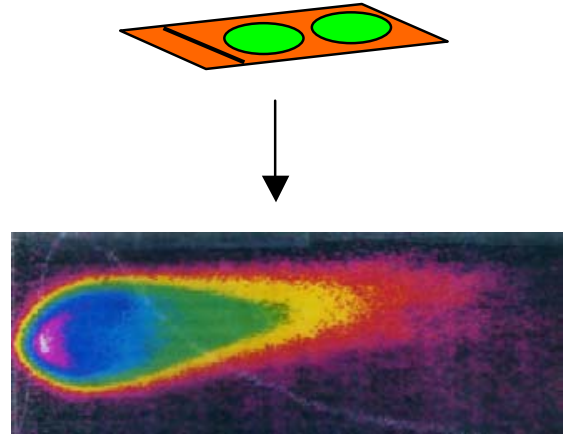

Fluorescent Image Analysis

Figure 2 Schematic of the neutral and oxidative comet assay procedure. 


\section{Statistical analysis of comet data}

The Kruskall-Wallis one-way analysis of variance by ranks was used as a nonparametric test to determine whether the distributions of the various tail parameters differed in exposure groups within a fuel treatment. By ranking the comet data comprehensively and taking the means of ranks, the outliers are included but the analysis is concentrated on the alike measurements. The nonparametric analysis of mean ranks specific to each data set is performed and the significances were evaluated by the Dunn's post test to compare group differences to the expected average difference. All rank analyses were performed using the WinStat statistical package (R. Fitch Software, Cambridge, MA).

\section{7 ${ }^{32}$ P-postlabeling Analysis and Detection of DNA adducts}

${ }^{32} \mathrm{P}$-postlabeling method has the ability to determine within one experiment the prescence of multiple adducts in the DNA sample formed from exposure to a wide range of compounds (Randerath and Randerath, 1994) with sensitivity of 1 adduct in $10^{9}-10^{10}$ bases (Beach and Gupta 1992). A significant advantage of ${ }^{32} \mathrm{P}$-postlabeling over other methods for determining of DNA damage is that this method is capable of detecting and quantiating DNA modifications of unknown structure, i.e. prior characterization of the adducts is not a prerequisite to its detection in biological samples. In this study, H411E cells were exposed indirectly to $10 \mu \mathrm{g} / \mathrm{ml}$ of JP- 8 for $4 \mathrm{~h}$ and for the positive control, H411E cells were exposed to $50 \mu \mathrm{M} \mathrm{BaP}$ at $37^{\circ} \mathrm{C}$ for $12 \mathrm{~h}$. DNA extraction was performed according to the DNAzol ${ }^{\mathrm{TM}}$ procedure (Invitrogen). Desired concentration of DNA $(1.6 \mu \mathrm{g} / \mu \mathrm{l})$ was achieved by precipitating with $10 \% 3 \mathrm{M}$ sodium acetate and EtOH followed by centrifugation for $10 \mathrm{~min}$ at 10,000 rpm. DNA was dissolved in TE buffer overnight at $37^{\circ} \mathrm{C}$. 
In this method, developed by Reddy and Randerath, (1986), $25 \mu \mathrm{g}$ of jet fuel modified DNA was enzymatically hydrolyzed to the corresponding deoxyribonucleoside 3' monophosphates (dNps $+\mathrm{dXps})$ by a mixture of micrococcal nuclease $(1 \mu \mathrm{g} / \mu \mathrm{l})$ and spleen phosphodiesterase $(2 \mu \mathrm{g} / \mu \mathrm{l})$ in buffer $(20 \mathrm{mM}$ sodium succinate, $10 \mathrm{mM}$ calcium chloride, pH6) at $37^{\circ} \mathrm{C}$ for $3 \mathrm{~h}$ (Figure 3). Nuclease P1 enhanced for xenobiotic-modified mononucleotides was performed $1 \mathrm{M}$ sodium acetate, $1 \mathrm{mM}$ zinc chloride with $8 \mu \mathrm{g}$ of nuclease $\mathrm{P} 1$ in a final volume of $17 \mu 1$ (Gupta and Early, 1988). Nuclease $\mathrm{P}_{1}$ enrichment is perferrable for detection of bulky compounds other than butanol extaction because many bulky adducts are resistant to dephosphorylation (Reddy and Randerath, 1986, Gupta and Early, 1988). After mixture was incubated at $37^{\circ} \mathrm{C}$ for $45 \mathrm{~min}, 3 \mu \mathrm{l}$ of 0.5 Tris base was added to each sample. This procedure forms nucleosides by dephosphorylating the 3 ' end of nucleotides, thereby leaving only adducts with a substrate for the subsequent kinase step. Adducts were labeled at the 5 'position with $\left[\gamma^{32} \mathrm{P}\right]$ adenosine 5 '-triphosphate (ATP), tetra (triethylammonium) salt (3000 Ci/mmol, $1 \mathrm{mCi} / 100 \mu \mathrm{l}$; New England Nuclear, Boston, MA) in the presence of T4 polynucleotide kinase (Invitrogen) in a labeling buffer, $(0.1 \mathrm{M}$ bicine, 0.1 $\mathrm{M} \mathrm{MgCl}_{2}, 0.1 \mathrm{M}$ dithiothreitol, $10 \mathrm{mM}$ spermidine, $\mathrm{pH} 9.0$ ).

The ${ }^{32} \mathrm{P}$-labeled aliquots $(8 \mu \mathrm{l})$ of adducted nucleotide bisphosphates were loaded on 20 X 20-cm polyethyleneimine (PEI) cellulose thin layer chromatography (TLC) plates (J.T. Baker, Phillipsburg, NJ) and developed in three directional TLC system (Figure 3). A 5-cmlong Whatman chrome filter paper was attached by stapling. This wick serves to collect residual labeled normal nucleotides and radioactive contaminants during chromatography. The plates were first developed overnight in the $\mathrm{D} 1$ direction with $1 \mathrm{M}$ sodium phosphate, $\mathrm{pH}$ 6.0. After D1, the wick, which contains $>98 \%$ of the input radioactivity is excised and 
discarded properly. The plate was washed twice in water (about $10 \mathrm{~min}$ each time) and dried thoroughly before being developed in the D2 direction in 3.5 M lithium formate, $8.5 \mathrm{M}$ urea, $\mathrm{pH}$ 3.5. After repeat washing and drying, the plate was cut in two at the mid point and developed in the D3 direction in 1.6 M lithium chloride, 0.5 M Tris- $\mathrm{HCl}, 8.5 \mathrm{M}$ urea, $\mathrm{pH} 8.0$ overnight. The dried chromatograms were wrapped in plastic and transferred into cassettes and the presence of radiolabeled adducts on the chromatograms was detected by phoshoimaging (Molecular Dynamics, Sunnyvale, CA).

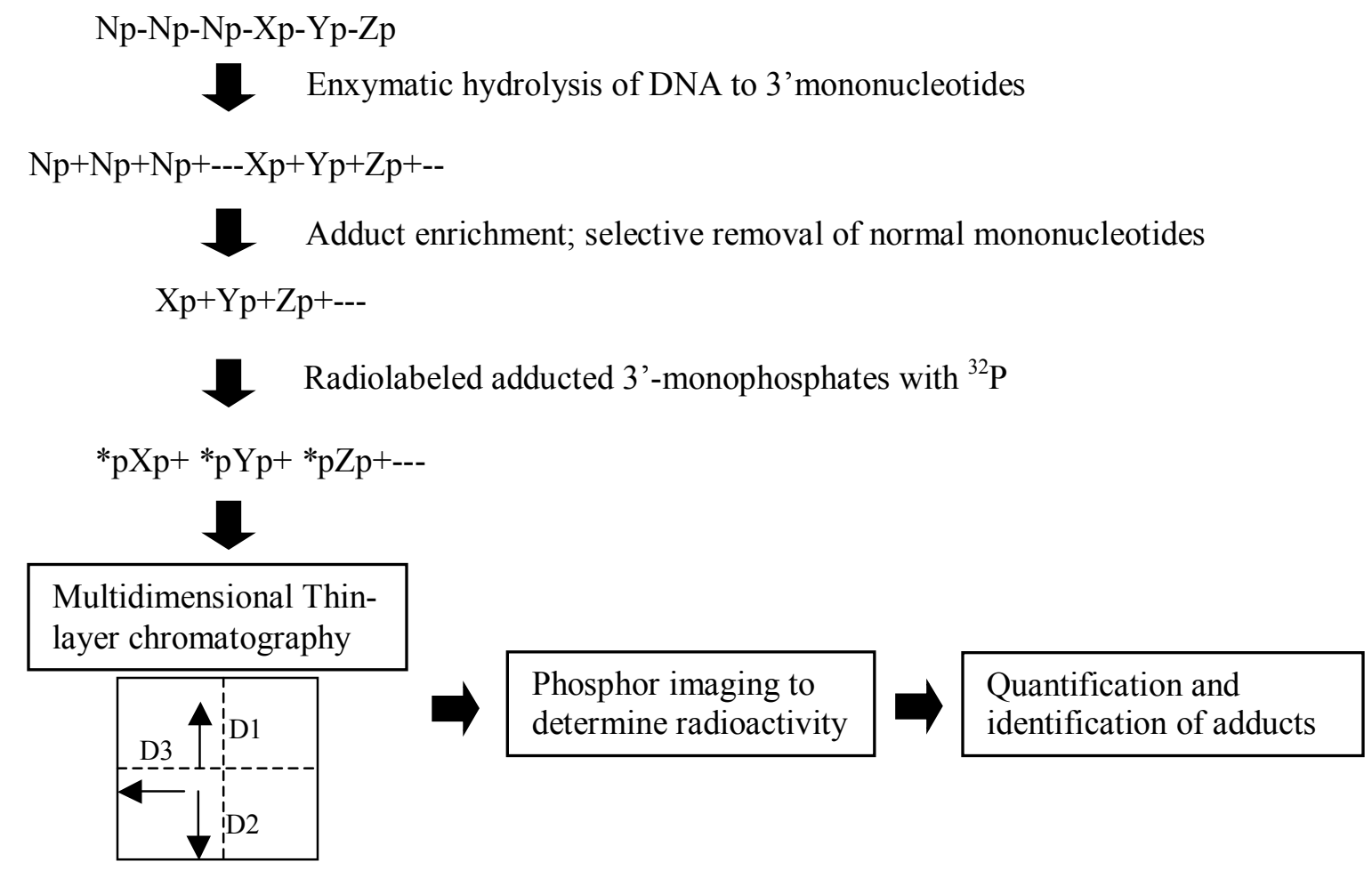

Figure 3 Schematic of the ${ }^{32} \mathrm{P}$-postlabeling technique. Modified DNA was digested with micrococcal endonuclease and spleen phosphodiesterase, which were further extracted with nuclease $\mathrm{P}_{1}$. These were labeled with $\gamma-{ }^{32} \mathrm{P}-\mathrm{ATP}$ via T4 polynucleotide kinase catalysis. The diphosphates were separated on a three directional (D1-D3) PEI -cellulose TLC. Figure adapted from Nath et al., 1996, Phillips, 1997. 


\section{RESULTS}

\subsection{Ames Results}

Studies on controls to confirm the genetic integrity of the bacteria demonstrated that the strain TA98 was intact and capable of functioning appropriately. On the crystal violet controls, to confirm the presence of the $r f a$ mutation, confluent growth was apparent on the plates, except for a clear zone of no growth around filter paper. The requirement for histidine to grow was shown to still be necessary by the fact that no colonies grew on the histidine deficient plates. The $u v r B$ deletion was still present because colony growth was only found on unirradated side. Ampicillian plates provided a sufficient environment for growth of single colonies, which confirms that the R-factor plasmid is still present in the bacterial genome. Insuring no growth on untreated plates controlled against agar plate contamination. These controls were performed in concert with every bacterial reversion test. The healthiness of the background lawn was examined under the microscope for each plate to insure the initial presence of histidine in the culture and that concentrations tested were not toxic to the bacteria.

In the Ames test, the jet fuels (JP-5, JP-8, JP-8+100) were not mutagenic towards the TA 98 strain at the concentrations tested, as is demonstrated by the lack of a dose related increase in the number of revertant colonies. The values of average histidine revertants per plate from three experiments for the three fuels without and with S9 activation are presented in Tables III and IV, respectively. None of the revertant colony counts for the three fuels examined doubled the DMSO control, which was required for a positive result. The Ames test performed with the S9 activation resulted in an increased number of colonies as compared to the test without metabolic activation but this result was still not significant. 
When concentrations higher than presented here were tested they proved to be toxic to the strain by decreasing colony and the background lawn growth (Data not shown). When concentrations lower than presented here were tested they also showed a non-mutagenic response (data not shown).

Table III Average histidine revertants/plate \pm standard deviation for Salmonella typhimurium exposed to jet fuels without $\mathrm{S} 9$ activation $(\mathrm{n}=3)$

\begin{tabular}{|c|c|c|c|}
\hline Exposure & JP-8 & JP-5 & JP-8 +100 \\
\hline Sodium Azide & $203 \pm 28$ & $217 \pm 18$ & $191 \pm 20$ \\
\hline DMSO Control & $61 \pm 22$ & $61 \pm 27$ & $67 \pm 14$ \\
\hline $5 \mu 1$ & $89 \pm 11$ & $100 \pm 10$ & $98 \pm 20$ \\
\hline $10 \mu 1$ & $86 \pm 24$ & $80 \pm 11$ & $97 \pm 15$ \\
\hline $15 \mu 1$ & $68 \pm 22$ & $78 \pm 7$ & $60 \pm 11$ \\
\hline $20 \mu 1$ & $73 \pm 9$ & $84 \pm 13$ & $72 \pm 13$ \\
\hline $30 \mu 1$ & $67 \pm 10$ & $77 \pm 14$ & $50 \pm 21$ \\
\hline $40 \mu 1$ & $80 \pm 13$ & $76 \pm 19$ & $67 \pm 16$ \\
\hline $50 \mu 1$ & $52 \pm 15$ & $68 \pm 13$ & $59 \pm 26$ \\
\hline
\end{tabular}

Table IV Average histidine revertants/plate \pm standard deviation for Salmonella typhimurium exposed to jet fuels with $\mathrm{S} 9$ activation $(\mathrm{n}=3)$

\begin{tabular}{|c|c|c|c|}
\hline Exposure & JP-8 & JP-5 & JP-8 +100 \\
\hline \hline Sodium Azide & $213 \pm 32$ & $246 \pm 20$ & $258 \pm 17$ \\
\hline DMSO Control & $83 \pm 22$ & $93 \pm 14$ & $87 \pm 10$ \\
\hline $5 \mu 1$ & $139 \pm 16$ & $100 \pm 37$ & $116 \pm 8$ \\
\hline $10 \mu 1$ & $103 \pm 12$ & $140 \pm 18$ & $134 \pm 35$ \\
\hline $15 \mu 1$ & $156 \pm 15$ & $72 \pm 35$ & $126 \pm 25$ \\
\hline $20 \mu 1$ & $110 \pm 33$ & $76 \pm 16$ & $86 \pm 19$ \\
\hline $30 \mu 1$ & $146 \pm 19$ & $97 \pm 16$ & $109 \pm 21$ \\
\hline $40 \mu 1$ & $80 \pm 18$ & $107 \pm 17$ & $117 \pm 14$ \\
\hline $50 \mu 1$ & $82 \pm 9$ & $98 \pm 23$ & $79 \pm 11$ \\
\hline
\end{tabular}


The positive control sodium azide $(1.5 \mu \mathrm{g})$ yielded revertants for JP-8, JP-5, and JP$8+100$ at $203 \pm 28,217 \pm 18$ and $191 \pm 20$, respectively without S9 activation (Table III) and $213 \pm 32,246 \pm 20$, and $258 \pm 17$, respectively with S9 activation (Table IV). These values are consistent with the expected revertant rate for sodium azide and show a 3.3, 3.6 and 2.9 fold increase for JP-8, JP-5, and JP-8+100, respectively without S9 activation. The fold increases with S9 activation did not increase for the JP-8, JP-5, and JP-8+100 at 2.6, 2.6, 3.0, respectively, which is expected since sodium azide does not require metabolic activity to produce its mutagenic effect.

\subsection{Cytotoxicity of Cell Lines Exposed to JP-8}

The cytotoxicity of the directly exposed lymphocytes to JP-8 was evaluated by MTT assay over 24 and $72 \mathrm{~h}$ exposure times to determine the $\mathrm{IC}_{50}$ for each cell type. The cytotoxicity curves from these experiments are shown in Figure 4 with A depicting the percent survival after a $24 \mathrm{~h}$ exposure and B following a $72 \mathrm{~h}$ exposure. The $\mathrm{IC}_{50}$ for 24 and $72 \mathrm{~h}$ exposure were determined to be at the 1:100 and 1:275 dilution of JP-8, respectively. The cytotoxicity results for the JP-5 and JP-8+100 showed the same $\mathrm{IC}_{50}$ range (Data not shown). The following experimentations employing lymphocytes exposed to jet fuel were performed under these limits.

Cytotoxicity was determined by the acid phosphatase assay for the cell lines (H411E, Hepa1c1c7, and V79) employed in this study. An earlier study, established an $\mathrm{IC}_{50}$ of $12.6 \pm$ $0.4 \mu \mathrm{g} / \mathrm{ml}$ for H4IIEs exposed to JP-8 (at a final EtOH concentration of $0.5 \%$ ) over $72 \mathrm{~h}$ (Grant et al., 1999), so this cytotoxicity experiment was not repeated. 
A.

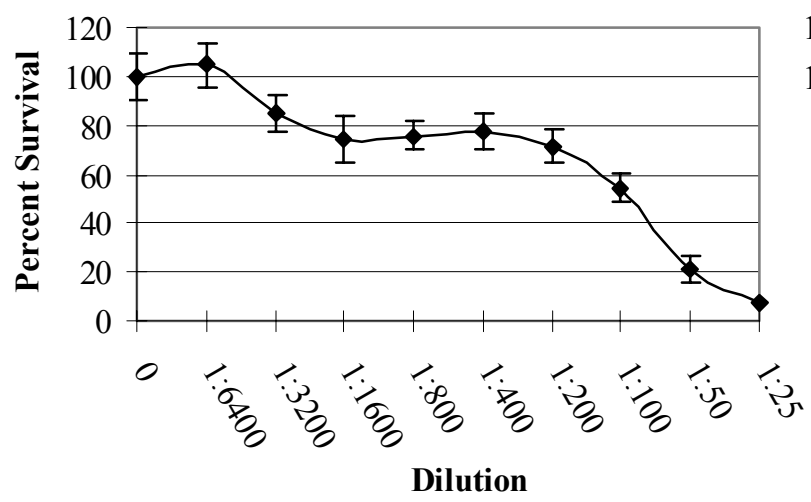

B.

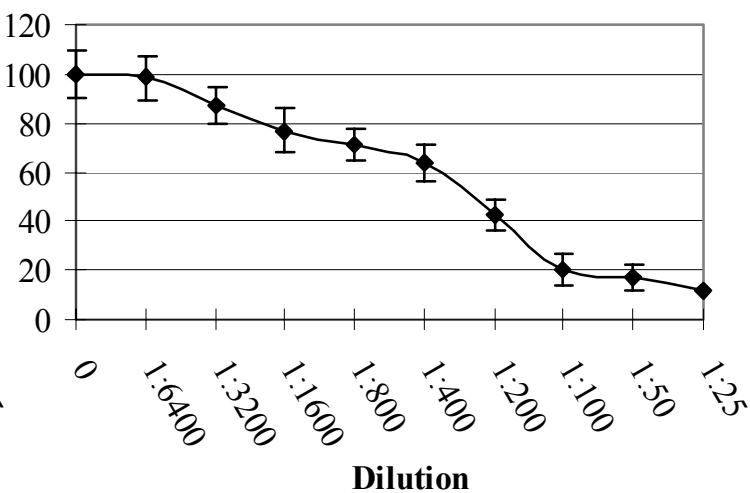

Figure 4 Cytotoxicity curves for peripheral lymphocytes directly exposed to JP-8. A. 24h exposure to JP-8 B. $72 \mathrm{~h}$ exposure to JP-8.

In contrast to the results obtained in the previous studies with JP-8 dissolved in $0.5 \% \mathrm{EtOH}$, no cytotoxicity as determined by AP assay was observed at $0.1 \% \mathrm{EtOH}$ final concentration for this JP-8 concentration range (results not shown). Investigations of the cytotoxicity ranges for the Hepa1c1c7 cell line exposed to JP-8 (at a final EtOH concentration of $0.5 \%$ ) over $72 \mathrm{~h}$ revealed relatively the same $\mathrm{IC}_{50}$ values as the $\mathrm{H} 411 \mathrm{E}$ cell line (data not shown). Upon investigations of the cytotoxicity ranges for the V79 cell line exposed to JP-8 (at a final EtOH concentration of $0.5 \%$ and $0.1 \%$ ) over $72 \mathrm{~h}$ revealed dramatically different $50 \%$ cell death values (Figure 5). The $\mathrm{IC}_{50}$ for the V79 cells exposed to JP-8 solubolized in EtOH at a final concentration of $0.5 \%$ were calculated at $115.1 \pm 2.3 \mu \mathrm{g} / \mathrm{ml}$. The $0.1 \%$ EtOH showed no cell death over the concentrations evaluated as was seen in the H411E and Hepalclc7 cell lines. 


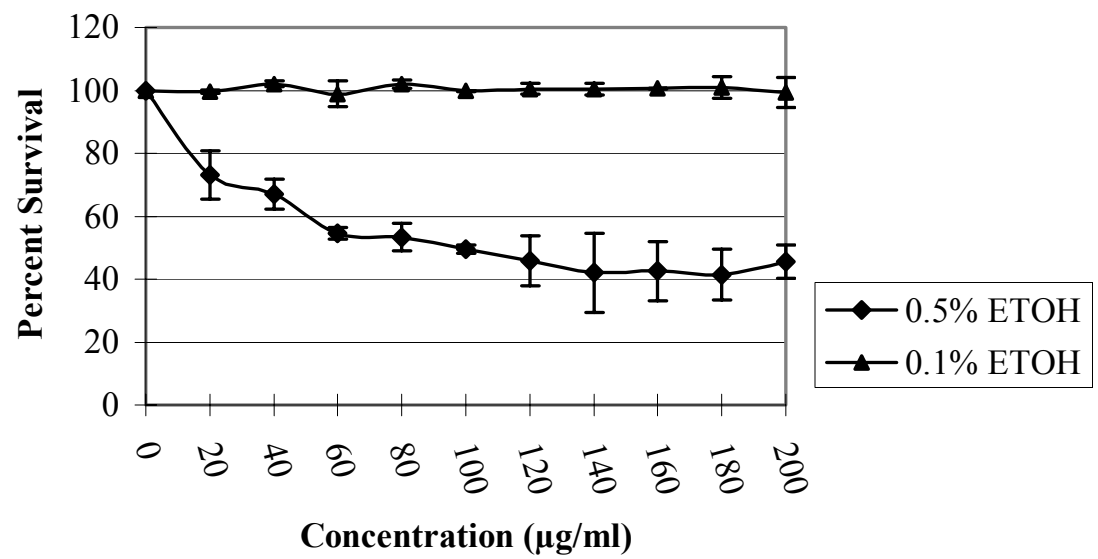

Figure 5 Cytotoxicity curves for V79 cells indirectly exposed to JP-8 (final EtOH concentration of $0.5 \%$ and $0.1 \%$ )

\subsection{Cytotoxicity Analysis of Deicer Alternatives}

The H411E, Hepa1c1c7 and V79 cell lines were dosed the test deicers (2,2-dimethyl[1,3]dioxolan-4-yl)-methanol, [1,3]dioxolan-4-yl-methanol, (2-methyl-[1,3]dioxolan-4-yl)methanol (Deicer 1,2 and 3, respectively) in concentrations ranging from $0.125 \%-2 \%$ in respective media. Figure 6 displays the cytotoxicity curves for the three cell lines, (A) H411E, (B) Hepa1c1c7 and (C) V79. The H411E cells demonstrated the greatest differential of the cell survival for the three deicers (Deicer 1, 2 and 3) with $\mathrm{IC}_{50}$ values at $0.88 \%$, $0.18 \%$ and $0.41 \%$, respectively.

The same toxicity effect was seen in the Hepa1c1c7 cells with Deicer 2 being the most toxic $\left(\mathrm{IC}_{50}=0.38 \%\right)$ followed by Deicer $3\left(\mathrm{IC}_{50}=0.47 \%\right)$ and then Deicer $1\left(\mathrm{IC}_{50}=\right.$ 0.59\%). The V79 cells showed a different response from the hepatic cell lines in that Deicer 3 was the most toxic with an $\mathrm{IC}_{50}$ of $0.17 \%$ and Deicer 1 and 2 had $\mathrm{IC}_{50}$ values of $0.83 \%$. 


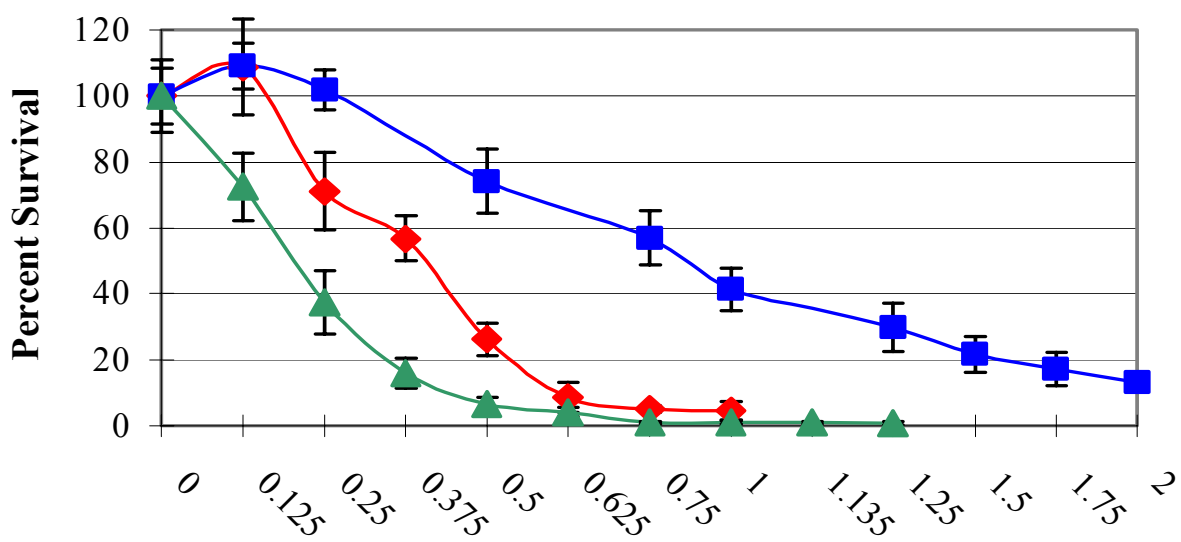

A

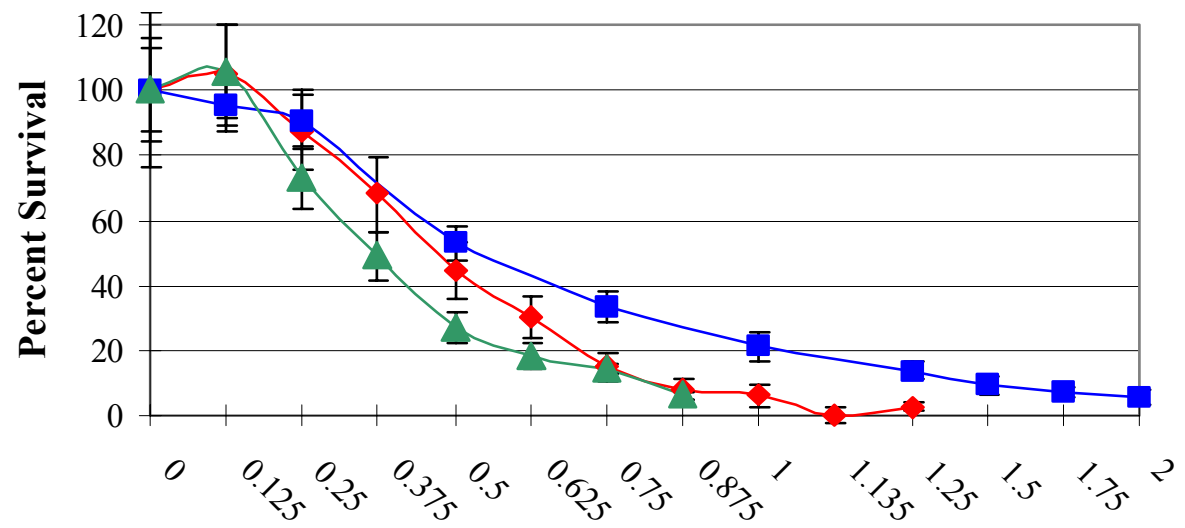

B

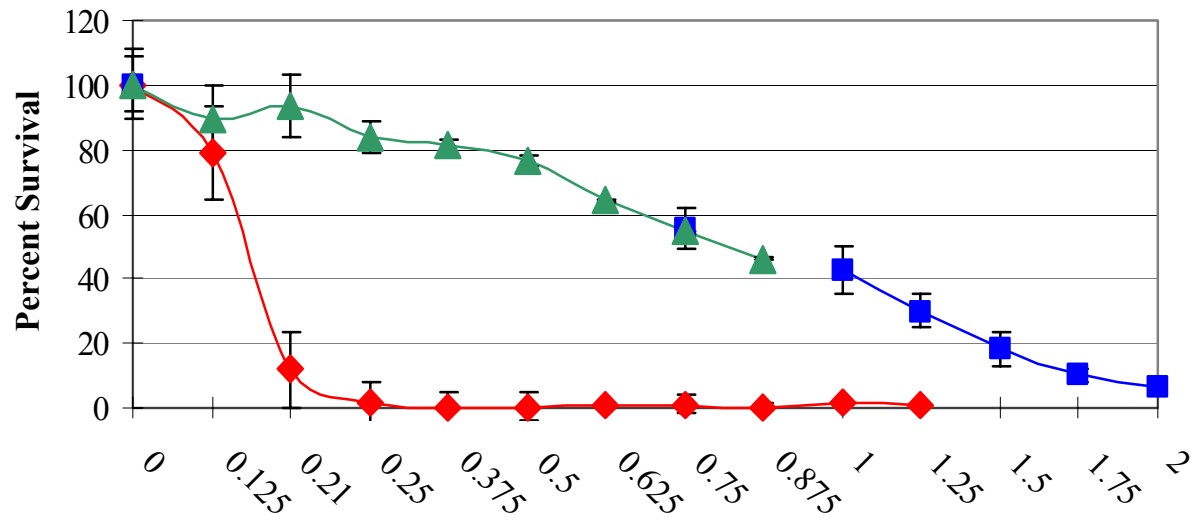

Concentration (\%)

(2-methyl-[1,3]dioxolan-4-yl)-methanol (Deicer 3)

(2,2-dimethyl-[1,3]dioxolan-4-yl)-methanol (Deicer 1)

$\triangle[1,3]$ dioxolan-4-yl-methanol (Deicer 2)

Figure 6 Cytotoxicity curves for deicer alternatives in H411E, Hepalc1c7 and V79 cells (A, $\mathrm{B}$, and $\mathrm{C}$, respectively). Note in graph $\mathrm{C}$, Deicers 1 and 2 have the same cytotoxicity pattern. 


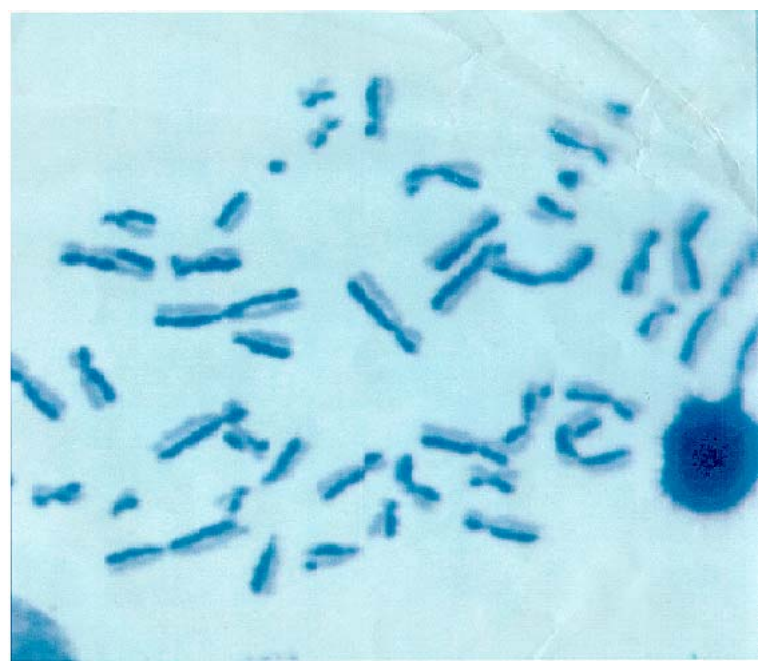

Figure 7 Harlequin stained chromosomes from second division metaphase spread from peripheral lymphocyte directly exposed to JP-8 (1:150 dilution) for 4h. SCE formation is apparent by the differential staining due to BrdU incorporation.

\subsection{Sister chromatid exchange of peripheral lymphocytes exposed to jet fuels}

This SCE investigation demonstrates an observed but not statistically significant induction of SCEs in peripheral lymphocytes with direct exposure to jet fuels. In vitro range finding studies were used to establish a dose response and indicated that fuel concentrations exceeding a 1:300 dilution induced $>50 \%$ cytotoxicity in the peripheral lymphocytes exposed for $4 \mathrm{~h}$. A preliminary study did not show a significant relationship between exposure duration, concentration and baseline SCE level so exposures were continued with $4 \mathrm{~h}$ time period. Figure 7 is a representative metaphase spread exposed to JP-8 (1:150 dilution) for 4h. There are apparent SCEs in many of the chromosomes.

The mean SCEs and proliferation indices of analyses of lymphocytes exposed to JP-5, JP-8 and JP- $8+100$ are compiled in Table V. The increasing frequency of SCEs with increasing dilution exposures to the various jet fuels on the frequency of SCE is clearly demonstrated for all fuels. At the highest exposure dilution (1:300) of JP-5, JP-8 and JP8+100 exposed lymphocytes the mean SCE frequency for was 7.43, 8.70, and 9.80, 
respectively. These respective frequencies are only $1.16,1.48$, and 1.49 times greater than the background level SCEs for JP-5, JP-8 and JP-8+100.

An increasing frequency of SCEs was also observed with exposure of peripheral lymphocytes to varying concentrations of jet fuel by linear regression analysis (significance of slope) as seen in Figure 8. There is a mild trend of increasing SCE formation with increasing fuel exposure. Analysis shows all slopes are significant. Notice the difference in slope between the three fuels (JP-5 $<$ JP-8 $<$ JP-8+100).

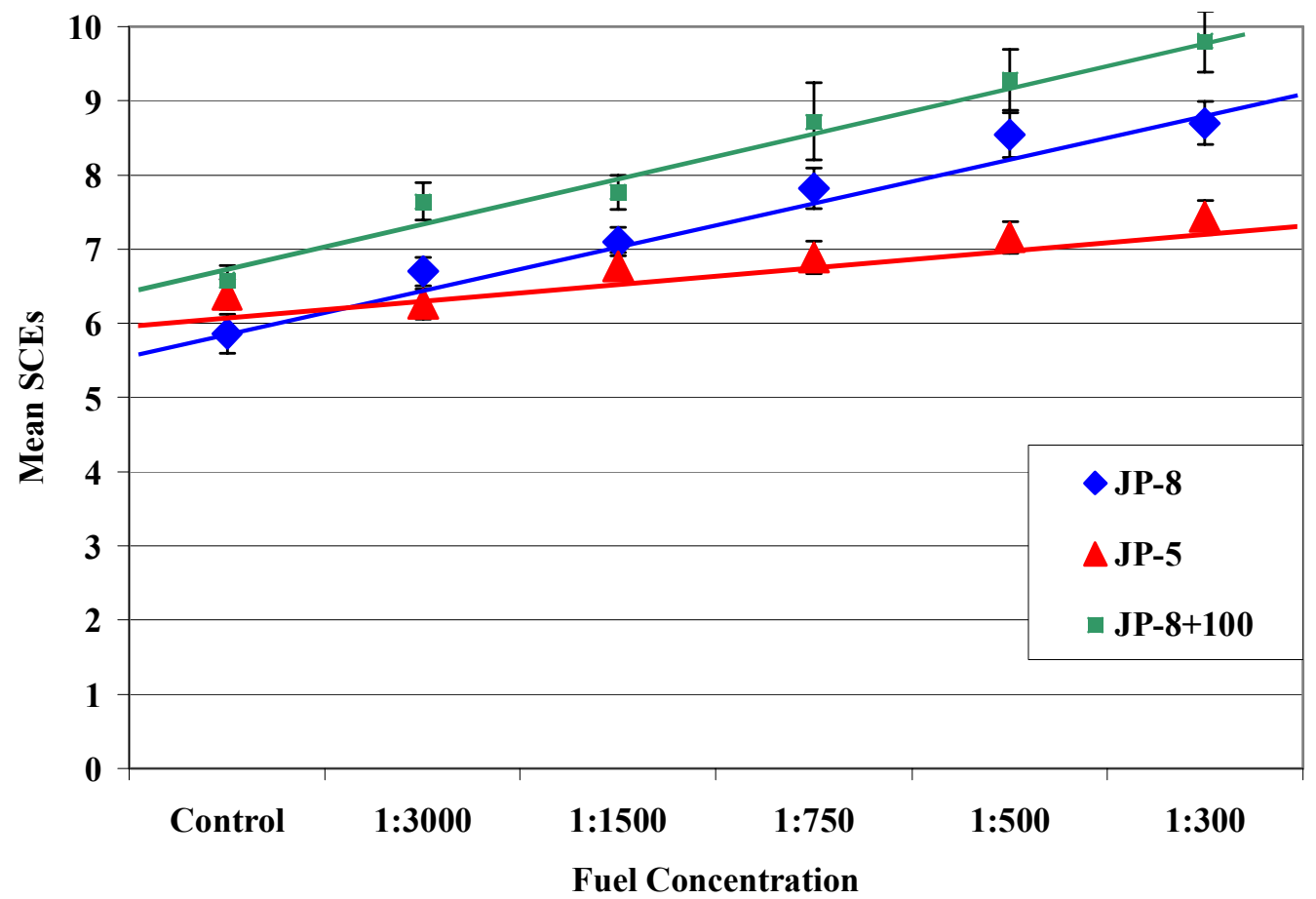

Figure 8 Linear regression analysis of mean SCE /Cell in peripheral lymphocytes exposed to JP-8, JP-5 and JP-8+100 for 4h.

In the JP-5 samples a slight increase in the formation of SCEs in peripheral lymphocytes with increasing concentrations of the fuel was observed. When compared with JP-5, JP-8 exhibits a greater increase in SCE formation. These observations are more pronounced at the higher fuel concentrations. With the addition of the thermal additive +100 
to the JP-8 fuel, there is an enhanced sensitivity by the cells, as observed by a greater increase in SCE formation. For statistical comparison the student's $t$ test was applied to compare the SCE increases in the fuel groups. The differences in control frequencies $(5.86$, 6.39, and 6.58) are not significant $(\mathrm{P}<0.05)$ according to the student's t test. Even though the data were not statistically significant it indicated a clear dose response for all three fuels. This data demonstrates a non-significant correlation between dose and response in each fuel investigated.

Table V Sister chromatid exchange frequencies and proliferation indices in peripheral lymphocytes directly exposed to jet propulsion fuels for $4 \mathrm{~h}$.

\begin{tabular}{|c|c|c|c|}
\hline $\begin{array}{c}\text { Fuel Type } \\
\text { Exposure Time } \\
\end{array}$ & $\begin{array}{l}\text { Exposure } \\
\text { Dilution } \\
\end{array}$ & $\begin{array}{c}\text { Mean SCEs per } \\
\text { cell } \pm \text { SD } \\
\end{array}$ & $\begin{array}{c}\text { Proliferation } \\
\text { Index }\end{array}$ \\
\hline \multirow{6}{*}{$\begin{array}{c}\text { JP-8 } \\
4 \mathrm{~h}\end{array}$} & Control & $5.86 \pm 0.26$ & 2.28 \\
\hline & $1: 3000$ & $6.70 \pm 0.19$ & 2.08 \\
\hline & $1: 1500$ & $7.12 \pm 0.19$ & 2.10 \\
\hline & $1: 750$ & $7.82 \pm 0.27$ & 2.16 \\
\hline & $1: 500$ & $8.54 \pm 0.31$ & 1.98 \\
\hline & $1: 300$ & $8.70 \pm 0.29$ & 1.98 \\
\hline \multirow{6}{*}{$\begin{array}{c}\text { JP-5 } \\
4 \mathrm{~h}\end{array}$} & Control & $6.39 \pm 0.21$ & 2.32 \\
\hline & $1: 3000$ & $6.26 \pm 0.20$ & 2.18 \\
\hline & $1: 1500$ & $6.77 \pm 0.19$ & 2.21 \\
\hline & $1: 750$ & $6.89 \pm 0.22$ & 2.16 \\
\hline & $1: 500$ & $7.16 \pm 0.21$ & 2.00 \\
\hline & $1: 300$ & $7.43 \pm 0.23$ & 2.03 \\
\hline \multirow{6}{*}{$\begin{array}{c}\mathbf{J P}-\mathbf{8}+\mathbf{1 0 0} \\
4 \mathrm{~h}\end{array}$} & Control & $6.58 \pm 0.20$ & 2.29 \\
\hline & $1: 3000$ & $7.64 \pm 0.25$ & 2.23 \\
\hline & $1: 1500$ & $7.77 \pm 0.23$ & 2.16 \\
\hline & $1: 750$ & $8.72 \pm 0.52$ & 2.01 \\
\hline & $1: 500$ & $9.28 \pm 0.41$ & 1.62 \\
\hline & $1: 300$ & $9.8 \pm 0.41$ & 1.62 \\
\hline
\end{tabular}




\subsection{Lymphocytes directly exposed to JP-5, JP-8, and JP-8+100 for 4 and $8 \mathrm{~h}$}

Comet assay analyses of DNA damage were carried out on lymphocytes directly exposed to three different propulsion fuels: JP-8, JP-5 and JP-8+100. Examples of typical digitized comet images are displayed in Figure 9. Marked damage was visible between the control cell (A) and the lymphocytes exposed to 1:150 dilution of JP-5 (B), JP-8 (C) and JP8+100 (D). Control cell (A) nuclei remained relatively intact and small amounts of DNA fragments appeared as "halos" surrounding the cells. In contrast, the jet fuel exposed lymphocytes displayed extensions of DNA fragments into tails, corresponding to the degree of DNA damage. The extension and intensity of the DNA fragments creating a comet tail

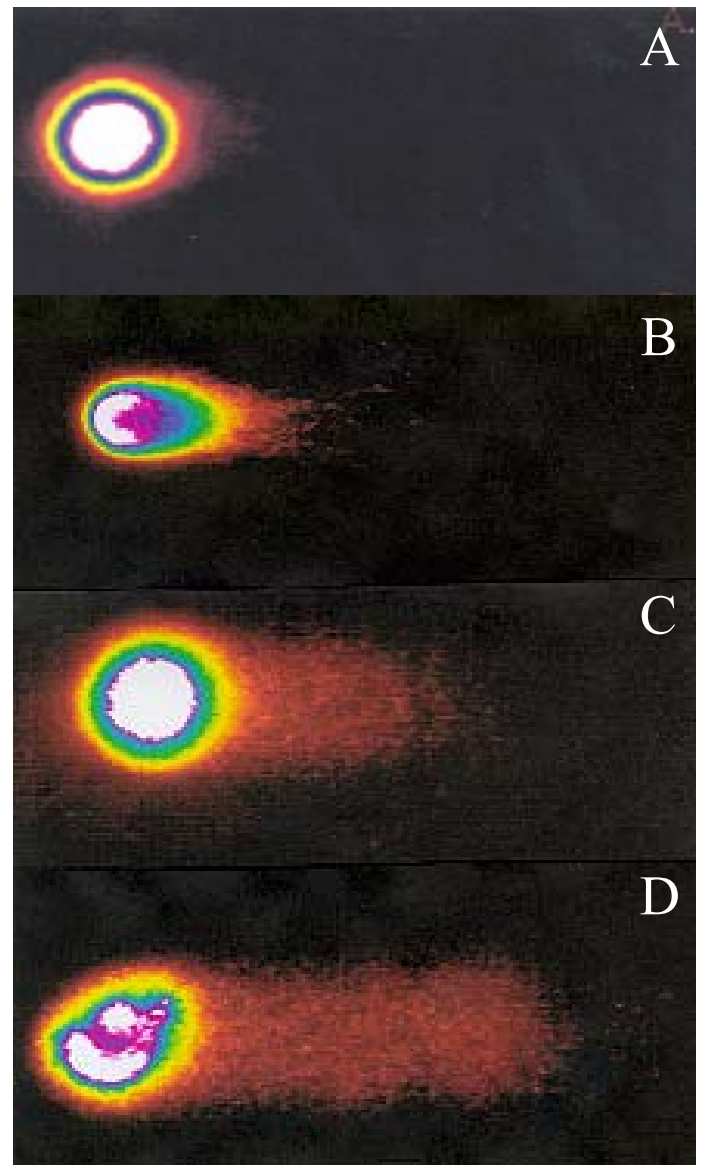

Figure 9 Selected peripheral lymphocytes from comet assay experiments with direct fuel exposure (1:150 dilution) for 4h. A. Lymphocyte not exposed to fuel. B. Lymphocyte exposed to JP-5. C. Lymphocyte exposed to JP-8. D. Lymphocyte exposed to JP-8+100. 
signify the induction of DNA damage. It must be noted that these are representative comet images of each exposure and not all comets in an experiment would correlate exactly to these degrees of damage. All of the comet images throughout these experimentations resemble the same formations depending on the amount of damage incurred by exposure.

Figures 10-21 illustrate representative distribution histograms of cells directly exposed to jet fuels, which visually compares the DNA damage incurred through various fuel exposures through shifts in the distributions. As the distributions move towards the increased measurements (towards the right on the x-axis), the amount of DNA damage increases.

Figures 10, 11 and 12 display the representative distribution histogram of tail moment and percent DNA measures for peripheral lymphocytes directly exposed to JP-5, JP-8 and JP$8+100$, respectively for $4 \mathrm{~h}$ at dilutions 1:75, 1:100, 1:150, 1:300 and 1:500.

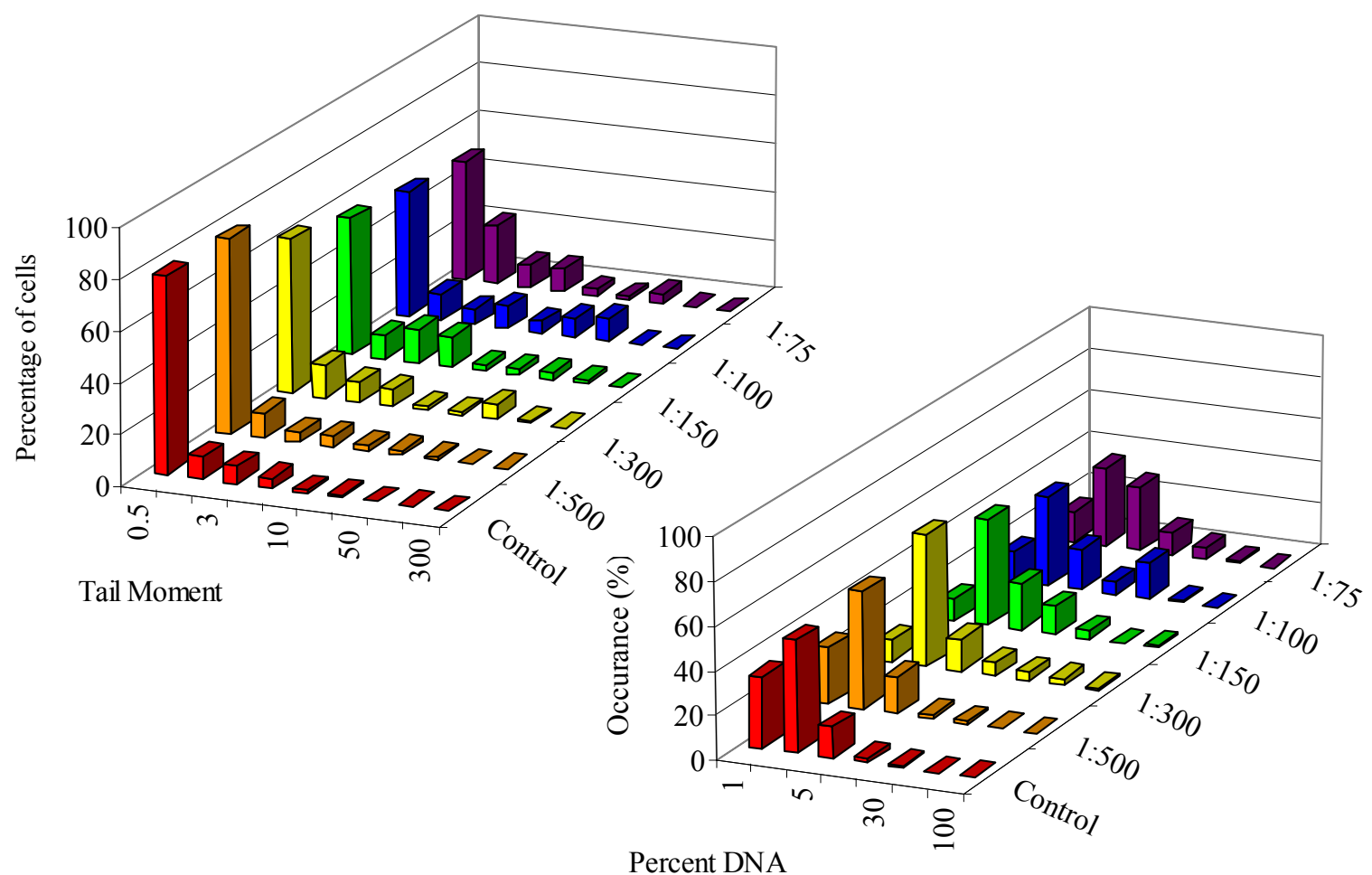

Figure 10 Distribution of tail moment and percent DNA measures of peripheral lymphocytes directly exposed (1:500-1:75 dilutions) to JP-5 for $4 \mathrm{~h}$. 


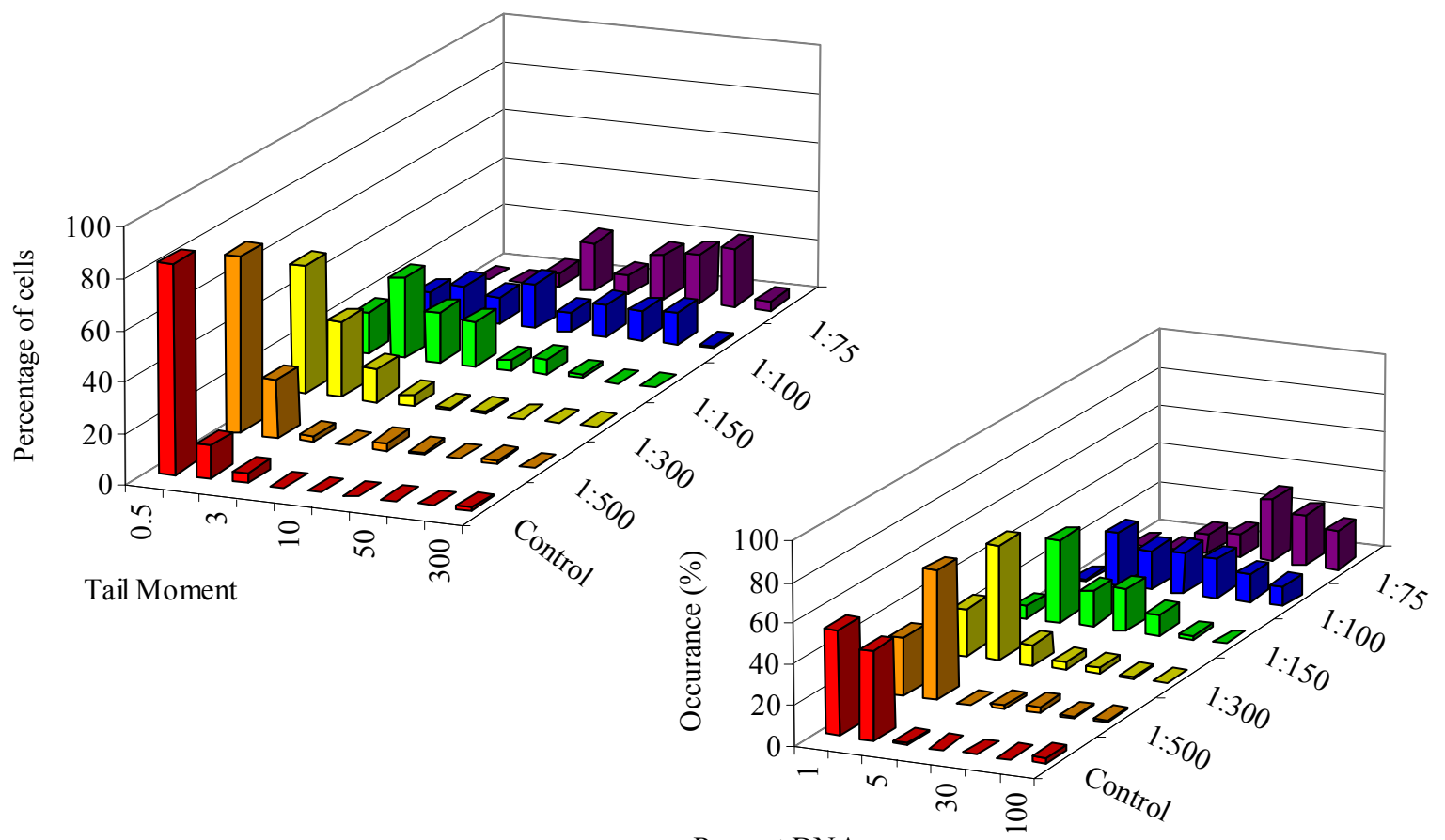

Percent DNA

Figure 11 Distribution of tail moment and percent DNA measures of peripheral lymphocytes directly exposed (1:500-1:75 dilutions) to JP-8 for $4 \mathrm{~h}$.

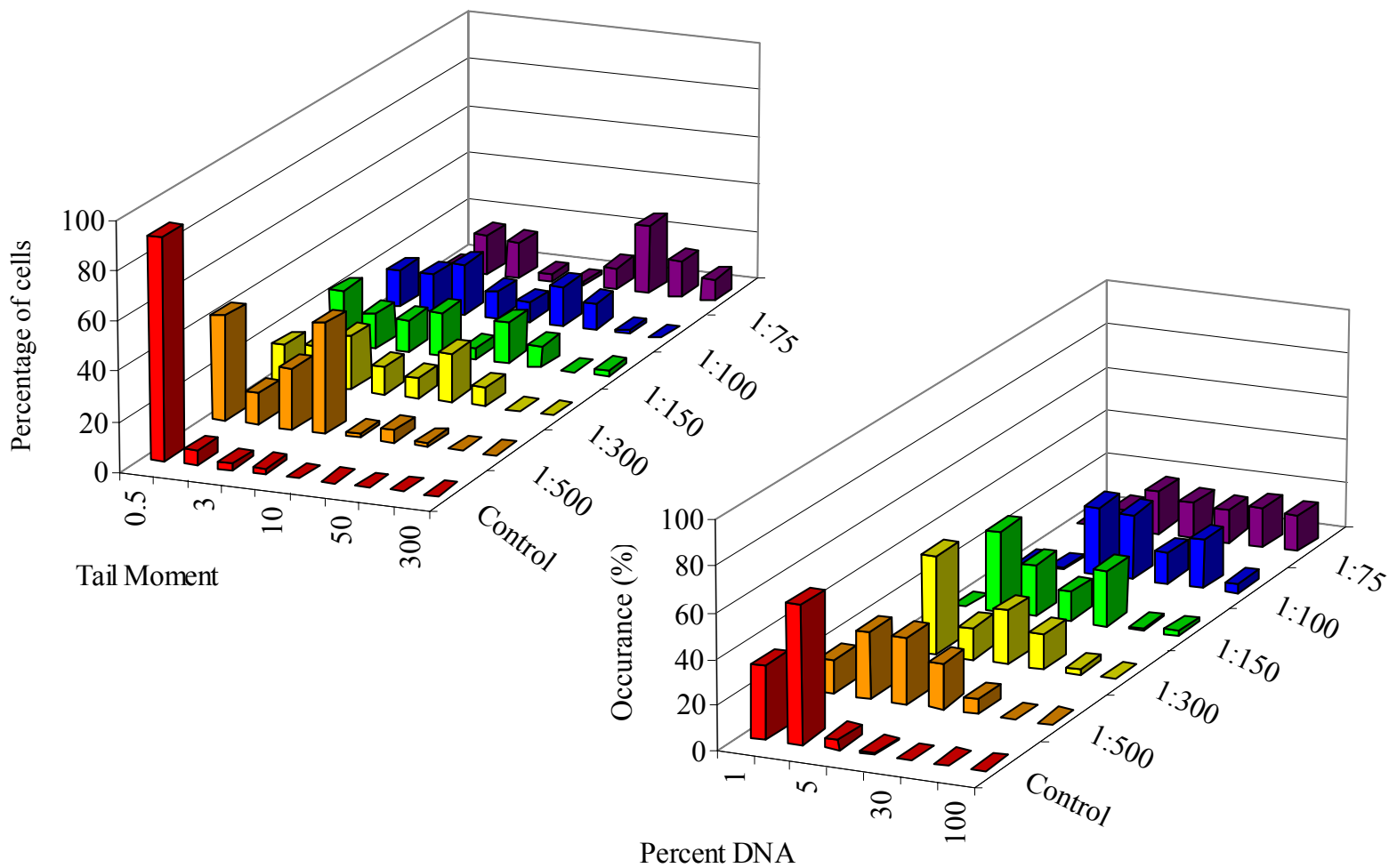

Figure 12 Distribution of tail moment and percent DNA measures of peripheral lymphocytes directly exposed (1:500-1:75 dilutions) to JP-8+100 for $4 \mathrm{~h}$. 
A small trend of increasing DNA damage with increasing fuel is apparent in the JP-5 exposed cells (Figure 10) but the majority of the exposed cell measurements remain in the same ranges throughout exposures. In Figure 11, JP-8 exposed lymphocytes are shown to increase with increased exposure. The distribution of the JP-8 DNA damage is more prevalent than that found in the JP-5 distributions. For example, as the JP-8 concentration increased, almost all the tail moment measures extended from a low range $(<3)$ in the control cells to a higher range $(7-300)$ in the 1:75 dilution, while in the JP-5 sample the majority remain in the control range $(<3)$ with only a few extending into the moderate range (7-50). In the JP-8+100 samples (Figure 12), the damage at the lower concentration exposures (1:5001:150) was greater than that seen in the JP-8 and JP-5 exposures. At the higher concentrations $(1: 100,1: 50)$, the damage trends in JP- $8+100$ were similar to those observed in the JP-8 samples.

Table VI summarizes the data for lymphocytes exposed for $4 \mathrm{~h}$ to the jet propulsion fuels: JP-8, JP-5 and JP-8+100. The mean tail moment and percent DNA with standard error for the JP- 8 and JP- $8+100$ fuels demonstrated elevated DNA damage with increasing exposure concentration. Table VI reiterates the fact that the effects of the JP-5 fuel on peripheral lymphocytes were not as severe when compared to the other fuels, especially at the higher exposures.

The statistical analyses of mean ranked data (not shown) revealed significant differences within each fuel exposure (Kruskal-Wallis $\mathrm{p}<0.1$ ) (Table VI) to determine which exposures were significantly different from the controls. The JP-5 and JP-8 exposed cells showed significant differences from the control cells for the 1:300 - 1:75 dilution exposures, while the 1:500 exposure failed to show significant differences for the JP-5 and JP- 8 treated 
cells. In the JP-8+100 fuel, a significant effect was seen between the control cells and all exposures, indicating a higher level of genotoxicity for JP-8+100. Consistent observations were made for both tail moment and percent DNA values.

Table VI Analysis of DNA damage measures by comet assay in peripheral lymphocytes exposed to jet fuels for $4 \mathrm{~h}$

\begin{tabular}{|c|c|c|c|}
\hline $\begin{array}{c}\text { Fuel Type } \\
\text { Exposure Time }\end{array}$ & Exposure Dilution & $\begin{array}{c}\text { Mean Tail } \\
\text { Moment } \pm \text { SE }\end{array}$ & $\begin{array}{c}\text { Mean Percent } \\
\text { DNA } \pm \text { SE }\end{array}$ \\
\hline \multirow{6}{*}{$\begin{array}{c}\text { JP-8 } \\
4 \mathrm{~h}\end{array}$} & Control & $0.101 \pm 0.010$ & $1.999 \pm 0.566$ \\
\hline & $1: 500$ & $0.358 \pm 0.043$ & $2.062 \pm 0.376$ \\
\hline & $1: 300$ & $1.741 \pm 0.266^{* *}$ & $3.399 \pm 0.397 * *$ \\
\hline & $1: 150$ & $3.649 \pm 0.445^{* *}$ & $5.379 \pm 0.628^{* *}$ \\
\hline & $1: 100$ & $14.424 \pm 2.087^{* *}$ & $17.875 \pm 1.934^{* *}$ \\
\hline & $1: 75$ & $32.041 \pm 2.599^{* *}$ & $34.957 \pm 2.559^{* *}$ \\
\hline \multirow{6}{*}{$\begin{array}{c}\text { JP-5 } \\
4 \mathrm{~h}\end{array}$} & Control & $0.111 \pm 0.019$ & $1.282 \pm 0.099$ \\
\hline & $1: 500$ & $0.309 \pm 0.756$ & $2.132 \pm 0.188$ \\
\hline & $1: 300$ & $1.278 \pm 0.376^{* *}$ & $3.640 \pm 0.577 * *$ \\
\hline & $1: 150$ & $1.254 \pm 0.537 * *$ & $3.944 \pm 0.571^{* *}$ \\
\hline & $1: 100$ & $1.848 \pm 0.421^{* *}$ & $5.561 \pm 0.616^{* *}$ \\
\hline & $1: 75$ & $1.314 \pm 0.474 * *$ & $4.852 \pm 0.865^{* *}$ \\
\hline \multirow{6}{*}{$\begin{array}{c}\mathbf{J P}-8+100 \\
4 \mathrm{~h}\end{array}$} & Control & $0.286 \pm 0.032$ & $1.793 \pm 0.242$ \\
\hline & $1: 500$ & $2.070 \pm 0.261 * *$ & $4.700 \pm 0.619^{* *}$ \\
\hline & $1: 300$ & $4.921 \pm 0.580 * *$ & $6.057 \pm 0.348^{* *}$ \\
\hline & $1: 150$ & $9.518 \pm 1.553 * *$ & $7.491 \pm 0.691 * *$ \\
\hline & $1: 100$ & $16.925 \pm 2.072 * *$ & $13.092 \pm 1.342 * *$ \\
\hline & $1: 75$ & $45.774 \pm 4.743^{* *}$ & $27.328 \pm 2.403^{* *}$ \\
\hline
\end{tabular}

$* *$ Highly significantly different $(\alpha=0.01)$ mean ranks as compared to the control values 
Lymphocytes exposed directly to JP- 5, JP- 8 and JP- $8+100$ for $8 \mathrm{~h}$

Figures 13, 14 and 15 (JP-5, JP-8, JP-8+100, respectively) depict the tail moment and percent DNA values for the peripheral lymphocytes exposed for $8 \mathrm{~h}$ at dilutions 1:75, 1:100, 1:150, 1:300 and 1:500. The same trends of damage that were observed in the $4 \mathrm{~h}$ comet measure were seen with the $8 \mathrm{~h}$ exposure. The tail moment and percent DNA distributions of the JP-5 exposure (Figure 13) increased only slightly with increasing concentration. This distribution was more pronounced in the JP-8 exposure (Figure 14) as there was an increase in DNA damage as the concentration increased. The largest amount of DNA damage based on exposure concentration was again apparent in the JP- $8+100$ exposed lymphocytes (Figure 15). The percentage of damaged comets at the lower concentrations increases as compared to the other fuels.

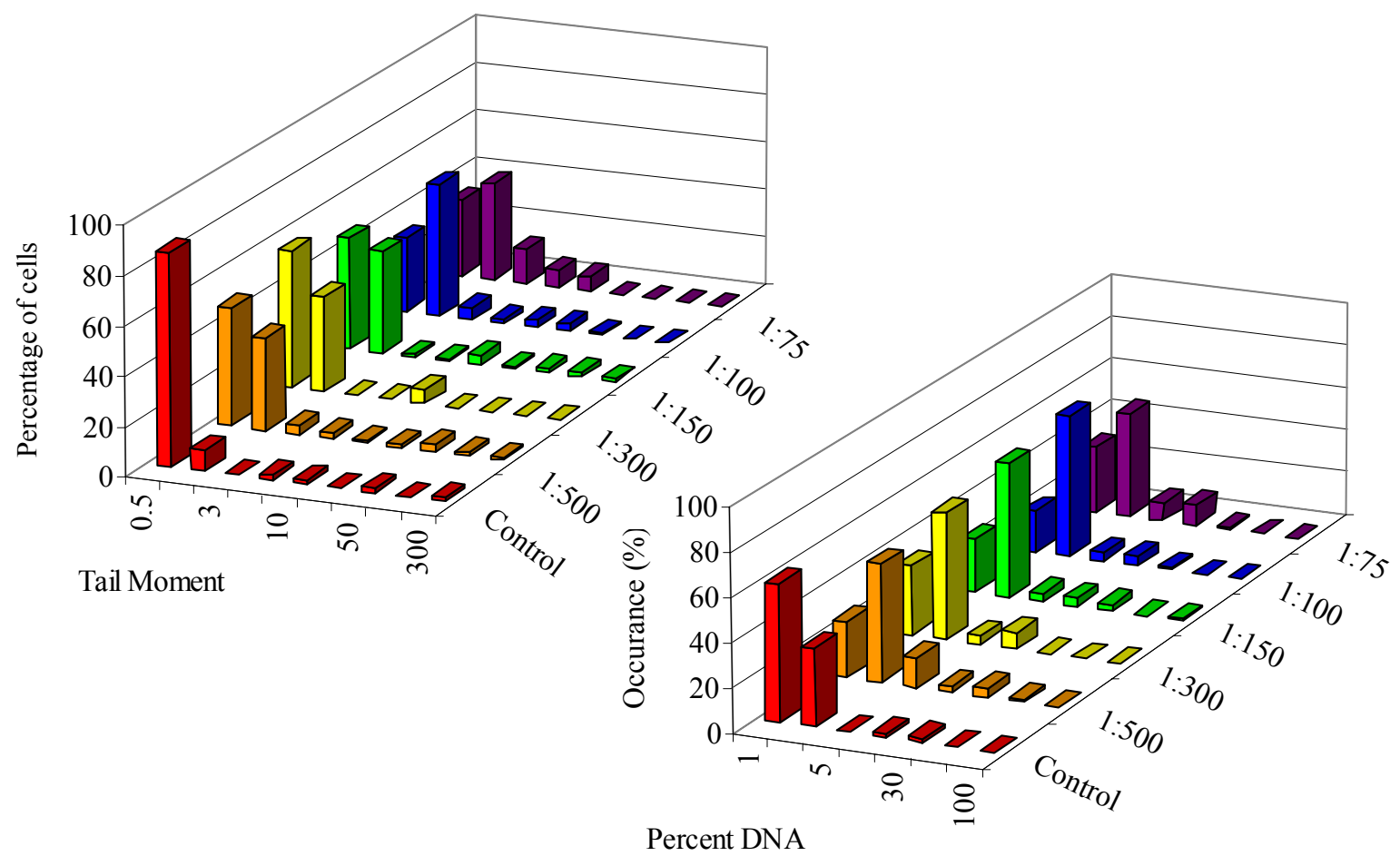

Figure 13 Distribution of tail moment and percent DNA measures of peripheral lymphocytes directly exposed (1:500-1:75 dilutions) to JP-5 for $8 \mathrm{~h}$. 


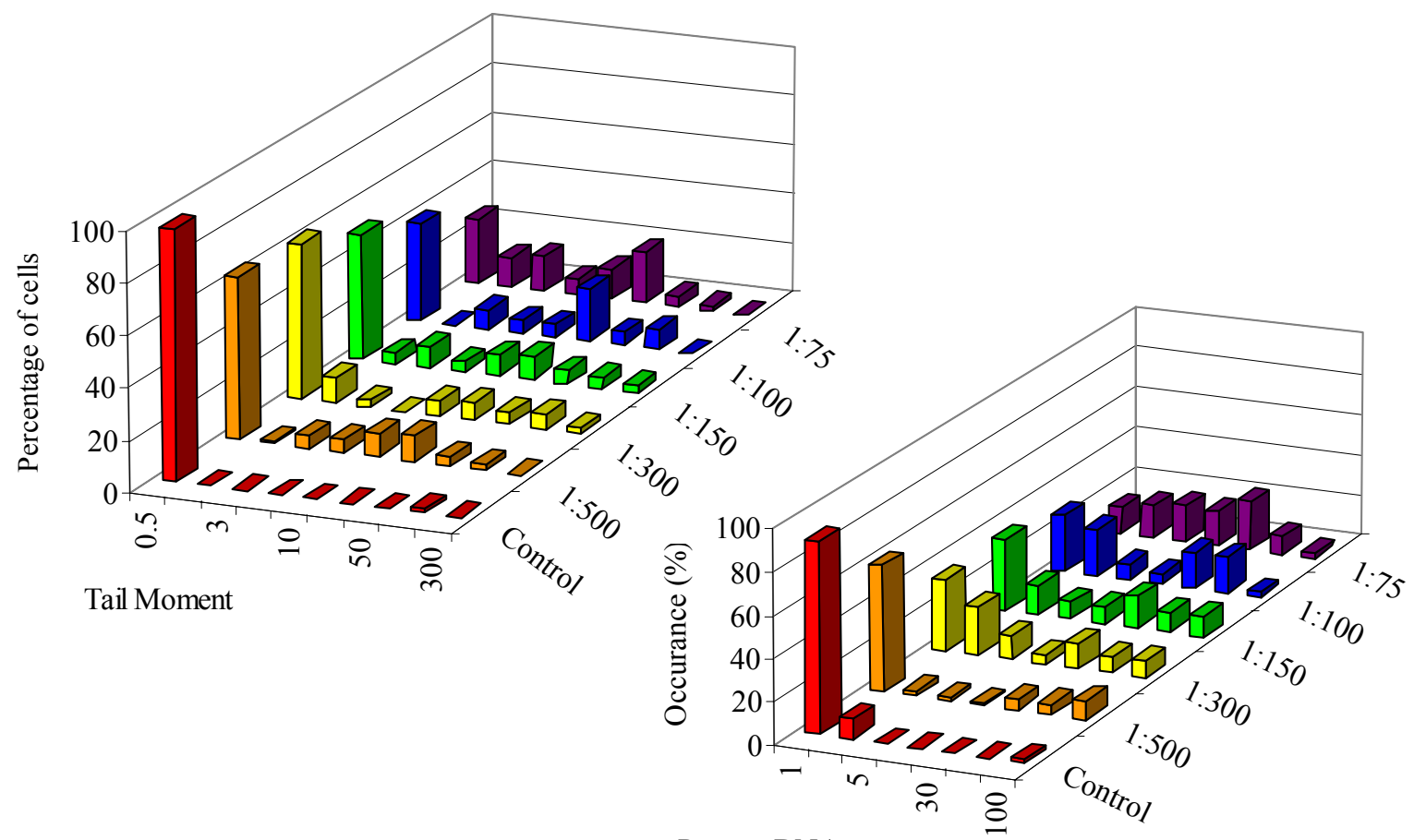

Percent DNA

Figure 14 Distribution of tail moment and percent DNA measures of peripheral lymphocytes directly exposed (1:500-1:75 dilutions) to JP-8 for $8 \mathrm{~h}$.

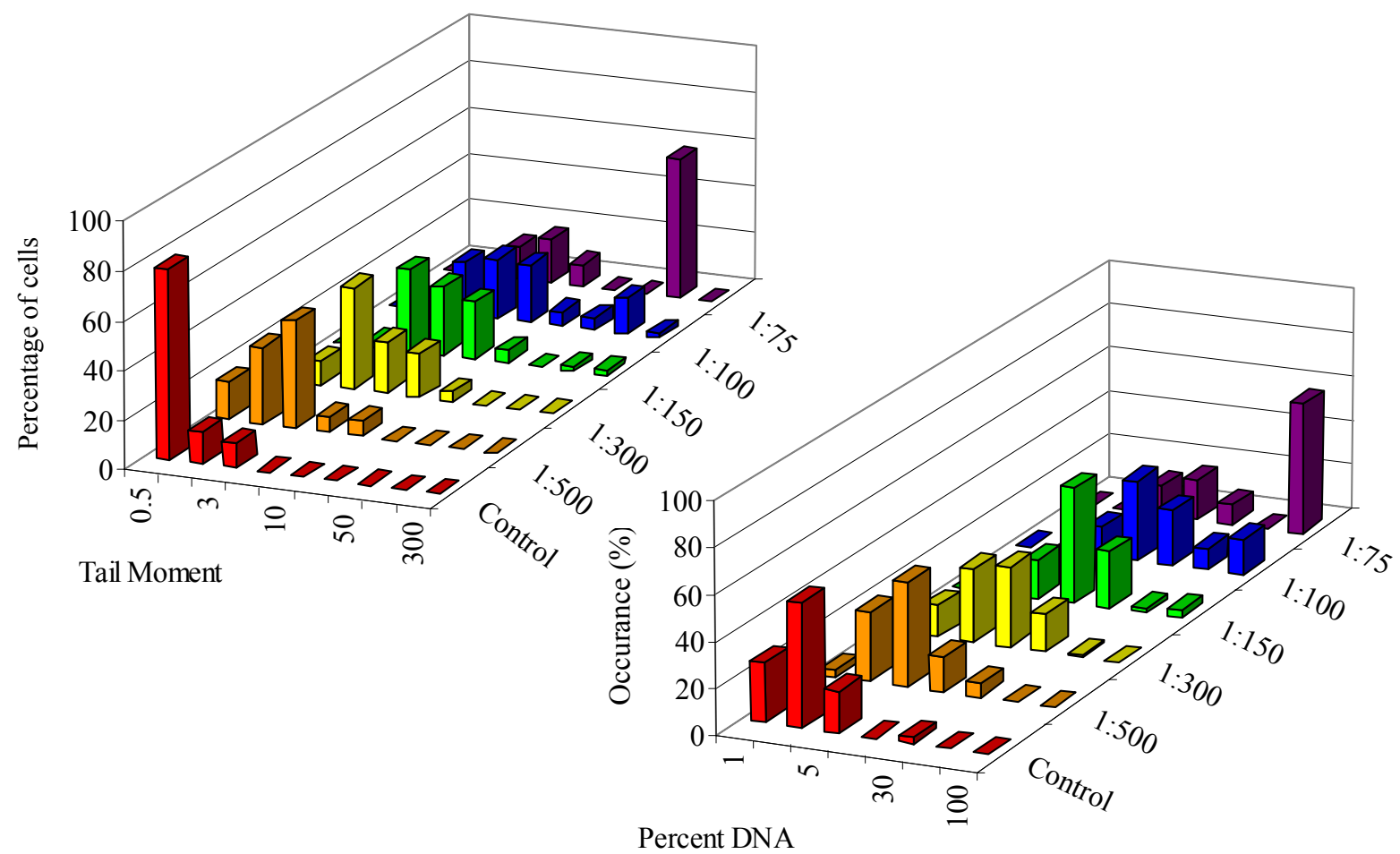

Figure 15 Distribution of tail moment and percent DNA measures of peripheral lymphocytes directly exposed (1:500-1:75 dilutions) to JP-8+100 for $8 \mathrm{~h}$. 
Table VII Analysis of DNA damage measures by comet assay in peripheral lymphocytes exposed to jet fuels for $8 \mathrm{~h}$

\begin{tabular}{|c|c|c|c|}
\hline $\begin{array}{c}\text { Fuel Type } \\
\text { Exposure Time } \\
\end{array}$ & Exposure Dilution & $\begin{array}{c}\text { Mean Tail } \\
\text { Moment } \pm \text { SE }\end{array}$ & $\begin{array}{c}\text { Mean Percent } \\
\text { DNA } \pm \text { SE }\end{array}$ \\
\hline \multirow{6}{*}{$\begin{array}{c}\text { JP-8 } \\
8 \mathrm{~h}\end{array}$} & Control & $0.141 \pm 0.016$ & $1.336 \pm 0.311$ \\
\hline & $1: 500$ & $2.179 \pm 0.509$ & $4.529 \pm 0.652$ \\
\hline & $1: 300$ & $4.867 \pm 0.896^{*}$ & $7.995 \pm 1.103^{*}$ \\
\hline & $1: 150$ & $6.067 \pm 1.393 * *$ & $9.833 \pm 1.427 * *$ \\
\hline & $1: 100$ & $10.477 \pm 2.284 * *$ & $11.006 \pm 1.592^{* *}$ \\
\hline & $1: 75$ & $13.501 \pm 1.830 * *$ & $14.645 \pm 1.444 * *$ \\
\hline \multirow{6}{*}{$\begin{array}{c}\mathbf{J P}-5 \\
8 \mathrm{~h}\end{array}$} & Control & $0.290 \pm 0.026$ & $0.752 \pm 0.160$ \\
\hline & $1: 500$ & $0.709 \pm 0.254$ & $2.276 \pm 0.239$ \\
\hline & $1: 300$ & $0.726 \pm 0.343^{*}$ & $1.930 \pm 0.143^{*}$ \\
\hline & $1: 150$ & $0.869 \pm 0.295^{*}$ & $3.147 \pm 0.922 *$ \\
\hline & $1: 100$ & $0.768 \pm 0.281^{*}$ & $2.498 \pm 0.330 *$ \\
\hline & $1: 75$ & $0.975 \pm 0.472^{*}$ & $4.815 \pm 2.589 *$ \\
\hline \multirow{6}{*}{$\begin{array}{c}\mathbf{J P}-\mathbf{8}+\mathbf{1 0 0} \\
8 \mathrm{~h}\end{array}$} & Control & $0.168 \pm 0.188$ & $1.737 \pm 0.858$ \\
\hline & $1: 500$ & $3.406 \pm 0.809^{*}$ & $4.182 \pm 0.284^{*}$ \\
\hline & $1: 300$ & $5.045 \pm 0.845^{* *}$ & $8.033 \pm 0.666^{* *}$ \\
\hline & $1: 150$ & $8.225 \pm 1.689 * *$ & $13.856 \pm 1.607^{* *}$ \\
\hline & $1: 100$ & $13.369 \pm 1.813 * *$ & $23.515 \pm 2.061 * *$ \\
\hline & $1: 75$ & $37.397 \pm 3.073 * *$ & $37.904 \pm 3.002 * *$ \\
\hline
\end{tabular}

*Significantly different $(\alpha=0.05)$ mean ranks as compared to the control values

**Highly significantly different $(\alpha=0.01)$ mean ranks as compared to the control values

Table VII summarizes the mean comet measures for the peripheral lymphocytes exposed to the jet propulsion fuels for $8 \mathrm{~h}$. The same fuel specific trends of damage are apparent as seen through the comet measures comparisons with the $4 \mathrm{~h}$ data set (Table VI). Additionally, with the extension of the peripheral lymphocyte exposures from 4 to $8 \mathrm{~h}$, no significant variations or increased damage was observed. The JP-5 shows the least variation 
throughout exposures while the JP- $8+100$ data exhibits a more severe divergence due to concentration exposure similar to the trends established in the $4 \mathrm{~h}$ exposures.

\subsection{Direct exposure of H411E cells to JP-5, JP-8 and JP-8+100 for 4 and $8 \mathrm{~h}$}

Figures 16, 17 and 18 display the representative distribution histogram of tail moment and percent DNA measures for H411E cells directly exposed to JP-5, JP-8 and JP-8+100, respectively for $4 \mathrm{~h}$ at dilutions $1: 75,1: 100,1: 150,1: 300$ and 1:500. The separate histograms detail the tail moment and percent DNA measures of damaged cells. For the most part the DNA damage trends are the same as found in the lymphocytes. The JP-5 exposure (Figure 16) revealed initial damage with little increase in damage with increasing concentration. The damage levels are slightly greater than that seen in the peripheral lymphocytes exposed to JP5 for 4 h (Figure 10).

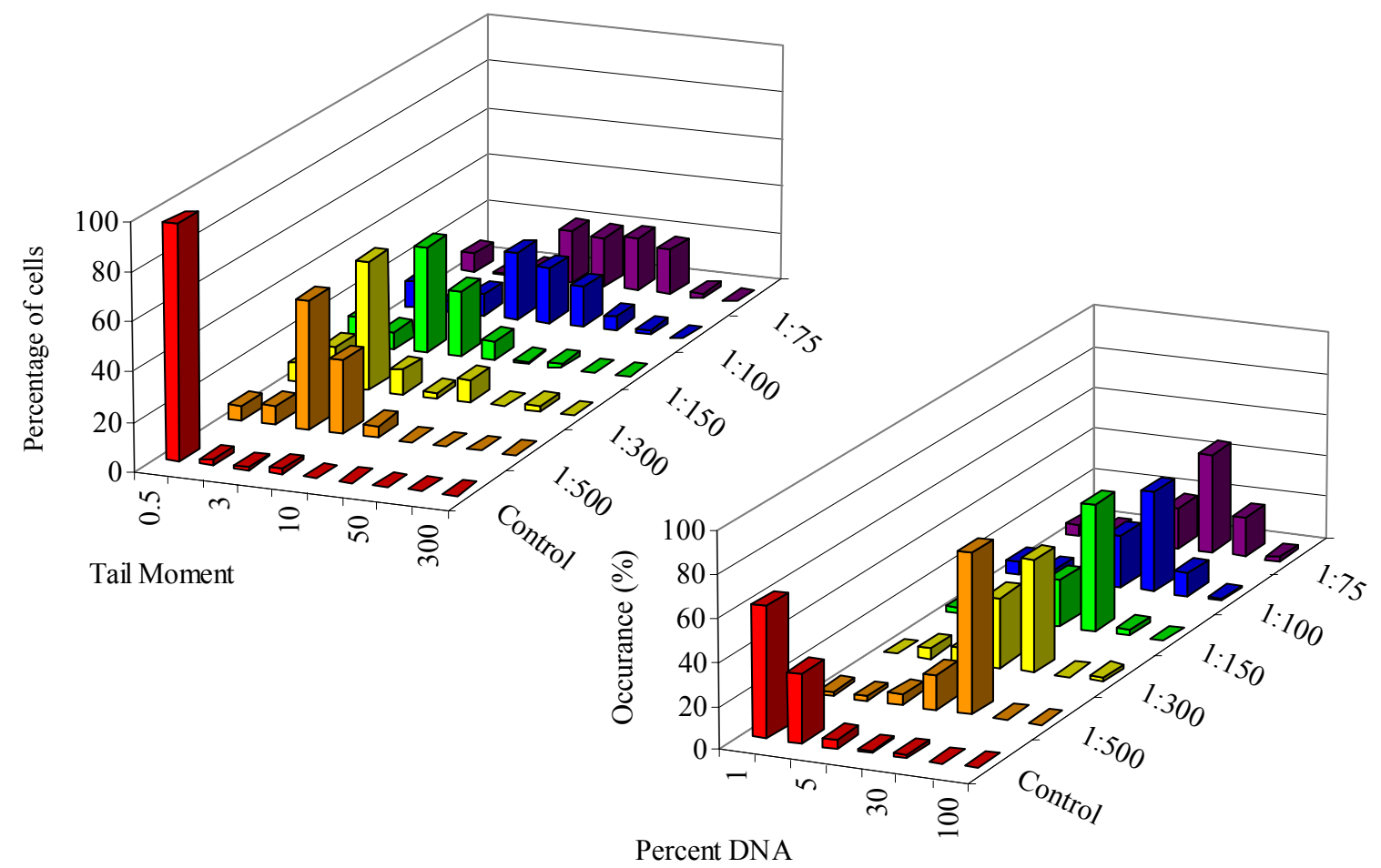

Figure 16 Distribution of tail moment and percent DNA measures of H411E cells directly exposed (1:500-1:75 dilutions) to JP-5 for $4 \mathrm{~h}$. 


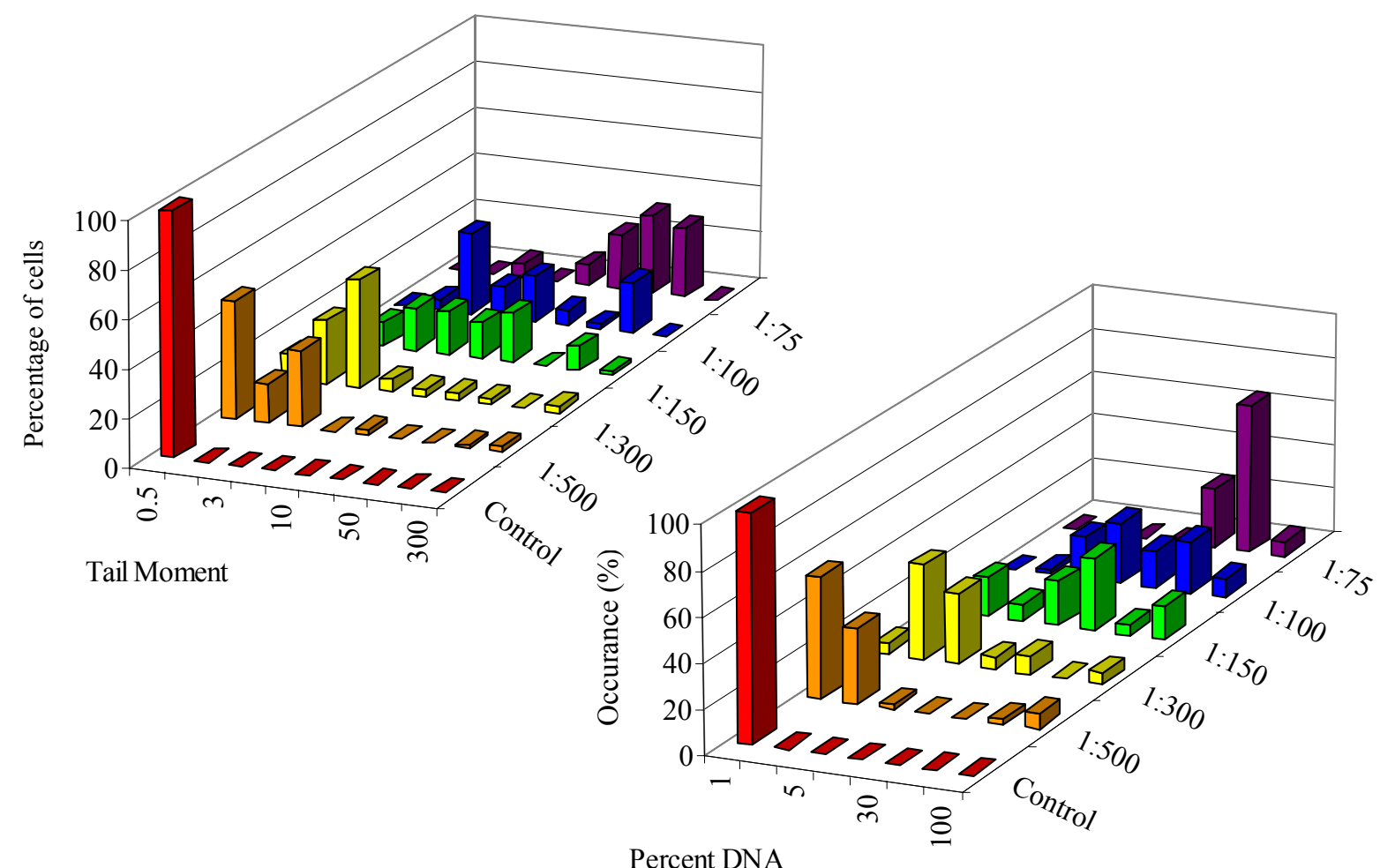

Figure 17 Distribution of tail moment and percent DNA measures of H411E cells directly exposed (1:500-1:75 dilutions) to JP-8 for $4 \mathrm{~h}$.

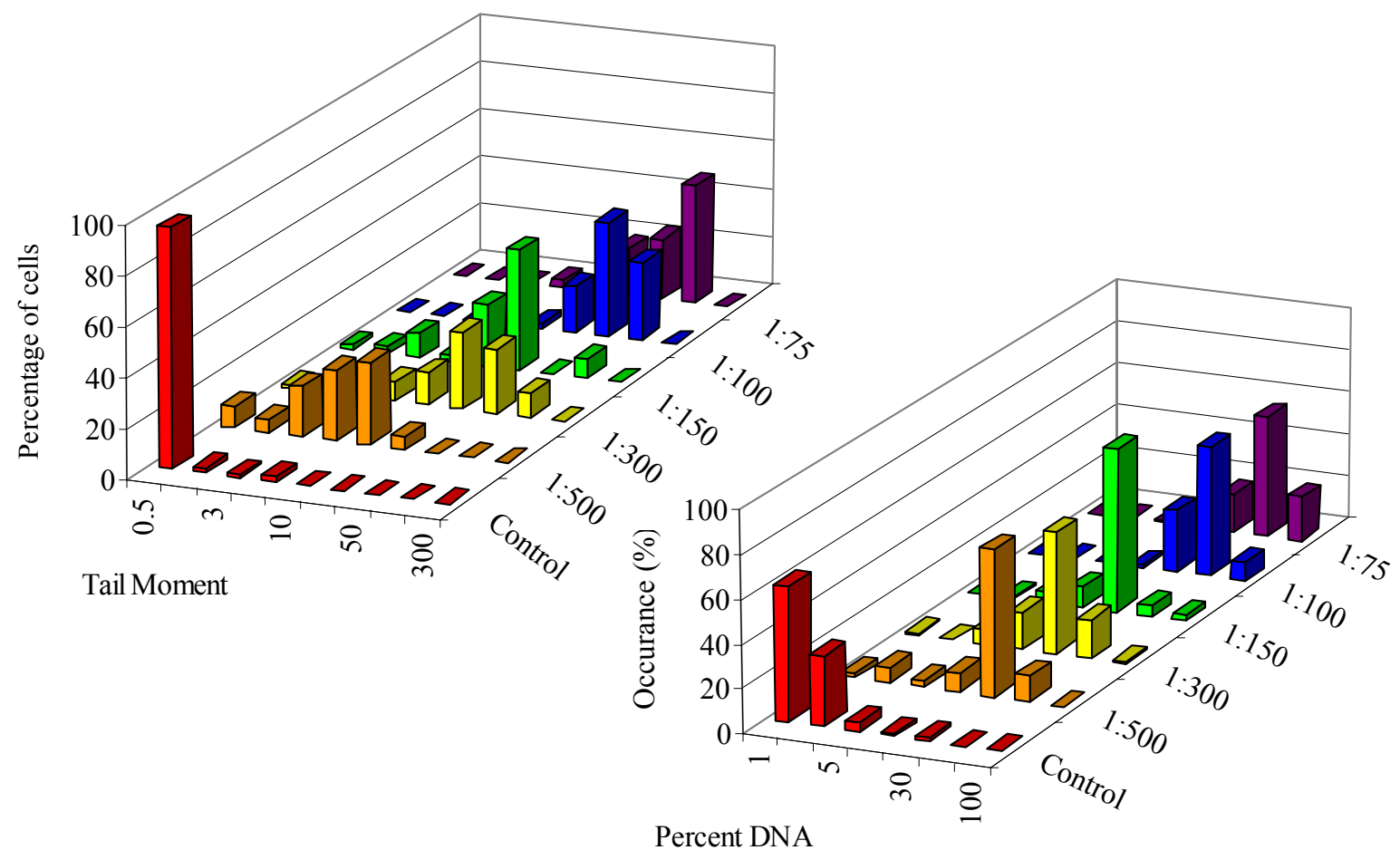

Figure 18 Distribution of tail moment and percent DNA measures of H411E cells directly exposed (1:500-1:75 dilutions) to JP-8+100 for $4 \mathrm{~h}$. 
The JP-8 exposed H411E cells (Figure 17) show an increase in tail moment and percent DNA measure with increase in concentration. The JP-8 distributions are more severe at the higher exposure dilutions than seen with the JP-5 exposed cells (Figure 16). JP-8+100 exposed H411E cells (Figure 18) demonstrate the greatest DNA damage of the three fuels. The initial damage the lowest concentration (1:500) is more severe than that seen in the JP-5 and JP-8 samples, however the trend of increasing damage with increasing exposure was still apparent. H411E cells exposed to JP-5, JP-8 and JP-8+100. Note that the initial damage from all of the jet fuel is more severe but the slight increase with increasing concentration is still apparent. The same significances found in the lymphocytes directly exposed to jet fuel (Table VI) for $4 \mathrm{~h}$ were found in the H411E cells exposed for $4 \mathrm{~h}$. Further statistical comparisons were made on the mean rank data to detect any significant differences between the exposure concentrations (1:500 -1:75) for the fuels to compare the trends of damage. The JP- $8+100$ exposed cells exhibited a significant difference between the 1:500 dilution compared to all higher exposures $(1: 300-1: 75)$ as was seen in the lymphocytes. This significant difference between exposure concentrations was not seen in the lower dilutions of JP-8 exposures and was not at all evident with the JP-5 fuel, implying that the JP-8+100 exposure is more severe in that the genotoxic effects are demonstrated even at the lowest dilution.

Direct exposure of H411E cells to JP-5, JP-8 and JP-8+100 for $8 \mathrm{~h}$

The separate histograms Figures 19, 20, and 21 detail the tail moment and percent DNA measures of H411E cells directly exposed to JP-5, JP-8, JP-8+100, respectively for 8h at dilutions 1:75, 1:100, 1:150, 1:300 and 1:500. 
Table VIII Analysis of DNA damage by comet assay in H411E cells directly exposed to jet fuels for $4 \mathrm{~h}$

\begin{tabular}{|c|c|c|c|}
\hline $\begin{array}{c}\text { Fuel Type } \\
\text { Exposure Time } \\
\end{array}$ & Exposure Dilution & $\begin{array}{c}\text { Mean Tail } \\
\text { Moment } \pm \text { SE }\end{array}$ & $\begin{array}{c}\text { Mean Percent } \\
\text { DNA } \pm \text { SE }\end{array}$ \\
\hline \multirow{6}{*}{$\begin{array}{c}\text { JP-8 } \\
4 \mathrm{~h}\end{array}$} & Control & $0.196 \pm 0.033$ & $1.856 \pm 0.249$ \\
\hline & $1: 500$ & $1.974 \pm 0.141$ & $6.798 \pm 1.022$ \\
\hline & $1: 300$ & $4.585 \pm 1.137 * *$ & $8.579 \pm 0.957 * *$ \\
\hline & $1: 150$ & $7.755 \pm 1.207 * *$ & $18.758 \pm 1.497 * *$ \\
\hline & $1: 100$ & $12.297 \pm 1.633^{* *}$ & $18.813 \pm 1.047 * *$ \\
\hline & $1: 75$ & $21.045 \pm 1.808 * *$ & $26.946 \pm 0.783 * *$ \\
\hline \multirow{6}{*}{$\begin{array}{c}\text { JP-5 } \\
4 \mathrm{~h}\end{array}$} & Control & $0.160 \pm 0.057$ & $1.398 \pm 0.273$ \\
\hline & $1: 500$ & $2.564 \pm 0.146$ & $13.252 \pm 0.536$ \\
\hline & $1: 300$ & $3.762 \pm 0.709 * *$ & $13.435 \pm 1.118^{* *}$ \\
\hline & $1: 150$ & $4.119 \pm 0.522 * *$ & $13.525 \pm 0.762 * *$ \\
\hline & $1: 100$ & $10.723 \pm 1.376^{* *}$ & $14.592 \pm 1.104 * *$ \\
\hline & $1: 75$ & $18.578 \pm 1.698 * *$ & $21.715 \pm 1.289 * *$ \\
\hline \multirow{6}{*}{$\begin{array}{c}\mathbf{J P}-8+\mathbf{1 0 0} \\
4 \mathrm{~h}\end{array}$} & Control & $0.193 \pm 0.062$ & $1.035 \pm 0.108$ \\
\hline & $1: 500$ & $4.529 \pm 0.384 * *$ & $18.720 \pm 1.029 * *$ \\
\hline & $1: 300$ & $18.011 \pm 1.692 * *$ & $19.820 \pm 1.285^{* *}$ \\
\hline & $1: 150$ & $22.469 \pm 1.844 * *$ & $19.548 \pm 1.140^{* *}$ \\
\hline & $1: 100$ & $36.725 \pm 1.750 * *$ & $35.082 \pm 1.050 * *$ \\
\hline & $1: 75$ & $37.983 \pm 2.287 * *$ & $39.964 \pm 1.283 * *$ \\
\hline
\end{tabular}

** Highly significantly different $(\alpha=0.01)$ mean ranks as compared to the control values Table VIII summarizes the mean tail moment and percent DNA measures for the

All of the of the fuels demonstrated the same trends of damage as previously described in the lymphocyte 4 and $8 \mathrm{~h}$ exposures and the H411E 4 h exposure. Additionally, no effect of duration of exposure was seen between the 4 and $8 \mathrm{~h}$ exposures. Table IX compares of the comet assay measures in exposed and control cells of the JP-5, JP-8 and JP-8+100 8h H411E exposure and demonstrates the same significances and trends found in the previous studies. 


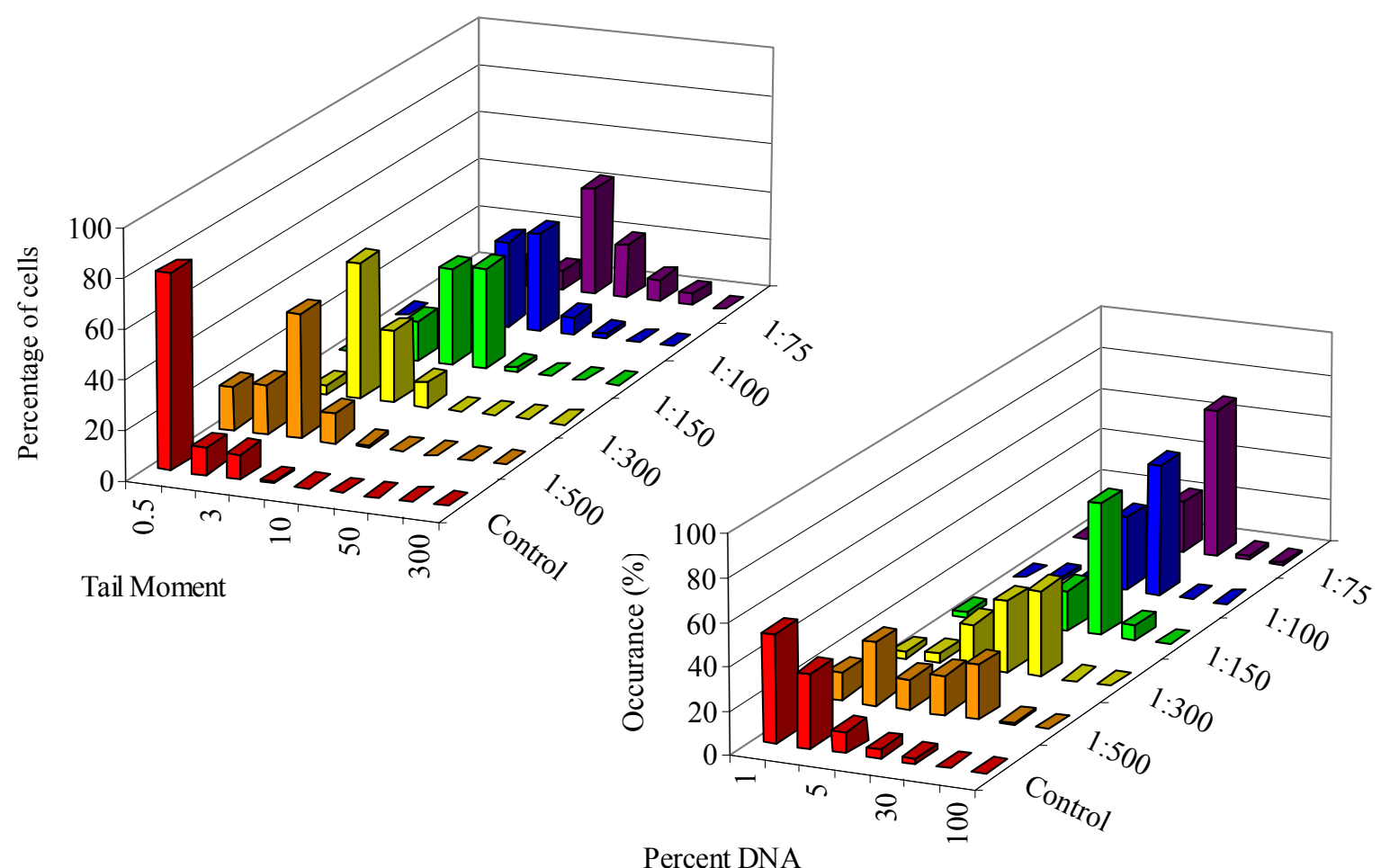

Figure 19 Distribution of tail moment and percent DNA measures of H411E cells directly exposed (1:500-1:75 dilutions) to JP-5 for $8 \mathrm{~h}$.

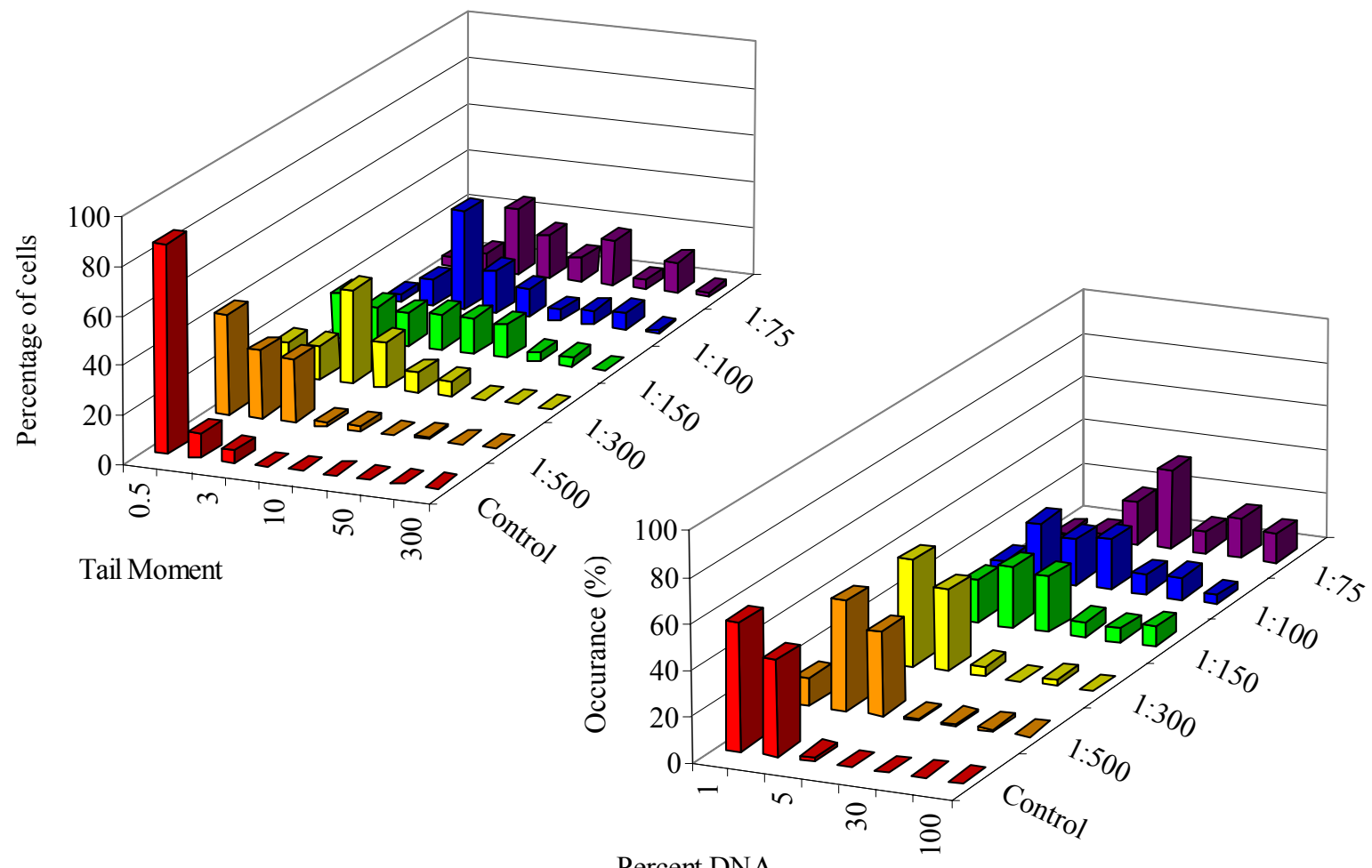

Figure 20 Distribution of tail moment and percent DNA measures of H411E cells directly exposed (1:500-1:75 dilutions) to JP-8 for $8 \mathrm{~h}$. 


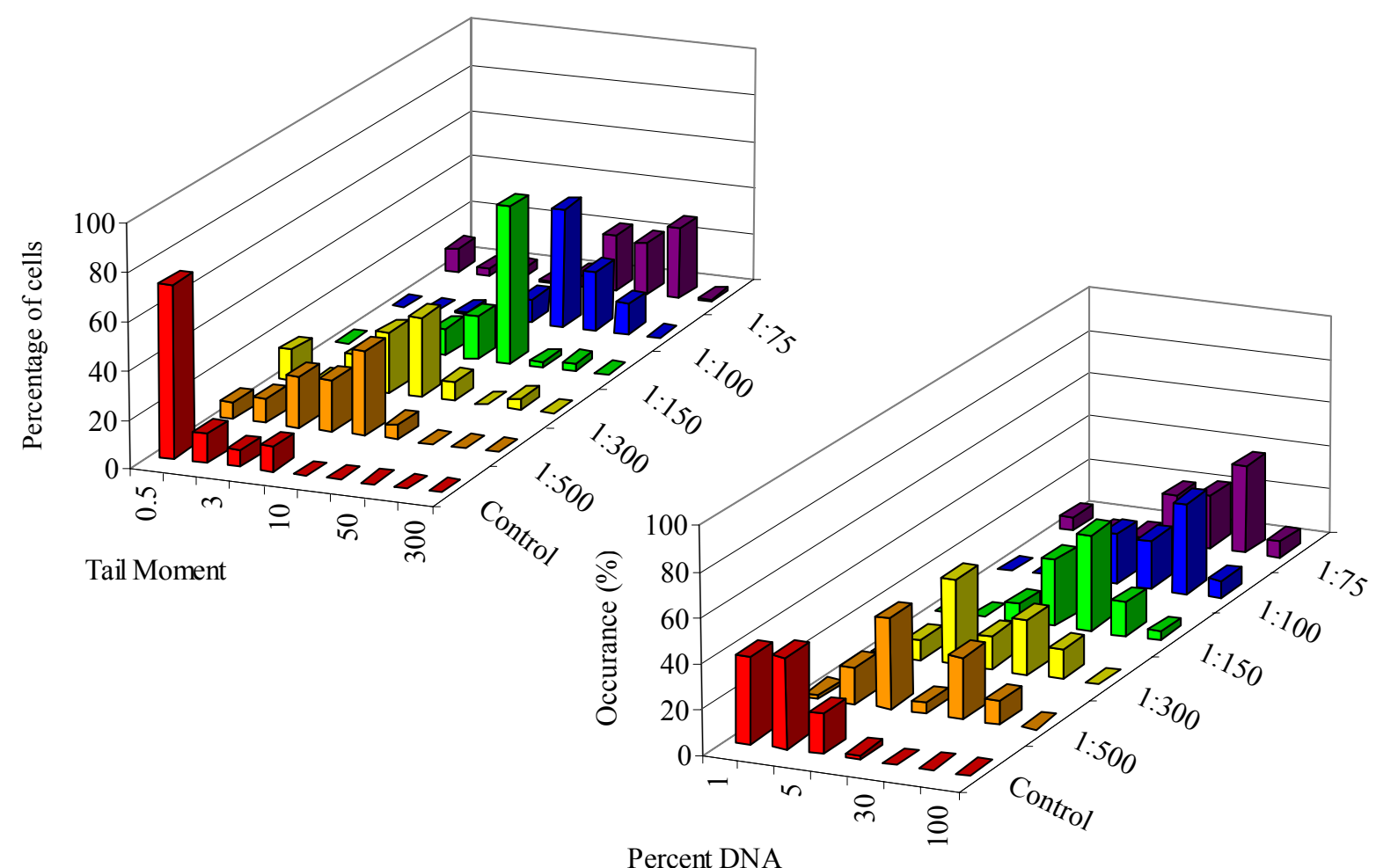

Figure 21 Distribution of tail moment and percent DNA measures of H411E cells directly exposed (1:500-1:75 dilutions) to JP-8+100 for $8 \mathrm{~h}$.

Based on the distribution trends seen in the peripheral lymphocytes and H411E cells directly exposed to the three fuels there is no discernible difference in the DNA damage for the 4 and $8 \mathrm{~h}$ exposures. This signifies that there is not a time dependent increase in DNA damage from the fuel exposures and the $8 \mathrm{~h}$ time point was not included in further experimentation. These results have also accurately demonstrated that the tail moment and percent DNA measure display the same trends of damage. Even though these two measures were evaluated in all experiments as quality insurance the percent DNA measures and distributions will no longer be shown. Due to the minimal difference in the lymphocytes and the H411E cells from jet fuel exposure as determines by the comet assay, the H411E cells are employed in further experimentation due to the inclusion of metabolic activation. 
Table IX Analysis of DNA damage by comet assay in H411E cells directly exposed to jet fuels for $8 \mathrm{~h}$

\begin{tabular}{|c|c|c|c|}
\hline $\begin{array}{c}\text { Fuel Type } \\
\text { Exposure Time } \\
\end{array}$ & Exposure Dilution & $\begin{array}{c}\text { Mean Tail } \\
\text { Moment } \pm \text { SE }\end{array}$ & $\begin{array}{c}\text { Mean Percent } \\
\text { DNA } \pm \text { SE }\end{array}$ \\
\hline \multirow{6}{*}{$\begin{array}{c}\mathbf{J P - 8} \\
8 \mathrm{~h}\end{array}$} & Control & $0.259 \pm 0.031$ & $0.892 \pm 0.053$ \\
\hline & $1: 500$ & $1.220 \pm 0.323$ & $2.317 \pm 0.115$ \\
\hline & $1: 300$ & $3.610 \pm 0.553^{* *}$ & $3.782 \pm 0.689^{* *}$ \\
\hline & $1: 150$ & $10.050 \pm 1.900^{* *}$ & $10.783 \pm 1.386^{* *}$ \\
\hline & $1: 100$ & $11.864 \pm 2.143^{* *}$ & $12.310 \pm 1.803^{* *}$ \\
\hline & $1: 75$ & $16.806 \pm 2.484^{* *}$ & $20.435 \pm 2.244^{* *}$ \\
\hline \multirow{6}{*}{$\begin{array}{c}\mathbf{J P}-5 \\
8 \mathrm{~h}\end{array}$} & Control & $0.366 \pm 0.061$ & $1.638 \pm 0.210$ \\
\hline & $1: 500$ & $1.600 \pm 0.120$ & $6.093 \pm 0.601$ \\
\hline & $1: 300$ & $2.911 \pm 0.150^{* *}$ & $8.995 \pm 0.548^{* *}$ \\
\hline & $1: 150$ & $4.782 \pm 0.214^{* *}$ & $11.855 \pm 0.453^{* *}$ \\
\hline & $1: 100$ & $6.342 \pm 0.585^{* *}$ & $13.910 \pm 0.921^{* *}$ \\
\hline & $1: 75$ & $12.747 \pm 1.327^{* *}$ & $17.740 \pm 0.937 * *$ \\
\hline \multirow{6}{*}{$\begin{array}{c}\mathbf{J P}-\mathbf{8}+\mathbf{1 0 0} \\
8 \mathrm{~h}\end{array}$} & Control & $0.406 \pm 0.059$ & $1.735 \pm 0.151$ \\
\hline & $1: 500$ & $4.362 \pm 0.306^{* *}$ & $12.325 \pm 1.248^{* *}$ \\
\hline & $1: 300$ & $11.553 \pm 4.593 * *$ & $13.425 \pm 1.403 * *$ \\
\hline & $1: 150$ & $17.806 \pm 1.190^{* *}$ & $19.480 \pm 1.565^{* *}$ \\
\hline & $1: 100$ & $28.600 \pm 1.847^{* *}$ & $26.652 \pm 1.603^{* *}$ \\
\hline & $1: 75$ & $33.434 \pm 2.493 * *$ & $28.472 \pm 2.004 * *$ \\
\hline
\end{tabular}

** Highly significantly different $(\alpha=0.01)$ mean ranks as compared to the control values 


\subsection{H411E indirectly exposed to JP-8 for $4 \mathrm{~h}$}

Jet fuels are complex mixtures that may contain both hydrophobic and hydrophilic components enabling them to be adequately solubolized by mixing with absolute ethanol (Grant et al., 2000). This indirect exposure through solubolization allows for a more accurate estimation of the amount of jet fuel exposure that occurs in the cells. Figure 22 is a graphical representation of the comet tail moments demonstrating the DNA damage incurred in H4IIE cells as a result of a $4 \mathrm{~h}$ indirect JP-8 exposure. Cells were exposed to $1,3,5,10,15$ and 20 $\mu \mathrm{g} / \mathrm{ml}$ (dissolved in $0.1 \% \mathrm{EtOH}(\mathrm{v} / \mathrm{v})$ ) for $4 \mathrm{~h}$. The media control is DMEM containing FBS $0.5 \%$ and the ethanol control is DMEM containing FBS $0.5 \%$ and EtOH $0.1 \%(\mathrm{v} / \mathrm{v})$. This representative graph for a single experiment shows distribution of comet tail moments in H4IIE cells exposed to increasing concentrations of JP-8.

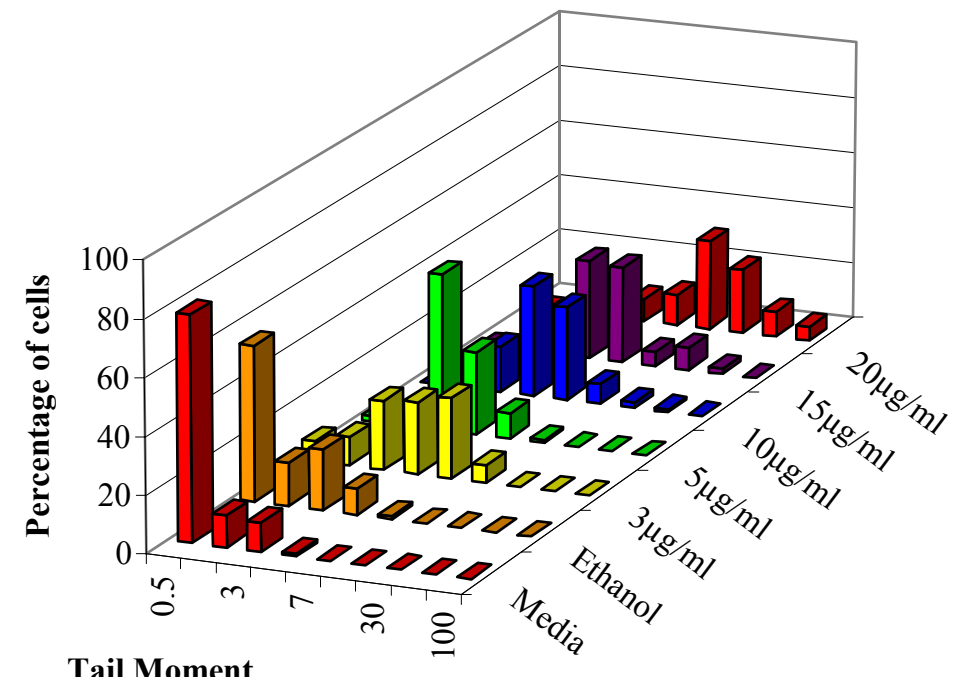

Figure 22 Effect of indirect JP-8 (0.1\% EtOH (v/v)) exposure on comet tail moment of H4IIE cells. 
Table X Mean tail moment measures for H411E cells indirectly exposed to JP-8 $(0.1 \% \mathrm{EtOH}(\mathrm{v} / \mathrm{v}))$

\begin{tabular}{|c|c|c|}
\hline $\begin{array}{c}\text { JP-8 Exposure } \\
(\boldsymbol{\mu g} / \mathbf{m l})\end{array}$ & $\begin{array}{c}\text { Average Mean Tail } \\
\text { Moment } \pm \text { SE }\end{array}$ & Fold increase \\
\hline Media Control & $0.43 \pm 0.07$ & \\
\hline Ethanol 0.1\% & $0.74 \pm 0.07$ & 4.23 \\
\hline 3 & $3.13 \pm 0.18^{* *}$ & 5.89 \\
\hline 5 & $4.36 \pm 0.32^{* *}$ & 7.29 \\
\hline 10 & $5.40 \pm 0.29 * *$ & 10.41 \\
\hline 15 & $7.70 \pm 0.52^{* *}$ & 15.17 \\
\hline 20 & $11.23 \pm 0.73^{* *}$ & \\
\hline
\end{tabular}

** Highly significant differences observed between JP-8 exposed cells and EtOH control as determined by the Dunn's post test $(\alpha=0.01)$.

Table IX contains the cumulative mean tail moment data for three experiments of JP8 exposed H411E cells exposed for $4 \mathrm{~h}$ to JP-8 (dissolved in $\mathrm{EtOH}$ at $0.1 \%(\mathrm{v} / \mathrm{v})$ ) to concentrations ranging from 1 to $20 \mu \mathrm{g} / \mathrm{ml}$. Exposure to JP-8 resulted in an overall increase in mean comet tail moments ranging from $0.74 \pm 0.065(0.1 \%$ EtOH control $)$ to $3.13 \pm 0.18$, $4.36 \pm 0.32,5.40 \pm 0.29,7.70 \pm 0.52$ and $11.23 \pm 0.73$ for JP-8 concentrations $3,5,10,15$ and $20 \mu \mathrm{g} / \mathrm{ml}$, respectively. This cumulative data indicates that as the concentration of JP-8 increases, a greater incidence of strand breakage and DNA lesions occur, which correlate with observed increased comet tail moment. Statistical analysis of the results demonstrated that there was a statistically significant difference between the tail moment for H4IIE exposed to $0.1 \%$ EtOH control and each of the 3, 5, 10, 15, and $20 \mu \mathrm{g} / \mathrm{ml} \mathrm{JP}-8$ concentrations (Table IX), indicating that the DNA damage is a result of the presence of JP-8. The media control was not significantly different to the EtOH control. Additional analysis revealed that the concentration comparisons $5 \mu \mathrm{g} / \mathrm{ml}$ to $10 \mu \mathrm{g} / \mathrm{ml}$ and $10 \mu \mathrm{g} / \mathrm{ml}$ to $20 \mu \mathrm{g} / \mathrm{ml}$ values were not 
significant. This result implies that the initial significance seen in the low concentrations does not continue to increase in a significant linear form.

\subsection{Comet analysis of Hepa1c1c7 and V79 cells exposed to JP-8}

The comet tail moment measures for Hepa1c1c7 cells indirectly exposed to increasing concentrations of JP-8 $(5,10$, and $20 \mu \mathrm{g} / \mathrm{ml}, 0.1 \% \mathrm{EtOH}$ final concentration) for $4 \mathrm{~h}$ are shown in Figure 23 in a representative distribution histogram. The distribution of comet tail moments increases with increasing exposure to JP-8 solubolized in EtOH. When compared to the JP-8 exposed H411E cells comet distributions (Figure 22), the Hepalc1c7 cells do not display as much DNA damage.

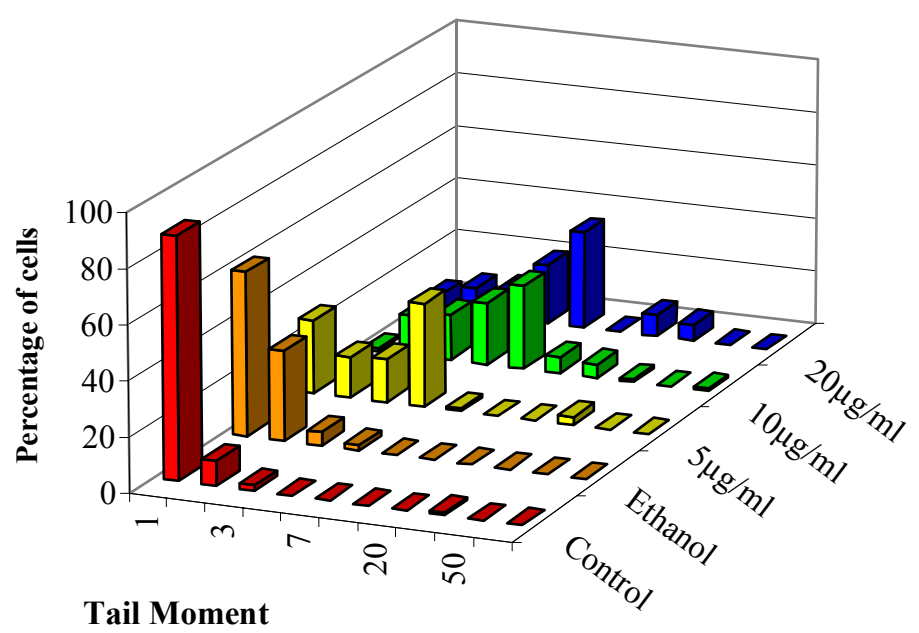

Figure 23 Effect of indirect JP-8 (0.1\% EtOH $(\mathrm{v} / \mathrm{v}))$ exposure on comet tail moment of Hepa1c1c7 cells.

Table XI contains the cumulative mean tail moment data for three experiments of JP8 exposed Hepalc1c7 cells exposed for $4 \mathrm{~h}$ to JP-8 (dissolved in EtOH at $0.1 \%(\mathrm{v} / \mathrm{v})$ ) to $5 \mu \mathrm{g} / \mathrm{ml}, 10 \mu \mathrm{g} / \mathrm{ml}$ and $20 \mu \mathrm{g} / \mathrm{ml}$. Exposure to JP-8 resulted in an overall increase in mean comet tail moments ranging from $0.98 \pm 0.04(0.1 \% \mathrm{EtOH}$ control $)$ to $3.98 \pm 0.16,5.53 \pm$ 
0.61 and $7.09 \pm 1.02$ for JP-8 concentrations 5,10 , and $20 \mu \mathrm{g} / \mathrm{ml}$, respectively. These cumulative data indicates as the concentration of JP-8 increases there is an increase in strand breakage through the observed increase in average comet tail moments. Statistical analysis of the results showed that each exposure concentration produced statistically significant difference compared to the $0.1 \%$ EtOH control. The media control was not significantly different to the EtOH control. Additional analysis revealed that the concentration comparison of $5 \mu \mathrm{g} / \mathrm{ml}$ to $20 \mu \mathrm{g} / \mathrm{ml}$ values was significant while the 5 to $10 \mu \mathrm{g} / \mathrm{ml}$ and 10 to $20 \mu \mathrm{g} / \mathrm{ml}$ values were not statistically significant by the post Dunn's test. When compared to the $\mathrm{H} 411 \mathrm{E}$ average tail moments for 5,10 , and $20 \mu \mathrm{g} / \mathrm{ml}(4.36 \pm 0.32,5.40 \pm 0.29$, and 11.23 \pm 0.77 , respectively) in Table $X$ the Hepalc1c7 values are similar except in the $20 \mu \mathrm{g} / \mathrm{ml}$ $(7.09 \pm 1.02)$ exposure, however all exposures and concentration comparison show the same significance.

Table XI Mean tail moment measures for Hepa1c1c7 cells indirectly exposed to JP-8 $(0.1 \% \mathrm{EtOH}(\mathrm{v} / \mathrm{v}))$

\begin{tabular}{|c|c|c|}
\hline $\begin{array}{c}\text { JP-8 Exposure } \\
(\boldsymbol{\mu} \mathbf{g} / \mathbf{m l})\end{array}$ & $\begin{array}{c}\text { Average Mean Tail } \\
\text { Moment } \pm \text { SE }\end{array}$ & Fold increase \\
\hline Media Control & $0.67 \pm 0.03$ & \\
\hline EtOH 0.1\% & $0.98 \pm 0.04$ & 4.1 \\
\hline 5 & $3.98 \pm 0.16^{* *}$ & 5.6 \\
\hline 10 & $5.53 \pm 0.61^{* *}$ & 7.2 \\
\hline 20 & $7.09 \pm 1.02^{* *}$ & \\
\hline
\end{tabular}

** Highly significant differences observed between JP-8 exposed cells and EtOH control as determined by the Dunns post test $(\alpha=0.01)$.

The V79 cells showed the least DNA damaging effect of the three cell lines investigated. As can be seen in Figure 24 the V79 cells exposed for 4 h to JP-8 (dissolved in $\mathrm{EtOH}$ at $0.1 \%(\mathrm{v} / \mathrm{v}))$ to $5 \mu \mathrm{g} / \mathrm{ml}, 10 \mu \mathrm{g} / \mathrm{ml}$ and $20 \mu \mathrm{g} / \mathrm{ml}$ resulted in a very minimal increase in 
distribution of tail moments with increasing concentration of exposure. Table XII further supports this comparative lack of damage with average tail moments of $2.40 \pm 0.24,3.45 \pm$ 0.38 and $5.72 . \pm .45$ for the 5,10 and $20 \mu \mathrm{g} / \mathrm{ml}$ exposures, respectively. Upon statistical analysis it was revealed that only the 10 and $20 \mu \mathrm{g} / \mathrm{ml}$ exposures were significant and produced very small fold increases when compared to the H411E cells (Table X) and Hepa1c1c7 (Table XI).

Table XII Mean tail moment measures for V79 cells indirectly exposed to JP-8 $(0.1 \% \mathrm{EtOH}(\mathrm{v} / \mathrm{v}))$

\begin{tabular}{|c|c|c|}
\hline $\begin{array}{c}\text { JP-8 Exposure } \\
(\boldsymbol{\mu g} / \mathbf{m l})\end{array}$ & $\begin{array}{c}\text { Average Mean Tail } \\
\text { Moment } \pm \text { SE }\end{array}$ & Fold increase \\
\hline Media Control & $0.53 \pm 0.04$ & \\
\hline Ethanol $0.1 \%$ & $1.27 \pm 0.29$ & \\
\hline 5 & $2.40 \pm 0.24$ & 1.9 \\
\hline 10 & $3.45 \pm 0.38^{* *}$ & 2.7 \\
\hline 20 & $5.72 . \pm .45^{* *}$ & 4.5 \\
\hline
\end{tabular}

$* *$ Highly significant differences observed between JP-8 exposed cells and EtOH control as determined by the Dunns post test $(\alpha=0.01)$.

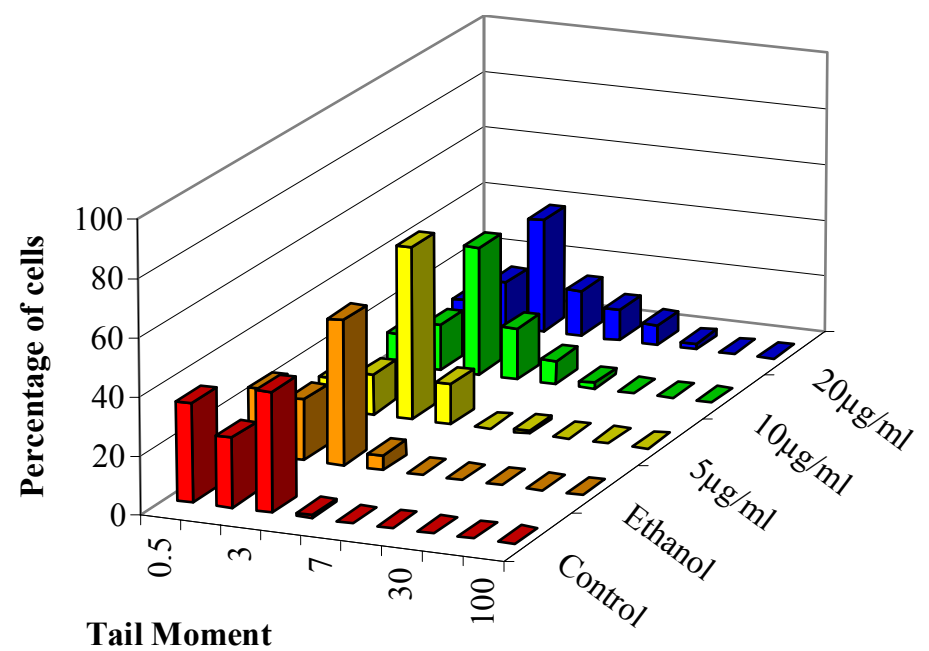

Figure 24 Effect of indirect JP-8 (0.1\% EtOH (v/v)) exposure on comet tail moment of V79 cells. 


\subsection{Ethanol Comparisons in H411E cells}

The concentration of EtOH used in the solubolization of the JP-8 was investigated in the $\mathrm{H} 411 \mathrm{E}$ cells to reveal if increased EtOH concentrations $(0.1 \%, 0.25 \%$ and $0.5 \%)$ were facilitating components penetration in to the cell, thus increasing DNA damage. In contrast to the results obtained in the cytotoxicity studies with JP-8 dissolved in $0.5 \%$ EtOH, no cytotoxicity as determined by the acid phosphatase assay was observed at $0.1 \% \mathrm{EtOH}$ final concentration for this JP-8 concentration range (results not shown). Figure 25 is a representative distribution histogram of tail moment measures of $\mathrm{H} 411 \mathrm{E}$ cells exposed to $0.1 \%, 0.25 \%$ and $0.5 \%$ EtOH with and without a JP-8 concentration of $10 \mu \mathrm{g} / \mathrm{ml}$.

The analyzed statistical signifcances for EtOH comparisons with and without JP-8 exposure $(10 \mu \mathrm{g} / \mathrm{ml})$ can be seen in Table XIII. As expected there was a significant difference between the EtOH controls and the $10 \mu \mathrm{g} / \mathrm{ml} \mathrm{JP}-8$ in all EtOH exposures (i.e. $10 \mu \mathrm{g} / \mathrm{ml} \mathrm{JP}-8$, $0.1 \%$ EtOH is statistically different than the $0.1 \% \mathrm{EtOH}$ control).

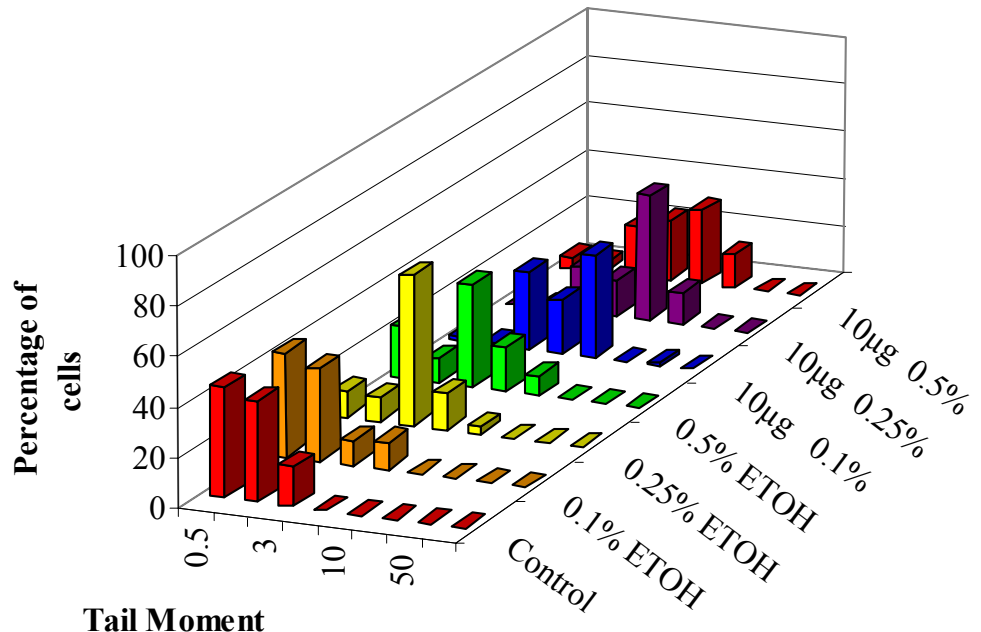

Figure 25 Tail moment measure of $\mathrm{H} 411 \mathrm{E}$ cells exposed to various $\mathrm{EtOH}$ concentrations with and without JP-8 $(10 \mu \mathrm{g} / \mathrm{ml})$ 
Table XIII Statistical comparisons of tail moment measures for H411E cells exposed to varying concentrations of EtOH with and without JP-8 $(10 \mu \mathrm{g} / \mathrm{ml})$

\begin{tabular}{|c|c|c|c|}
\hline Exposure & $\begin{array}{c}\text { Average Mean } \\
\text { Tail Moment } \pm \\
\text { SE }\end{array}$ & $\begin{array}{l}\text { Comparisons of } \\
\text { EtOH and JP-8 }\end{array}$ & $\begin{array}{c}\text { Mean Rank } \\
\text { Difference }\end{array}$ \\
\hline Media Control & $0.73 \pm 0.07$ & & \\
\hline \multirow{3}{*}{ Ethanol $0.1 \%$} & \multirow{3}{*}{$1.76 \pm 0.26$} & vs $0.25 \% \mathrm{EtOH}$ & 86.65 \\
\hline & & vs $0.5 \%$ EtOH & 84.89 \\
\hline & & vs $0.1 \% \mathrm{JP}-8$ & $226.56^{* *}$ \\
\hline \multirow{2}{*}{ Ethanol $0.25 \%$} & \multirow{2}{*}{$2.47 \pm 0.18$} & vs $0.5 \% \mathrm{EtOH}$ & 33.24 \\
\hline & & vs $0.25 \%$ JP- 8 & $225.59 * *$ \\
\hline Ethanol $0.5 \%$ & $3.11 \pm 0.23$ & vs $0.5 \% \mathrm{JP}-8$ & $117.04 * *$ \\
\hline \multirow{2}{*}{ JP-8 $10 \mu \mathrm{g} 0.1 \%$ EtOH } & \multirow{2}{*}{$4.80 \pm 0.45^{*}$} & vs $0.25 \%$ JP- 8 & 85.68 \\
\hline & & vs $0.5 \%$ JP- 8 & 10.37 \\
\hline JP-8 $10 \mu \mathrm{g} 0.25 \%$ EtOH & $6.76 \pm 0.48^{*}$ & vs $0.5 \% \mathrm{JP}-8$ & -75.31 \\
\hline JP-8 $10 \mu \mathrm{g} \quad 0.5 \%$ EtOH & $5.30 \pm 0.37^{*}$ & & \\
\hline
\end{tabular}

** Highly significant differences observed between JP-8 exposed cells and EtOH control as determined by the Dunns post test $(\alpha=0.01)$.

No significant differences were determined between any of the JP-8 concentrations (i.e. JP-8, 0.1\% EtOH compared to JP-8, $0.5 \% \mathrm{EtOH}$ ). Additionally, no significances were seen in any of the EtOH concentrations (i.e. $0.1 \% \mathrm{EtOH}$ compared to $0.25 \% \mathrm{EtOH}$ ), suggesting that the amount of EtOH used to solubolize the JP-8 does not contribute to addition DNA damage from the jet fuel over and above what would be expected from this known oxidizer.

\subsection{Evaluation of DNA repair occurence in $\mathrm{H411E}$ cells indirectly exposed to JP-8}

The level of DNA repair resulting from JP-8 exposure was investigated by combining the comet assay and DNA repair inhibitors to analyze the total DNA damage and the 
contribution of repair. Figure 26 A-E illustrates the effect of repair during exposure of H4IIE cells to increasing concentrations of JP-8 and a combination of $2 \mathrm{mM}$ : $20 \mu \mathrm{M}$ or $4 \mathrm{mM}$ : 40 $\mu \mathrm{M}$ DNA repair inhibitors HU: Ara-C, respectively. These concentrations were chosen by cytotoxicity assays (acid phosphatase) to result in 0 and $5 \%$ cell death (results not shown). In Figure 26 tail moments are for A: Control (Control: DMEM containing FBS 5\% (v/v)), 2:20: Control containing $2 \mathrm{mM} \mathrm{HU}$ and $20 \mu \mathrm{M}$ Ara-C, 4:40: $4 \mathrm{mM} \mathrm{HU}$ and $40 \mu \mathrm{M}$ Ara-C, 2:20E: 2:20 containing EtOH 0.1\% (v/v), 4:40E: 4:40 containing 0.1\% EtOH (v/v). B: $3 \mu \mathrm{g} / \mathrm{ml} \mathrm{JP}-8$ DMEM containing FBS 5\% and inhibitors, C: $5 \mu \mathrm{g} / \mathrm{ml}$ JP-8 DMEM containing FBS 5\% and inhibitors, D: $10 \mu \mathrm{g} / \mathrm{ml} \mathrm{JP-8} \mathrm{DMEM} \mathrm{containing} \mathrm{FBS} \mathrm{5 \%} \mathrm{and} \mathrm{inhibitors} \mathrm{E:} 20 \mu \mathrm{g} / \mathrm{ml} \mathrm{JP}-8$ DMEM containing FBS 5\% and inhibitors. The inclusion of DNA repair inhibitors without JP-8 resulted in a small, but statistically significant increase in tail moment, indicating the arrest of normal DNA repair occurring in the H4IIE cells as seen in Figure 26 A. However, the combination of JP-8 and HU/Ara-C resulted in a greater shift in ranked tail moment with increasing concentrations of JP-8 (Figure $26 \mathrm{~B}-\mathrm{E}$ ). This indicates that DNA repair occurs as a normal process in the H4IIE cells however, the combination of JP-8 and HU/Ara-C results in a much greater shift in tail moment distribution as the JP-8 concentration increases.

Table XIV illustrates that the mean tail moments and respective fold increases of combined inhibitors and JP-8, increases relative to the JP-8 exposure alone. Addition of DNA repair inhibitors hydroxyurea (HU) and cytosine arabinoside (Ara-C) to cell culture with JP-8 resulted in accumulation of DNA damage strand breaks and increases in comet tail moment. Inclusion of $4 \mathrm{mM} \mathrm{HU}$ and $40 \mu \mathrm{M}$ Ara-C with 3, 5, 10 and $20 \mu \mathrm{g} / \mathrm{ml} \mathrm{JP}-8$ concentrations resulted in increased mean tail moments to $5.94 \pm 0.43,10.12 \pm 0.72,17.03 \pm$ 0.96 , and $29.25 \pm 1.55$, respectively. 
A
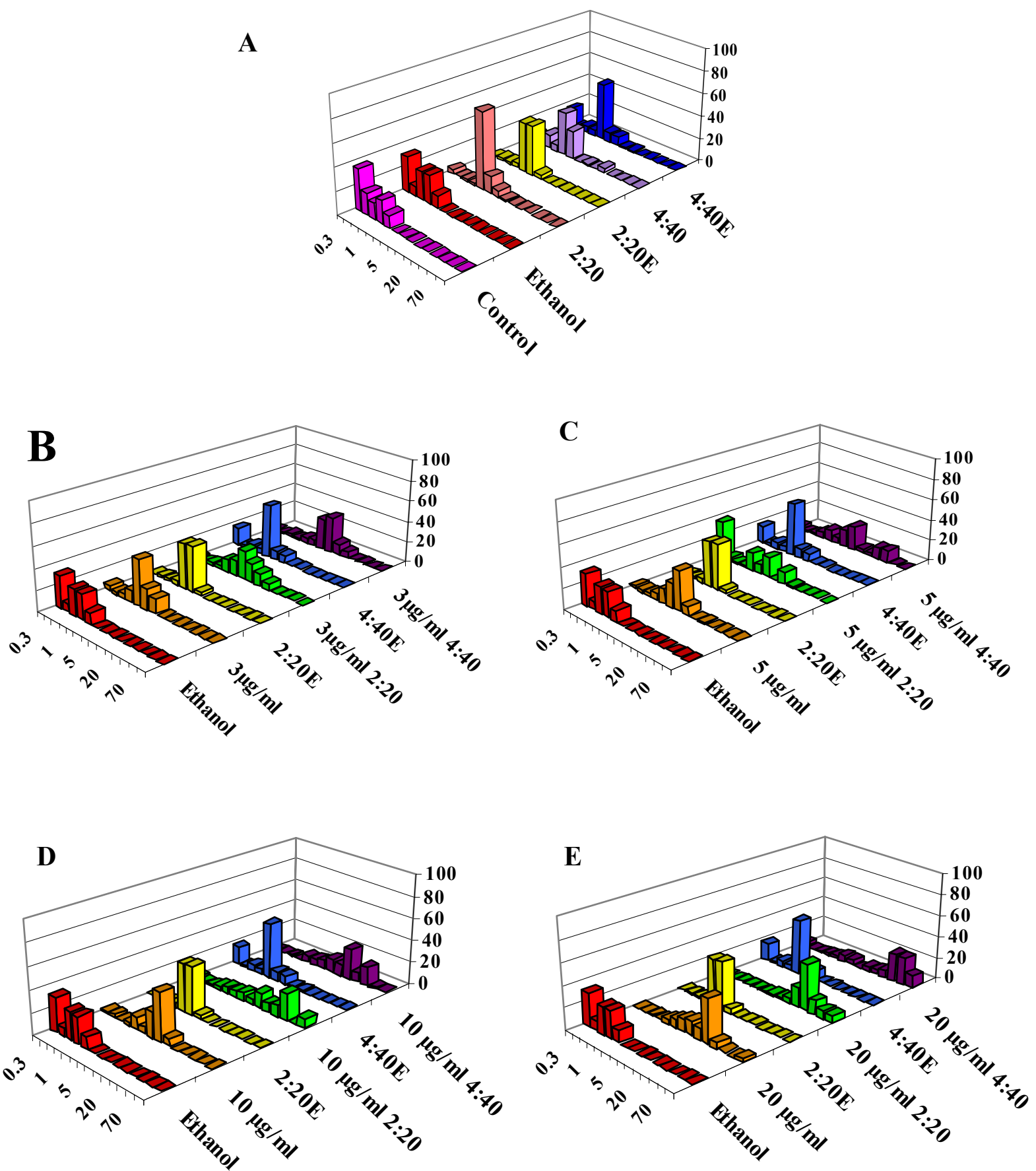

Figure 26 Effect of DNA repair inhibitors on comet formation in H411E cells indirectly exposed to JP-8. Tail moments are for A: Control (Control: DMEM containing FBS 5\% $(\mathrm{v} / \mathrm{v})), 2: 20$ : Control containing $2 \mathrm{mM}$ HU and $20 \mu \mathrm{M}$ Ara-C, 4:40: $4 \mathrm{mM} \mathrm{HU}$ and $40 \mu \mathrm{M}$ Ara-C, 2:20E: 2:20 containing EtOH 0.1\% (v/v), 4:40E: 4:40 containing 0.1\% EtOH (v/v). B: $3 \mu \mathrm{g} / \mathrm{ml} \mathrm{JP}-8$ DMEM containing FBS 5\% and inhibitors, C: $5 \mu \mathrm{g} / \mathrm{ml} \mathrm{JP}-8$ DMEM containing FBS 5\% and inhibitors, D: $10 \mu \mathrm{g} / \mathrm{ml} \mathrm{JP-8} \mathrm{DMEM} \mathrm{containing} \mathrm{FBS} \mathrm{5 \%} \mathrm{and}$ inhibitors E: $20 \mu \mathrm{g} / \mathrm{ml} \mathrm{JP}-8$ DMEM containing FBS 5\% and inhibitors. 
Table XIV Mean tail moments for H411E cells indirectly exposed to JP-8 $(3-20 \mu \mathrm{g} / \mathrm{ml})$ $(0.1 \% \mathrm{EtOH}(\mathrm{v} / \mathrm{v}))$ in the presence of DNA repair inhibitors

\begin{tabular}{|c|c|c|c|}
\hline $\begin{array}{c}\text { JP-8 } \\
\text { Exposure } \\
(\mu \mathrm{g} / \mathrm{ml}) \\
\end{array}$ & $\begin{array}{c}\text { DNA inhibitor } \\
\text { mM HU/ } \boldsymbol{\mu M} \text { Ara-C }\end{array}$ & $\begin{array}{c}\text { Average Mean } \\
\text { Tail Moment } \pm \\
\text { SE } \\
\end{array}$ & $\begin{array}{c}\text { Fold } \\
\text { increase* }^{*}\end{array}$ \\
\hline \multirow{3}{*}{$\begin{array}{l}\text { Media } \\
\text { Control }\end{array}$} & -- & $0.44 \pm 0.04$ & \\
\hline & $2 / 20$ & $1.43 \pm 0.08$ & \\
\hline & $4 / 40$ & $1.38 \pm 0.08$ & \\
\hline \multirow{3}{*}{ Ethanol $0.1 \%$} & -- & $0.65 \pm 0.05$ & \\
\hline & $2 / 20$ & $1.66 \pm 0.25$ & \\
\hline & $4 / 40$ & $1.71 \pm 0.10$ & \\
\hline \multirow{3}{*}{3} & -- & $2.47 \pm 0.16$ & \\
\hline & $2 / 20$ & $3.60 \pm 0.33 * *$ & 1.46 \\
\hline & $4 / 40$ & $5.94 \pm 0.59 * *$ & 2.40 \\
\hline \multirow{3}{*}{5} & -- & $3.37 \pm 0.22$ & \\
\hline & $2 / 20$ & $5.30 \pm 1.17 * *$ & 1.57 \\
\hline & $4 / 40$ & $10.11 \pm 1.21 *$ & 3.00 \\
\hline \multirow{3}{*}{10} & -- & $5.96 \pm 0.65$ & \\
\hline & $2 / 20$ & $13.97 \pm 1.53$ & \\
\hline & $4 / 40$ & $17.03 \pm 1.61 * *$ & 2.86 \\
\hline \multirow{3}{*}{20} & -- & $8.99 \pm 0.55$ & \\
\hline & $2 / 20$ & $19.81 \pm 1.01$ & \\
\hline & $4 / 40$ & $29.25 \pm 2.45^{* *}$ & 3.25 \\
\hline
\end{tabular}

* Fold increase over JP-8 exposure alone, corrected for EtOH and inhibitor exposure. ** Highly significant difference between sample and EtOH control as determined by the Dunn's post test $(\alpha=0.01)$.

Mean tail moments and the differential fold rise in tail moment fold were elevated as the concentration of repair inhibitors and JP-8 was increased relative to JP-8 exposure alone. Statistical analysis indicated that for the higher DNA inhibitor concentration $4 \mathrm{mM}: 40 \mu \mathrm{M}$, the mean tail moment for each JP-8 concentration was statistically significantly increased over JP-8 exposure alone. A maximum fold increase in mean tail moment of 3.3 was achieved with $20 \mu \mathrm{g} / \mathrm{ml}$ combined with $4 \mathrm{mM}$ HU: $40 \mu \mathrm{M}$ Ara-C. For the lower inhibitor concentrations $2 \mathrm{mM}$ : $20 \mu \mathrm{M}$ there is a statistically significant increase in mean tail moment 
between the $3 \mu \mathrm{g} / \mathrm{ml}$ JP-8 concentration point and the combined $3 \mu \mathrm{g} / \mathrm{ml}$ JP-8 $2 \mathrm{mM}$ : $20 \mu \mathrm{M}$. The same is true for $5 \mu \mathrm{g} / \mathrm{ml} \mathrm{JP}-8$. However for the 10 and $20 \mu \mathrm{g} / \mathrm{ml} \mathrm{JP}-8$ inhibitor concentrations the difference was not significant, suggesting an induction of repair over and above that which the low level of inhibitor could inhibit.

\subsection{Oxidative DNA evaluation of JP-8 exposed H411E cells by the FLARE Assay}

An adaptation of the comet assay employing the enzymatic activity of the DNA repair enzyme E.coli Formamidopyrimidine-DNA glycosylase (FPG) to detect oxidative damage was applied to the H411E cells exposed indirectly to JP-8 $(10-20 \mu \mathrm{g} / \mathrm{ml})$. Figure 27 displays a representative distribution histogram of tail moment measures for $\mathrm{H} 411 \mathrm{E}$ cells indirectly exposed to JP-8 for $4 \mathrm{~h}$ with and without the inclusion of the FPG enzyme. As the

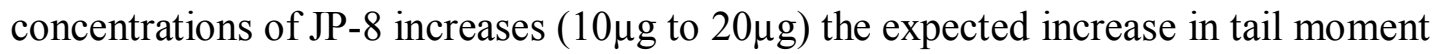
measures is apparent.

Comparisons of the tail moment data (Table XV) reveals that the 10 and $20 \mu \mathrm{g} / \mathrm{ml} \mathrm{JP}-8$ exposures produce average mean tail moments of $6.89 \pm 0.67$ and $11.65 \pm 1.07$, respectively (values in the same range of the previous H411E indirect JP-8 exposures (Table X). While the 10 and $20 \mu \mathrm{g} / \mathrm{ml} \mathrm{JP}-8$ exposures with the additional FPG incubation have average mean tail moment measures of $16.73 \pm 0.84$ and $25.89 \pm 1.53$, respectively. This difference is more aptly displayed in the fold increases where the fold for the $10 \mu \mathrm{g} / \mathrm{ml}$ exposure increases from a 3.9 to 5.2 with the inclusion of the FPG enzyme. With the inclusion of the repair enzyme FPG the tail moment measures increase over those observed for the jet fuel exposures especially in the $10 \mu \mathrm{g} / \mathrm{ml}$ exposure. 


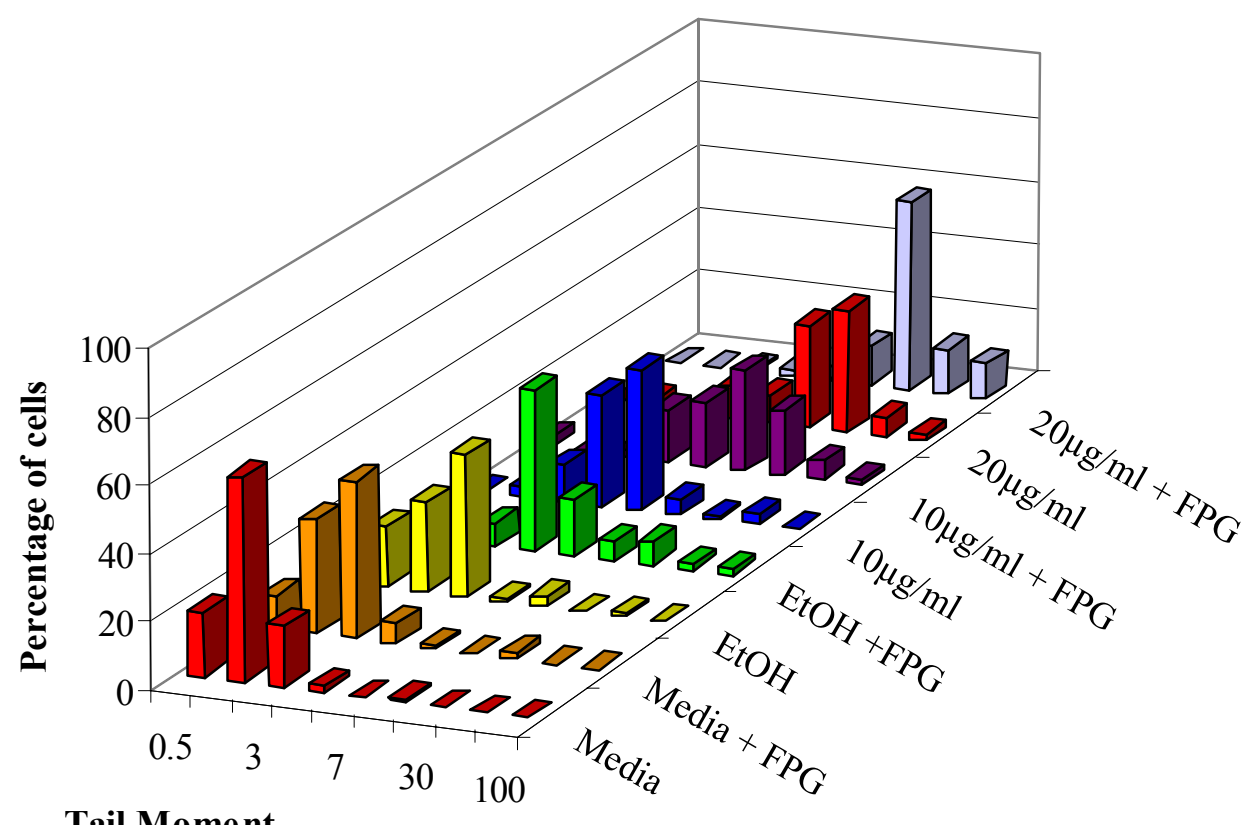

Tail Moment

Figure 27 Comet tail moments in H4IIE cells indirectly exposed to JP-8 (10 and $20 \mu \mathrm{g} / \mathrm{ml})$ $(0.1 \% \mathrm{EtOH}(\mathrm{v} / \mathrm{v}))$ for $4 \mathrm{~h}$ analyzed by the FLARE assay for oxidative DNA damage.

This difference in fold increase is also observed in the $20 \mu \mathrm{g} / \mathrm{ml}$ sample with a 6.7 fold increase over the EtOH control with the jet fuel alone to a 8.0 fold increase with the inclusion of the enzyme. Statistical analysis of the data reveals all jet fuel exposures with and without the repair enzyme significant to their respective EtOH control. There is no significant difference between the media control with the inclusion of the enzyme. However the EtOH with FPG control did produce a significant effect over the EtOH exposure alone, which is to be expected since EtOH is a known oxidizing agent.

Additional statistical evaluations were performed on the data to insure that the increase in tail moment observed were in fact due to the jet fuel exposure an not to the EtOH used in the solubolization process. Upon this analysis it was determined that the jet fuel exposed cells differed statistically with the inclusion of the FPG enzyme. The comparison of the tail moment measures for the H411E cells indirectly exposed to JP-8 with and with out 
the inclusion of the DNA repair enzyme reveal that oxidative DNA damage is occurring as a result of jet fuel exposure.

Table XV Mean tail moment measures for JP-8 indirectly exposed (0.1\% EtOH (v/v)) H4IIE cells $(10$ and $20 \mu \mathrm{g} / \mathrm{ml})$ analyzed by the FLARE assay for oxidative DNA damage

\begin{tabular}{|c|c|c|}
\hline $\begin{array}{c}\text { JP-8 Exposure } \\
(\boldsymbol{\mu g} / \mathbf{m l})\end{array}$ & $\begin{array}{c}\text { Average Mean Tail } \\
\text { Moment } \pm \text { SE }\end{array}$ & Fold increase \\
\hline Media Control & $1.04 \pm 0.27$ & \\
\hline Media with FPG & $1.38 \pm 0.38$ & \\
\hline Ethanol 0.1\% & $1.74 \pm 0.13$ & 3.9 \\
\hline Ethanol 0.1\% with FPG & $3.23 \pm 0.83^{* *}$ & 5.2 \\
\hline 10 & $6.89 \pm 0.67 * *$ & 6.7 \\
\hline 10 with FPG & $16.73 \pm 0.84 * *$ & 8.0 \\
\hline 20 & $11.65 \pm 1.07 * *$ & \\
\hline 20 with FPG & $25.89 \pm 1.53^{* *}$ & \\
\hline
\end{tabular}

** Highly significant differences observed between JP-8 exposed cells and EtOH control as determined by the Dunns post test $(\alpha=0.01)$.

\subsection{Detection of DNA adduct formation with ${ }^{32} \mathrm{P}$-postlabeling}

DNA adduct formation by ${ }^{32} \mathrm{P}$-postlabeling assay with nuclease $\mathrm{P} 1$ enhancement in a rat hepatoma (H411E) model system exposed to $10 \mu \mathrm{g} / \mathrm{ml}$ of JP-8 (solubolized in $(\mathrm{EtOH})$ at $0.1 \%$ final concentration $(\mathrm{v} / \mathrm{v}))$ for $4 \mathrm{~h}$ in vitro was investigated. The DNA isolated from $\mathrm{H} 411 \mathrm{E}$ cells analyzed by ${ }^{32} \mathrm{P}$-postlabeling detected no adduct formation in the autoradiographs of the chromatograms (Figure $28 \mathrm{~A}$ ). The negative control DNA adduct profile for H411E DNA exposed to DMEM containing FBS 5\% and EtOH 0.1\% final concentration $(\mathrm{v} / \mathrm{v})$ for $4 \mathrm{~h}$ was not shown due to the lack of adduct formation as expected. The positive control BaP-DNA adduct is accurately detected (Figure $28 \mathrm{~B}$ ) and had 
characteristic mobility of the major product of the reaction of BaP 7,8-diol-9, 10-oxide, the ultimate carcinogenic metabolite of BaP. The adduct migrated diagonally on the TLC plate, extending from the origin located at the lower right-hand corner to the upper left hand corner. In one of the experiments small artifacts were found on the developed JP- 8 exposed TLC plate but were concluded not be representative of DNA adducts, especially since they were not found in the two other experiments performed. These spots may represent background radioactivity from [gamma- ${ }^{32}$ P]ATP (Reddy et al., 1997).

A

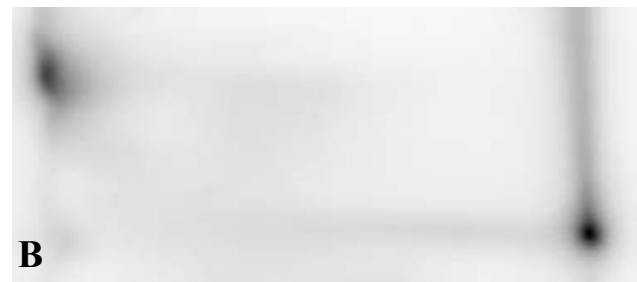

Figure 28 Representative chromatographic pattern obtained after nuclease P1 enrichment and ${ }^{32} \mathrm{P}$-postlabeling analyses by TLC of DNA adducts from H411E cells exposed to JP-8 and BaP. A: DNA adduct profile for H411E DNA exposed to DMEM containing FBS 5\% and $10 \mu \mathrm{g} / \mathrm{ml}$ of JP-8 $(0.1 \% \mathrm{EtOH}(\mathrm{v} / \mathrm{v}))$ for $4 \mathrm{~h}$. B: DNA adduct profile for H411E DNA exposed to DMEM containing FBS $5 \%$ and $50 \mu \mathrm{M} \mathrm{BaP}$ for $12 \mathrm{~h}$. 


\section{DISCUSSION}

To understand the range of genotoxic effects of jet propulsion fuels, biological endpoints at the DNA level were determined in vitro. Genotoxic agents can be defined functionally as having the ability to alter DNA replication and genetic transmission (Fairbairn et al., 1995). DNA single strand breaks (ssb) and double strand breaks (dsb) can originate from the direct modification of DNA by chemical agents or their metabolites (Marnett et al., 2000, Møller and Wallin, 1998, Horváthová, 1998), from the process of DNA repair (Ma et al., 1995, Barnes et al., 1993), replication, and recombination, or from the process of apoptosis (Eastman and Barry, 1992). Commonly, the major endpoints of shortterm genotoxicity assays include DNA damage, point mutations and chromosome aberrations. The SCE and Ames assay were used as a biomarker of effect to evaluate the extent of genetic insult. DNA adducts and comet assay experiments were performed as biomarkers of exposure to detect the amount and characterize the type of DNA damage that could occur from jet fuel exposure. This study is not intended to be a complete molecular epidemiological investigation of jet fuel but an in vitro evaluation employing selected genotoxicity biomarkers to obtain an insight into the potential DNA damaging effects of the fuels. This is the first demonstration of genotoxicity as a result of exposure to jet propulsion fuel.

\section{Ames assay investigation}

The Ames/ Salmonella/ microsomal mutagenesis assay was performed to investigate the mutagenic effects of JP-8, JP-5 and JP- $8+100$. Based on the results presented in this investigation, the DMSO extracts of the fuels are considered nonmutagenic since there is no 
dose related increase in the number of revertant colonies observed in all three independent experiments with Salmonella typhimurium strain TA98 without metabolic activation. These fuels produced a weakly mutagenic dose response but not a doubling of revertants per plate relative to the control. The fuels could not be tested at higher doses because it would exceed the toxicity limits to the bacteria. The Ames assay has been modified to improve sensitivity to complex mixtures such as petroleum oils and distillation fractions (Blackburn et al., 1984,1986). Since the detection of PAHs in complex mixtures by the Ames assay depends on their concentrations relative to the concentration and behavior of components not requiring metabolic activation (Löfroth, 1981), experiments with and without metabolic activation were performed. Even though DMSO extraction and the inclusion of the S9 fraction enables the aqueous and metabolic dependent components to interact better with the tester bacteria, no mutagenicity was found associated with JP-8, JP-5 or JP-8+100.

JP-8 by direct application was not found to be mutagenic in the TA98 strain through a previous Ames assay evaluation (Brusick and Matheson, 1978). While the Ames investigation of jet fuel is limited, much work has been done on the diesel and kerosene and their particulates employing strain TA98. The mutagenic effect of diesel exhaust is more than three times higher than that of gasoline exhausts, which is attributed to the nitropyrene and aromatic fractions (Morimoto et al., 1986, Salmeen et al., 1984, Löfroth, 1981). The high-end boiling petroleum distillate fractions have been shown to have a positive response in the Ames assay and have previously been classified as mutagenic and some carcinogenic (Blackburn et al., 1986). Studies on straight run PMDs such as jet fuel generate tumors but show a low or negative response in the Salmonella mutagenesis test. McKee et al. (1994) found that PMDs were not mutagenic in the Ames assay as long as the fuel did not contain 
cracked stocks, which elevated the levels of PAHs. These conflicting mutagenic responses to petroleum hydrocarbon mixtures is thought to be due to differences in solvent refining, which quantitatively removes PAHs from the oils and helps to decrease the carcinogenic activity. Since jet fuel is highly refined it is reasonable that no mutagenicity is detected by the Ames assay. However, it must be noted that this noncarcinogenicity is assuming that the jet fuel is from a pure stock with no cracked components.

A negative response, although predictive of noncarcinogenicity, cannot be considered definitive for classification of the fuels. Even though this screening method is valuable in studies of complex mixtures containing a multitude of compounds not yet identified or quantified by chemical analysis (Löfroth, 1981), only the soluble components of fuel can be evaluated to insure interaction with the bacteria. This poor correlation to mutagenicity could be attributed to inadequate interaction of the total fuel mixtures with the tester bacteria. Further evaluation of the biological and mutagenic effects of various fuel components could help to identify the specific extracts that are interacting with DNA and causing the DNA damage seen elsewhere in this genotoxic evaluation. However, this investigation of specific fuel extracts still would not produce a complete evaluation of the mutagenic effect of the fuels.

\section{Cytotoxicity investigations}

Preliminary investigations on the in vitro cytotoxicity and electrophysiological toxicity of JP-8 on a number of cell lines has been investigated resulting in the conclusion that cell types will express different sensitivities to jet fuel (Grant et al., 2000, Stoica et al., 2001, Rosenthal et. al., 2001, Allen et al., 2001). These results suggest that each organ/tissue 
reacts to JP-8 exposure in a different manner and that there are multiple cellular procedures involved in the cell's ability to deal with fuel exposure. Since previous investigations showed that cell types exhibit differential sensitivity to JP-8 both in their ability to survive exposure and susceptibility to damage, the cytotoxicity limits from exposure to JP-8 were investigated in each cell line employed in this study. The studies presented here were are performed at concentrations under a $50 \%$ cell death since DNA damage, as primary or secondary effect, is associated with common pathways of cytotoxicity.

An in vitro cytotoxicity battery with the H411E, Hepa1c1c7, and V79 cells was implemented to perform initial toxicity evaluation on synthesized fuel deicer alternatives (2,2-dimethyl-[1,3]dioxolan-4-yl)-methanol (Deicer 1), [1,3]-dioxolane-4-methanol (Deicer 2), (2-methyl-[1,3]dioxolan-4-yl)-methanol (Deicer 3). The hepatic cells demonstrated that Deicer 2 was the most potent in cytotoxicity. The fact that the V79 cells with their low metabolic abilities did not demonstrate the same effect suggests that the toxicity of Deicer 2 is a result of metabolic breakdown. As a result of these investigations [1,3]dioxolan-4-ylmethanol has been dismissed as a potential deicer based on the formaldehyde breakdown product that will produce high toxicity rates at concentrations needed for efficient deicing function. Deicer 3, (2-methyl-[1,3]dioxolan-4-yl)-methanol, showed severe cytotoxicity in the V79 cells, suggesting that the non-metabolized form of the deicer could result in cell injury. Deicer 1 has been shown to have excellent potential properties as a deicing agent and also has been shown to be the least toxic in all cell lines used in this investigation. However, (2,2-dimethyl-[1,3]dioxolan-4-yl)-methanol does have a higher dermal permeability than present deicing agents (ex. diEGME) due in part to its higher lipophilicity (Mushrush et al., 1999) which could increase its exposure concentrations. Both 2,2-dimethyl-1,3-dioxoland-4 
methanol and 2-methyl-1,3-dioxoland-4 methanol are predicted to be relatively nontoxic at the concentrations necessary for inhibiting ice formation. The 1,3-dioxolane-4-methanol as expected was found to induce cytotoxicity because of the formation of formaldehyde upon decomposition. Given the responses from these in vitro tests, more appropriate toxicological investigations, such as in vivo evaluations should be pursued before a decision is made on an appropriate and safe deicer alternative.

\section{Sister chromatid exchange investigation}

Lymphocytes in general and $\mathrm{T}$ cells in particular are important regulators of immune responses that are essential for the defense against various agents that can have serious shortterm and long-term consequences on the health of the organism. Chemicals can enter the blood stream at the capillaries right below the epidermis making peripheral lymphocytes the first line of defense for the system. Lymphocytes may or may not serve as a biomarker for metabolic capability since they contain few metabolic enzymes.

Peripheral lymphocytes directly exposed to JP-5, JP-8 and JP- $8+100$ for $4 \mathrm{~h}$ demonstrated an observed but not statistically significant induction of sister chromatid exchanges when analyzed by the SCE technique. SCE induction is a sensitive indicator of chemically induced perturbations in DNA and cytotoxic damage (Latt et al., 1981) and is an accepted measure of detection of environmental mutagens and carcinogens (Tucker et al., 1993). Cytogenetic analysis of chromosomal aberrations in peripheral lymphocytes has been used extensively as a biomarker of exposure to potential carcinogens and chemicals. This examination of genotoxic insult at the chromosome level has previously been shown to be sensitive system for cytogenetic damage detection for exposures to chemicals, complex 
mixtures and PAHs (Krishna et al., 1984, Wilmer et al., 1990, Palma et al., 1993, Albertini et al., 2000, Morimoto et al., 1986, Knudson, et al. 1998, Jacobson-Kram et al., 1993, McDiarmid et al., 1995, Lemasters et al., 1997, 1999a).

Previously the genotoxic effects of aircraft maintenance personnel exposed to low levels of solvents and fuel have been investigated in biomonitoring studies. Lemasters et al., (1997, 1999a) and Pitarque et al., (1999a) found increases in mean SCEs in fuel exposed personnel, however these results were not found to be statistically significant. Lemasters et al. (1997) showed that SCEs could be efficiently formed in response to exposure to substances that form covalent adducts to DNA or affect metabolism of DNA precursors. It has been postulated that a decrease in immune cell number could explain the negative SCE effects as fuel exposure increases (Lemasters et al., 1997). The majority of studies on gasoline and oil refineries have shown benzene and toluene exposed workers to have a non significant increase in SCE frequency as a consequence of low continuous exposure (Popp et al. 1992, Carere et al., 1995a,b 1998, Major et al. 1994). However, soldiers serving in Kuwait while oil fires burned found to have highly significant increases in mean SCEs (McDiarmid et al., 1995). The results presented in this study are in accord with previous investigations, in that the fuel demonstrates an increase but not a significant increase in SCE frequency. The simple presence of increased SCE frequency does suggest that there is a fuel-DNA interaction and justify further experimentation of direct DNA damage through the comet assay. 


\section{Comet Assay}

The comet assay has been shown in many evaluations to be a sensitive test for genotoxicity to identify possible human mutagens and carcinogens at the individual cell level (McKelvey-Martin et al., 1993, Fairbairn et al., 1995, Collins et al., 1997, Pitarque et al., 1999a, b, Anderson et al., 1998). This technique enables DNA damage to be evaluated in many different cell types providing information that spans the fields of genetic toxicology, ecotoxicology, radiation biology, DNA repair, apoptosis, human and environmental biomonitoring, medical, epidemiological and environmental research. A broad spectrum of DNA damaging effects have been investigated by analysis of increased DNA migration in the comet assay: UV and ionizing radiation (Olive, 1999, Singh et al., 1998, Tice et al., 1995, Gedik et al., 1992, Olive et. al., 1990) free radicals and alkylating agents (Collins et al., 1997, Horváthová et al., 1998), adduct formation (Anderson et al., 1995, Andreoli et al., 1997), repair processes, and DNA crosslinks (Olive and Banath, 1995, Olive, 1999, Tice et al., 2000). A confirmed positive result by the comet assay is regarded as an indication of a genotoxic effect related to exposure to an agent (Møller et al. 2000).

The comet assay provides a method to predict the genotoxicity of potentially mutagenic and carcinogenic pollutants that could cause insult to various types of cells (Hartmann and Speit, 1995, Fairbairn et al., 1995) and to assess the persistence of these effects. Additionally, the potential of the comet assay to quantitate DNA damage at the single cell level is decisively advantageous, allowing the identification of susceptible cell subpopulations and thus increasing the chance of detecting mild or borderline effects (Andreoli et al., 1997, McKelvey-Martin et al., 1993). The method can be used to detect the induction of DNA damage in almost any cell type, including cultivated cells in tissue culture 
and primary cells in suspension culture, with the main restriction of not being hypersensitive to additional DNA damage induced during the assay itself (Rojas et al., 1999, Olive, 1999, Tice et al., 2000,).

The neutral electrophoresis assay performed in this study gives consistent results, shows good dose responses and is valuable for estimating a wide range of damage (Angelis et al., 1999). Even though the neutral electrophoresis conditions limit the general utility of the assay, it was a sufficient approach for the endpoint of this investigation as it sensitively detects double strand breaks. Dsbs are more severe than ssbs, in that they cause an immediate loss of transcriptional ability, and are unlikely to be repaired correctly leading to broken chromosomes and cell death (Eastman and Barry, 1992). The measure of the formation of dsbs serves as an appropriate indicator of DNA instability (Filatov at al., 1998).

\section{Comet assay investigations with direct fuel exposure}

This study investigated the biological endpoint of DNA strand breaks to determine the genotoxic effects of JP-5, JP- 8 and JP-8 +100 over 4 and 8 h exposures in human peripheral blood lymphocytes and H411E cells in vitro. Comparisons of the trends of DNA damage detected by the comet assay, from JP-5, JP-8, and JP- $8+100$ fuel exposures provided insight into the extent of genetic insult from exposure. Cultured primary lymphocytes and H411E cells subjected to increasing concentrations (1:500 - 1:75) of the JP-8 fuel for 4h, show statistically significant tail moments indicating increasing DNA damage with increasing volume of fuel. The JP-8 exposure shows a linear increase in damage as exposures increase. JP-5 demonstrates initial insult to DNA that does not increase with exposure. The JP-8+100 exposed cells demonstrate the most severe DNA damage from exposures even at low concentrations. 
Peripheral blood as a secondary lymphoid tissue has been shown to be a sensitive system for testing exposure to fuel (Harris et al., 1997a). Based on the JP-8 absorption studies (Riviere et al., 1999, McDougal et al., 2000, Baynes et al., 2001) and the immunotoxicity investigation (Allen et al., 2000, 2001, Ullrich, et al., 1999, Ullrich and Lyons, 2000, Harris et al., 1999b, 2000, 2001a) it is apparent that the fuel penetrates the skin barrier enough to induce an immune response. The fact that absorbed jet fuel can induce an immunotoxic response further supports the possibility that the jet fuel can induce a genotoxic response. These studies suggest the importance of investigating the genotoxic effects of fuels in a primary cell system. The comet assay has extensively been applied to peripheral lymphocytes primarily in genotoxicity testing and as a tool for human biomonitoring of environmental and or occupational exposure to carcinogenic and mutagenic agents (Hartmann et al., 2001, Møller et al., 2000, Pitarque et al., 1999a,b, Srám et al., 1998, Andreoli et al., 1997, Hartmann and Speit, 1995, 1997, Anderson et al., 1995). Studies on human peripheral lymphocytes have highlighted the sensitivity of the assay in the detection of DNA damage in smoking habits (Betti et al., 1995), diet (Green et al., 1994), benzene and its metabolites (Anderson et al., 1995) genotoxic drugs (Hartmann and Speit, 1995, Vaghef et al., 1996), oxidative DNA damage and DNA repair (Collins et al., 1993, 1995, 1996).

The JP-8 fuel exposed lymphocytes and H411E cells displayed a recognizable increase in damage as a function of concentration. The increased damage noted for the JP-8 versus the JP-5 fuel is possibly attributable to the additives in JP-8, which are not present in JP-5. The significant effects induced by JP- $8+100$ were observed even at the lowest concentration tested. The primary difference between the composition of JP- $8+100$ and JP- 8 is the inclusion of a thermally stable additive package consisting of an antioxidant, solvent 
oil and surfactants. It is conceivable that the solvent oil and/or detergents aid in the uptake of the hydrocarbons and/or other genotoxic agents into the cell, which may explain the increase in DNA damage seen with the lowest concentration of the JP-8+100 fuel.

This potential explanation can be supported by the differential percutaneous absorption of the components (tridecane, nonane, naphthalene and toluene) of JP-8 and JP$8+100$ previously determined (Kanikkannan et al., $2001 \mathrm{a}, \mathrm{b}$ ). Dermal absorption studies of three JP- 8 and JP- $8+100$ hydrocarbon components (naphthalene, dodecane and hexadacane) revealed that the levels of skin penetration differed between fuel components (Riviere et al., 1999). The JP- $8+100$ also has been shown to produce significant changes in barrier functions of the skin. The increased DNA damage could be due to the higher permeability coefficients of aromatic compounds than the aliphatic compounds (Kanikkannan et al., 2001b, McDougal et al., 2000).

The known performance additives in the JP- 8 base fuel, diEGME, Stadis 450 , and DC1-41, have been shown to be capable of synergistic or antagonistic effects on dermal disposition including increased absorption of the fuel and other associated products (Baynes et al., 2001). Due to the hydrophilic nature of the deicing agent diEGME it can facilitate the absorption of nonpolar compounds. The deicing component diEGME has been found to increase the retention of jet fuel components further increasing their potential systemic absorption (Baynes et al., 2001). The findings in this study further suggest the additive involvement in the transport rates of jet fuel components that are normally slower diffusing (i.e. aliphatic components) and potentially increasing the amount of deleterious exposure to the body. However, a more complete study controlled for the presence of the additives is required to determine their impact on the observed genotoxicity. 
Direct interest to this investigation of jet fuel is the ability of the comet assay to accurately detect overall genotoxic insult including DNA adduct formation and oxidative damage. The comet assay has been previously shown to be a sensitive biological indicator of low level hydrocarbon exposure (i.e. BaP) (Pitarque et al., 1999a, 1999b, Andreoli et al., 1997, Speit et al., 1996, Hartman and Speit, 1995, Anderson et al., 1995, Vaghef et al., 1994). In addition the DNA damaging effects of benzene and its metabolites has been accurately detected by the comet assay (Andreoli et al., 1997, Anderson et al., 1995). Specifically, Andreoli et al., (1997) found an excess of DNA damage in lymphocytes of gasoline station attendants exposed to low levels of benzene and other petroleum products. The results reported here are similar to those reported by Pitarque et al., (1999a) detecting DNA damage using an alkaline comet assay with peripheral blood lymphocytes of airport personnel.

Based on the distribution trends seen in the peripheral lymphocytes and H411E cells directly exposed to the three fuels there is no discernible difference in the DNA damage for the 4 and $8 \mathrm{~h}$ exposures. This signifies that there is not a time dependent increase in DNA damage from the fuel exposures and so the $8 \mathrm{~h}$ time point was not included in further experimentation. Since there is no difference in the lymphocytes and the H411E cells genotoxic response to the fuels, the H411E cells are used in further in comparison with other cell lines to determine why the DNA damage was caused. These results have also accurately demonstrated that the tail moment and percent DNA measures display the same trends of damage supporting the idea that they are compatible for the examination of DNA damage and are not cell type dependent. These two measures have been recommended as measures to 
be used for comparison of results within or between laboratories (Collins et al., 1997, Tice et al., 2000).

These data support that jet fuels (JP-5, JP-8, and JP-8+100) induce DNA strand breaks as measured by the comet assay. The effects observed in the exposed cells could be due to induced DNA damage or strand-break formation during excision repair (Tice et al., 2000). The JP-5 directly exposed sample results indicate that a great portion of the induced lesions are eliminated very rapidly and/or no further excision of damage takes place with increasing concentrations. The increase in DNA damage as quantitatively detected by the comet assay, revealed a significant genotoxic insult as a result of jet fuel exposure, indicating the potential for genotoxic hazard. The complete effects and ramifications of jet fuel exposure on individuals in the field have yet to be determined. However, the results from this in vitro study suggest that the more complex formulations of JP-8 and JP- $8+100$ are more genotoxic than the simpler JP-5 fuel.

\section{Comet assay investigations with indirect JP-8 exposure}

The $4 \mathrm{~h}$ simulated occupational exposure to $3-20 \mu \mathrm{g} / \mathrm{ml} \mathrm{JP}-8$ in $0.1 \%$ EtOH also resulted in DNA damage as measured by comet tail moment in H4IIE cells. This analysis of DNA damage by comet assay indicated that increasing concentrations of JP-8 resulted in DNA damage that was independent of the EtOH used for JP-8 solubilization. The mean comet tail moment for exposed H4IIE cells increased with JP-8 concentration over the $4 \mathrm{~h}$ test

period, with the maximum damage apparent at $15-20 \mu \mathrm{g} / \mathrm{ml}$ of JP-8. This dose-responsive trend for DNA damage is similar to what was found in the previous comet assay 
investigations involving direct jet fuel exposure using the a rat hepatoma model. Therefore, it is evident from these results that JP-8 exposure induces dsbs in H4IIE DNA.

Due to the increases in hepatic mixed function oxidase activity, previously identified in jet fuel exposure (Dössing et al., 1985), it was necessary to evaluate JP-8 with metabolic competence. Many compounds foreign to the human body are metabolized in the cell by a series of enzymes such as cytochrome P450s and a number of conjugating enzyme systems to reactive metabolites. It is necessary to develop appropriate test systems to investigate metabolic activity on an individual and molecular level. The hepatic cell lines (H411E and Hepa1c1c7) were chosen as experimental systems due to the fact that the liver is the major site of detoxification of exogenous and endogenous compounds in the body (Hathway, 2000). H411E and Hepa1c1c7 cells have been accurately shown to induce aryl hydrocarbon hydroxylase activity when exposed to certain classes of compounds (Yu et al., 1996, Dudley et al., 2001). As a result of these properties, H4IIE and Heapa1c1c7 cells have been used extensively for in vitro hepatocyte studies as a detection system for toxic substances and toxic metabolites (Sawyer and Safe, 1982, Yu et al., 1996). It is the balance between the exposure to or production of the genotoxic components of a chemical and the extent of detoxification that determines the amount of overall genotoxic insult to the DNA.

Genotoxic chemicals can be either direct acting or require metabolic activation, which normally is tissue and cell type specific (Hathway, 2000, Conney, 1982). It has been previously shown that the activities of protective enzymes as well as DNA strand break repair capabilities vary considerably between cell types (Duthie and Collins, 1997). The analysis in the different cell lines was performed to attempt to relate the differences in DNA damage responses to differences in activities of detoxifying and DNA repair enzymes. Both 
H411E and Hepa1c1c7 showed a severe increase in DNA damage with exposure to JP-8 as compared to the response in the V79 cells. The different comet assay measures seen in the hepatic cell lines versus the low metabolically capable V79 cell line suggest the possibility of metabolic involvement in JP-8 components. Each cell has its own biochemical characteristics making them more or less susceptible to JP-8 induced damage. This result suggests that the difference in cell susceptibility to JP-8 in this study is due to different detoxifying enzyme activities. In addition, these results demonstrate the increased sensitivity of the H4IIE cells as a model system for the jet fuel induced DNA damage. More studies are needed to determine the metabolic enzymatic profile of this complex mixture of JP-8.

\section{DNA repair investigations}

The combination of repair inhibitors has been incorporated into the comet assay to accumulate DNA breaks at sites of incomplete repair to further understand the mechanism of damage and the potential repair (Martin et al., 1999, Horváthová et al., 1999, Andreoli et al., 1997, Gedik and Collins, 1991). To evaluate the induction and effect of DNA repair the H4IIE cells were exposed to increasing concentrations of JP-8 and a combination of $2 \mathrm{mM}$ HU: $20 \mu \mathrm{M}$ Ara-C or $4 \mathrm{mM}$ HU: $40 \mu \mathrm{M}$ Ara-C DNA repair inhibitors. Addition of DNA repair inhibitors to the H411E cultures exposed indirectly to JP-8 resulted in additional accumulation of DNA strand breaks. Repair of the JP-8 induced DNA damage is apparent, by the finding that inclusion of repair inhibitor in JP-8 exposure of H4IIE resulted in an inhibition of DNA repair and a corresponding increase in the number of strand breaks, hence increased mean tail moments compared with JP-8 alone. The increases in mean tail moments were significant for all concentrations at the higher inhibitor concentrations (4 mM HU: 40 
$\mu \mathrm{M}$ Ara-C), but not significant at the higher JP-8 concentrations with the lower inhibitor concentrations ( $2 \mathrm{mM}$ HU: $20 \mu \mathrm{M}$ Ara-C). DNA repair is induced over and above the normal level, resulting in enzyme activity that was not inhibited by $2 \mathrm{mM} \mathrm{HU}: 20 \mu \mathrm{M}$ Ara-C. However, when the inhibitor concentration was increased to $4 \mathrm{mM} \mathrm{HU}$ : $40 \mu \mathrm{M}$ Ara-C, there was sufficient inhibition of repair, resulting in significant mean tail moment increases. This induction of repair indicates that sufficient DNA damage had occurred due to JP-8 exposure to trigger DNA repair mechanisms in liver cells.

\section{Comet assay and SCE comparison}

The damage measurements by SCEs at the chromosome level can be compared to the DNA level by direct strand break measurements from comet assay results (Betti et al., 1995, Hartmann et al., 1995, Pitarque et al., 1999a). In general, direct estimation of DNA damage is less tedious than examinations of alterations at the chromosome level. In addition, even though the SCE method allows for measurement of disturbances in cell proliferation and genotoxic damage, it is limited to proliferating cells (Latt et al., 1981). The advantages of the comet assay include its simplicity, inexpense and rapid performance, its sensitivity to a broad spectrum of DNA damage, the analysis of data at the single cell level, and use of extremely small samples. Both methods are accurate measures of DNA damage in lymphocytes, however Hartmann et al., (1995) have shown that the sensitivity of these two assays in lymphocytes can be compound dependent.

A comparison is made here between the induction of DNA damage (comet assay) and SCE formation in human peripheral human lymphocytes exposure to primary jet fuels to emphasize that the comet assay proves to be a more sensitive for genotoxic evaluation of fuel 
exposure. In this investigation the same trend of increasing damage with increasing direct exposure of different fuel types is apparent in both the comet assay analysis and SCE formation in peripheral lymphocytes. When comparing the three different fuels (JP-5, JP-8, and JP-8+100) the extent on the damage induced is more variable in the comet assay measures then the SCEs.

The increased sensitivity of the comet assay over SCE formation as a cytogenetic endpoint is a common finding when such a comparison is made. This increased sensitivity might be due to the lymphocytes being evaluated at the $\mathrm{G}_{0}$ stage with the comet assay and the SCEs being assessed in metaphase after the DNA repair processes (Betti et al., 1995). This finding of increased sensitivity of the comet assay over the SCE evaluation supports the involvement of an oxidative DNA damage mechanism of the fuel induced genotoxic insult, in that oxidatively induced DNA strand breaks can be quickly repaired and not detected by the SCE assay which detects long lived damage only in the S phase.

\section{Oxidative DNA damage investigation}

The comet assay due to its high sensitivity can be used for more targeted applications to demonstrating the type of repair occurring and identify the specific classes of DNA damage present i.e. induced by alkylating agents, intercalating agents and oxidative damage (Henderson et al., 1998, Fairbairn et al., 1995, Collins et al., 1995, 1997, Horváthová et al., 1999, Tice et al., 2000). The adaptation of the comet assay employing the enzymatic activity

of the DNA repair enzyme FPG to detect oxidative damage was applied to the H411E cells exposed indirectly to JP-8 $(10-20 \mu \mathrm{g} / \mathrm{ml})$. The oxidative comet assay was performed on the H411E cells to include metabolic action and because transformed cells have been shown to 
be more sensitive to oxidative attack from $\mathrm{H}_{2} \mathrm{O}_{2}$ than human lymphocytes, which are also less proficient in repair (Collins et al., 1995). This assay resulted in a positive response for oxidative damage as demonstrated by increased comet tail moments. The DNA damage observed in H411E cells exposed indirectly to JP-8 was partly oxidative in nature as shown by the oxidative comet assay.

Very few agents (i.e. ionizing radiation) actually directly attack the DNA, the insult is normally from the formation of free radicals. Direct reactive oxygen species (ROS) activity will result in base modifications and DNA breakage by reacting with the bases and sugars of the DNA. As middle distillates fuels age and are exposed to the atmosphere they deteriorate and oxidize, resulting in the production of ROSs. Oxygen by-products such as ROSs(i.e. superoxide, hydrogen peroxide, and hydroxyl radical) can provoke various cellular responses and macromolecular modifications including oxidation of proteins, DNA, RNA and peroxidation of lipids, which have potential genotoxic, mutagenic and cytotoxic consequences. Direct oxidative DNA damage may constitute the most common type of DNA lesion (Møller and Wallin, 1998). Oxidative stress has multiple sources and clearly is not created solely by free radicals for instance singlet oxygen, peroxides, reactive aldehydes, nitric oxide also interact with the DNA and potentiate genotoxic insult. (Yu et al., 1996, Cadet et al., 1997). Non genotoxic consequences of oxidative stress include alterations in metabolic functions and cytoskeletal disruption. Free oxygen radicals have been implicated in degenerative and inflammatory disorders, aging and cancer (Møller and Wallin, 1998).

Oxidative damage to the cells cannot be pinpointed to one particular mechanism or cause due to the chain of possible reactions and damage that the radicals can produce. Oxidative DNA damage is not induced by direct attack of $\mathrm{O}_{2}$ and $\mathrm{H}_{2} \mathrm{O}_{2}$ because neither 
chemical undergoes any chemical reaction with the DNA since there is no evidence of alterations in deoxyribose or nucleotides. The popular mechanistic theory is through Fenton chemistry $\left(\mathrm{M}^{\mathrm{n}+}+\mathrm{H}_{2} \mathrm{O}_{2} \Rightarrow \mathrm{M}^{(\mathrm{n}=1)^{+}}+\mathrm{OH}^{-}+\mathrm{OH}\right)$ (Halliwell and Aruoma, 1991). Most of the hydroxyradicals $(\mathrm{OH})$ generated in vivo originate from metal-dependent reduction of $\mathrm{H}_{2} \mathrm{O}_{2}$. The hydroxyradical formation will be site specific to the points at which metal promoters of reaction such as $\mathrm{Fe}, \mathrm{Cu}$, and $\mathrm{Ca}$ are located. (Blakely et al., 1990, Horváthová et al., 1998, Halliwell and Aruoma, 1991). If the DNA is with in close proximity to this reaction, either the metal catalysts are associated with the DNA or metals are released as a result of oxidative stress, then $\mathrm{H}_{2} \mathrm{O}_{2}$ and $\mathrm{O}_{2}$-production leads to hydroxyradical dependent base modifications or strand breakage within the cell. If the metal catalysts are attached to membrane lipids then peroxidation can occur (Burcham, 1999, Marnett, 2000).

Oxygen radicals may be required at steps preceding the actual DNA breakage. Active forms of oxygen are constantly produced by oxidative stresses such as by-products of mitochondrial electron transport, inflammatory reactions, and other processes associated with aerobic metabolism. (Halliwell and Aruoma, 1991, Breimer, 1990, Marnett, 2000). Oxidative stress itself can be involved in the triggering of chemical and enzymatic lipid peroxidation and calcium release. (Cerutti et al., 1989). A rise in free calcium, which activates the $\mathrm{Ca}^{2+}$-dependent endonucleases, can result in fragmentation of the DNA (McConkey et al., 1988). This theory complicates the oxidative mechanism due to the fact that some of the strand breaks may result from a $\mathrm{Ca}^{2+} / \mathrm{Mg}^{2+}$ dependent endonuclease rather than direct attack. The prevailing theory (Figure 29) combines these different modes of thinking into a combined hypothesis since oxidative damage is a complex process. 


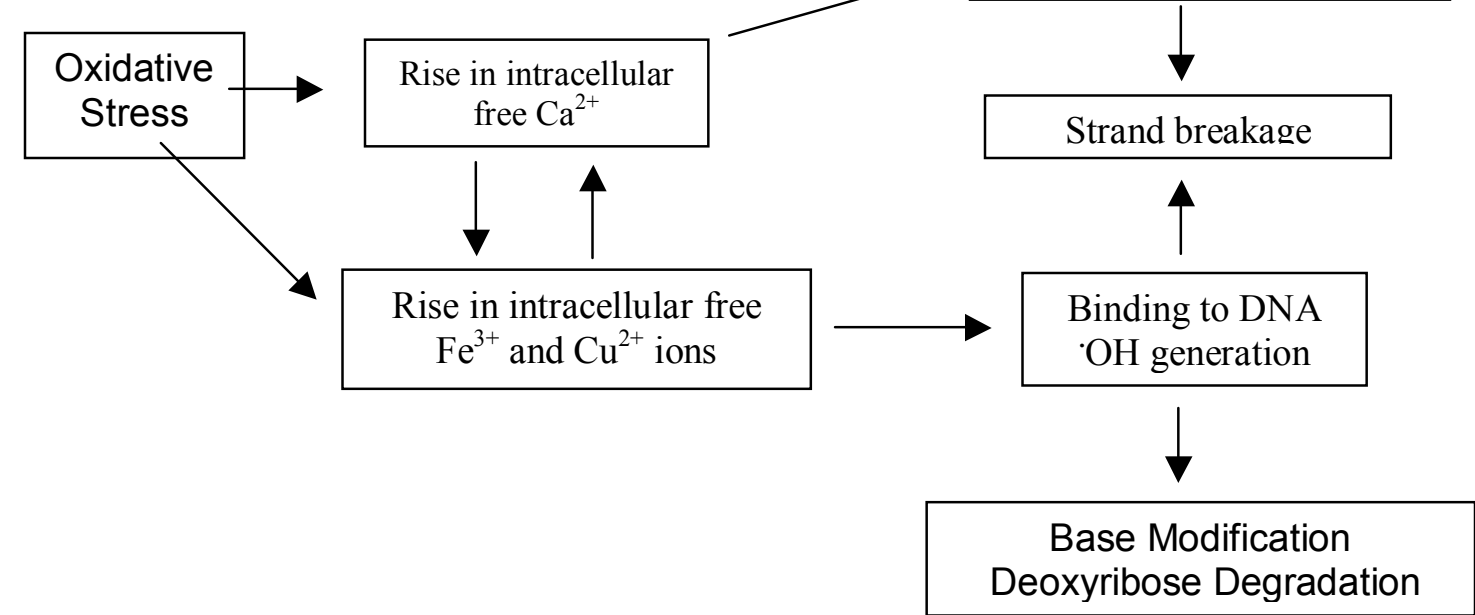

Figure 29 Oxidative DNA damage schematic. Reproduced from Halliwell and Aruoma 1991

The estimation of the amount of oxidative damage incurred from natural sources of oxidation products formed during normal cellular metabolism is tens of thousands of hits per day (Ames and Gold, 1990). Oxidative damage occurs via direct insult to the nucleotides or through incorporation of damaged nucleoside triphosphates during replication (Møller and Wallin, 1998). ROS induced degradation of DNA has been shown to increase both single and double strand breaks, altered bases and the presence of AP sites (Blakely et al., 1990, Breimer, 1990, Collins et al., 1995, Marnett, 2000, Duthie and Collins, 1997). The radical normally attacks at the sugar residue, abstracting hydrogen atoms from deoxyribose producing sugar radicals which lead to the strand breaks and the release of purines and pyrimidines forming AP sites. Levels of modified bases are elevated in cells following treatment by a wide variety of mutagenic agents. Principally these damaged bases are oxidation products of pyrimidines (i.e. thymine glycols and cytosine glycols), purines (i.e. 8oxodG and 8-oxo-dA) and imidazole ring fragmentation products of pryrimidines (i.e. formamidopyridines)(Appendix B) (Møller and Wallin, 1998). 
Among the oxidative base modifications of DNA, the most common primary

oxidative base lesion is a ring saturated purine derivative 8-hydroxyguanine (8-OHgua). The 8-OHgua lesion is premutagenic and forms an 8-hydroxy-2'-deoxyguanosine (8-OxodG), which exerts the highest affinity of formation in DNA and is generated by hydroxyl radical attack via the Fenton reaction (Møller and Wallin, 1998). 8-hydroxyguanine normally leads to mutations by inducing misreading of base and can potentially cause multiple amino acid substitutions by inserting bases without specificity (Breimer, 1990, Barnes et al., 1993). 8OxodG is considered to be a sensitive, stable and intergral biomarker for molecular epidemiological assessment of cancer risk from oxidative damage due to its high prevalence and mutagenic potential (Marnett, 2000). It is believed to be the most biologically relevant substrate for the formamidopyrimidine-DNA glycosylase repair enzyme in the base excision repair pathway (Barnes et al., 1993). Detecting the frequency of these FPG-sensitive sites provides a valuable tool to assess the extent of oxidative DNA damage.

The three predominant mutations induced by oxidative damage are, G:C to A:T base pair transitions (G-T mutations) and G:C to C:G or T:A tranversion ( C-T, G-C) (Breimer, 1990). The C-T transition results from damaged cytosines mispairing with adenine instead of guanine during replication (Møller and Wallin, 1998). Additionally, the hydoxy radical can chemically change the nucleotides, which can lead to long-term errors such as base pair changes and frameshift mutations.

Extensive enzymatic and non-enzymatic processes act to defend against the potential damage induced by these oxidants. It is only when the defenses lapse or the oxidants are too abundant that damage occurs. Generally before causing damage, ROSs are scavenged by enzymes such as superoxide dismutase, and catalases, and by antioxidants such as 
glutathione peroxidases, asorbic acid and vitamins $\mathrm{C}$ and $\mathrm{E}$, which also prevent calcium release (Breimer, 1990, Green et al., 1994, Horváthová et al., 1998). Cellular defense against oxidative damage is twofold. The first line of defense of the DNA to damage is the shielding by antioxidant enzymes that scavenge ROSs and decrease their concentration. Secondly, the cells defensive system via repair processes actively removes damaged nucleosides from helix and repair breaks that incurred despite the first line defenses. Most of oxidative DNA lesions are repaired by base excision repair but some forms of oxidative damage are repaired by systems that recognize elements of DNA double helix distortion such as nucleotide excision repair (Duthie and Collins, 1997).

The ability of ROSs to cause DNA damage and alter gene expression creates the possibility that they could be involved in all stages of carcinogenesis (Burcham, 1998). Oxidized DNA bases are mutagenic and induce mutations commonly observed in mutated human genes, which activate protooncogenes. Increased expressions of protooncogenes c-fos and c-myc have been shown in mammalian cell types with oxidative stress (Ceruiti et al., 1989). In order for the cancer to be promoted there must be a change in gene expression and the progression of the cancer requires an additional DNA change that will eventually lead to the malignancy.

Oxidative damage does not always lead to a cancerous effect, the low-level damage is repaired and the high levels of damage induce cell death. If the DNA repair mechanisms cannot repair the damage or if the lesions are too abundant the cell will progress into programmed cell death or apoptosis. McConkey et al., (1988) demonstrated that generation of oxidative stress in rat hepatocytes can activate endonuclease activity and other processes similar to those observed during apoptosis. Apoptosis keeps cell number in tissue and organs 
constant, helps remove superfluous and damaged cell protecting the organism from potentially harmful abnormal cells. During apoptosis the cells undergo various morphological and molecular changes including the formation of apoptotic blebs of the membrane, DNA fragmentation, condensation of chromatic and externalization of phosphatidylserine to the extracellular side of the membrane (Olive and Banath, 1995, Roser et al., 2001, Eastman and Barry, 1992). The other type of cell death that is not organized is necrosis and is associated with cell swelling, rupture of membranes and dissolution of organized structure (Eastman and Barry, 1992). The same agent can cause both apoptosis and necrosis depending on cell type, dose, and type of exposure (Fairbairn et al., 1995). Apoptosis and necrosis result in the extensive formation of dsbs and produce additional dsbs from the endonuclease cleavage of the DNA fragments (Eastman and Barry, 1992). The increased DNA migration accompanying the DNA fragmentation associated with cytotoxicity arising through necrosis or apoptosis makes it important to determine the presence of these two processes.

These results obtained in the oxidative comet assay add to the previous observation that the increase in DNA migration is not due to cell death processes, since it actually identifies a specific DNA damage mechanism. This oxidative DNA damage evaluation has confirmed that JP-8 induces oxidative damage in H411E cells. However, the exact mechanism by which the fuel causes oxidative damage cannot be defined due to the complexities of the fuel and various types of oxidative insult. For example, the oxidative damage (additional ROSs) could arise from the fuel itself, from the repair activities induced by JP-8 exposure, or from increases in metabolism to detoxify the cells. Additionally, Jet fuel exposure stimulates cell signaling as shown by the activation of the cytokine cascades and 
apoptosis induction (Allen et al., 2000, Stoica et al., 2001, Rosenthal et al., 2001), which could also activate transcription factors that enhance the production of these ROSs.

\section{DNA adduct investigations}

Another possible route of DNA damage involves the tendency of potential carcinogens or their bioactivation products to attack the electron rich centers within DNA generating chemically altered bases known as DNA adducts (Miller and Miller, 1981). These DNA modifications result from covalent interaction of chemical entities to nucleotides in bulky or unbulky form (Randerath and Randerath, 1994, Phillips, 1997). These monofunctional adducts comprise several modifications that disturb the confirmation of the helix by covalently binding to the DNA and inducing all types of DNA damage in addition to producing secondary products from reactions with proteins and lipids (Møller and Wallin, 1998).

To determine the genotoxicity of JP-8 at the nucleotide level the biological endpoint of DNA adduct formation was evaluated through the ${ }^{32} \mathrm{P}$-postlabeling assay incorporating nuclease P1 enhancement. This method is widely employed to accurately detect and measure a wide range of chemical effects and specific DNA modifications induced by potential genotoxic compounds (Randerath and Randerath, 1994, Phillips, 1997, Beach and Gupta, 1992, Gupta and Early, 1988, Møller et al., 2000). This technique is beneficial for investigating complex mixtures such as JP- 8 because it is a global assessment of the effects of the individual components, thereby factoring in all contributing factors including crossreactions between exogenously and endogenously formed adducts (Phillips, 1997). The composition of JP-8 suggests DNA adduct formation could occur through exogenous 
carcinogenic exposure from its PAH content, free radical production potential (oxidative attack), and/ or lipid peroxidation. This study attempted to detect the bulky hydrocarbon adducts. This DNA adduct evaluation is a global measure of specific DNA alterations in the whole genomic DNA as the DNA is extracted from heterogeneous cell populations.

The DNA adduct forming potential is a useful marker of the biological or genotoxic potential of various single compounds and complex mixtures such as fossil-fuels and refienry products (Phillips, 1997). The DNA binding activity of many complex mixtures have been determined through ${ }^{32} \mathrm{P}$-postlabeling identification and correlated with their mutagenic and/or carcinogenic activites. While there have been no published reports of DNA adduct investigations with jet fuel, a variety of DNA adducts have been detected in exposures to diesel exhaust and petrol lubricating oils (Schoket et al., 1989, Phillips et al., 1990, Reddy et al., 1997, Carmichael et al., 1990).

In particular, evaluations of petroleum extracts by the ${ }^{32} \mathrm{P}$-postlabeling assay have detected adduct patterns pertaining to the PAHs and their metabolites present in the fuel (Reddy et al., 1997, Schoket et al., 1989, Carmichael et al., 1990). Correlations between DNA adduct levels and mutagenicity for petroleum fractions have been established in a direct relationship especially for PAH containing mixtures (Reddy et al., 1997). These studies have validated the ${ }^{32} \mathrm{P}$-postlabeling assay for an evaluation of potentially carcinogenic fuel extracts though its useful and accurate screen of DNA adduct formation and correlation to mutagenicity. PAHs can be released by the incomplete combustion of organic material such as jet fuel and as a result are present in the chemical composition (Phillips et al., 1990). There is evidence that PAHs can induce DNA strand breaks in various test systems especially in liver cells where metabolism activity is high (Hartmann and Speit, 1995, Vaghef et al., 
1996, Conney, 1982,). Based on these studies and the PAH content of petroleum fuels, it is reasonable to suggest the potential for genotoxicity from DNA strand breaks and adduct formation resultant from the fuel.

However, DNA adduct formation (detected by the ${ }^{32} \mathrm{P}$-postlabeling assay with nuclease P1 enhancement) is not observed in isolated DNA samples from H411E cells exposed to JP-8 in this investigation. The results presented here may vary from the previous investigation because the petroleum extracts previously evaluated were not as refined as jet fuel, in that they contain more PAHs and other potentially carcinogenic extracts. In addition the type and concentrations of aromatics present in the JP-8 may not be sufficient to induce damage.

Another possible explanation as to why DNA adduct levels were not elevated in the JP-8 exposed rat hepatoma DNA is that this experimental design is meant to detect only the bulky aromatic DNA adducts. Smaller adducts such as 8-hydroxy-2'deoxyguanosine and the methylation/alkylations of DNA bases would not have been detected in this study. If DNA adducts had been detected then the oxidative damage previously described could have been a side reaction of DNA binding molecules. Assessing the possibility of other types of DNA adducts (i.e. lipid peroxidation products) in various cell systems and through different enhancement procedures (ex. n-butanol extraction) could increase our understandings of the potential DNA adduct effects of JP-8 exposure.

The extensive list of endogenous chemicals that may form DNA adducts include free radicals derived from $\mathrm{O}_{2}$, alkylating agents (S-adenosylmethionine), reactive nitrogen species (peroxynitrous acid), glycososylating monosaccarides (glucose-6-phosphate), products of intermediary metabolism (isoprene, ethylene/ethylene oxide), amino acids and lipid 
peroxidation products (Reddy and Randerath, 1994). These endogenous adducts are produced indigenously in healthy tissue primarily from normal metabolic products (lipid peroxidation species), oxidative stress and biological sources (hormones) (Gupta and Spencer-Beach, 1996, Nath et al., 1996). The endogenous compounds result in DNA damage such as basebase and base-sugar intrastrand crosslinkages and induce several bulky lesions. In many cases these adducts can be positively correlated with oxidative stress formed by direct oxidation and other unidentified intrastrand crosslinks (Randerath and Randerath, 1994, Nath et al., 1996). For example, lipid peroxidation induced DNA damage might contribute to spontaneous mutagenesis in a similar manner to that caused by other oxidative stress mediators producing $\mathrm{OH}, \mathrm{H}_{2} \mathrm{O}_{2}, \mathrm{O}_{2}$, and peroxyl radicals. Lipid peroxidation involves a radical chain process so that one oxidizing agent can cause many molecules of fatty acid to be oxidized (Møller and Wallin, 1998). Since endogenous lipid peroxidation products have a higher mutagenic potential than small base lesions, oxidative DNA damage studies have been extended beyond the commonly recognized oxidative species such as $\mathrm{O}_{2}{ }^{-}$and $\mathrm{OH}$. Reactive aldehydic products from lipids have a relatively longer half-life (compared to free radicals), high affinity, high attraction to both hydrophobic and hydrophilic regions, and their proximity to targets within the membrane (Marnett, 2000). To support lipid peroxidation as a possible contributor to the increase in DNA and oxidative DNA damage it has been found that petroleum hydrocarbons n-alkanes, benzene and toluene found in the jet fuels have previously stimulated a dose dependent and time dependent increase in lipid peroxidation (Suleiman, 1987). The endogenous presence of these potentially mutagenic compounds and cheimcals may be a confounding factor in bioassay and risk assessment of exogenous genotoxic agents (Nath et al., 1996). 


\section{Final comments and conclusions}

The fact that straight run PMDs cause skin tumorigenicity in mice from repeated dermal exposure (McKee et al., 1994, Nessel et al., 1999) suggests the potential harmful effects of the base fuel itself. These dermal studies found the mechanism of damage to be nongenotoxic possibly resulting from frequent cell damage and repair. However, Blackburn et al., 1986 found evidences of mutagenicity of PMDs through the Ames assay, suggesting the tumorigenicity effect could be related to a genotoxic mechanism. Equivalence between cytogenetic assays and bacterial assays cannot be made since the genetic endpoint and data analyses are different for each assay.

Even though benzene is present in the fuels and its metabolite p-benzoquinone is an established DNA damaging agent, its known effects on SCE and DNA adduct formation are not apparent in this study. However, the route of action of benzene as a mutagen is by covalently binding its reactive metabolites to cellular macromolecules, leading to oxidative DNA damage through the formation of hydroxyl radicals via hydrogen peroxide (Anderson et al., 1995, Snyder et al., 1996, Hathway, 2000), so the effects could have been detected by the oxidative comet assay. It is also possible that the DNA damaging effects of benzene are negligible due to its low concentrations in the jet fuel formulation.

The hydrocarbon content of jet fuel suggests the potential for genotoxicity, DNA strand breaks and DNA adduct formation. Based on this evaluation the PAH content of the jet fuels is not elevated enough to induce a carcinogenic effect. This observation is supported by both the Ames results and the DNA adduct investigations. Mutagens are known to damage DNA through several mechanisms. Since it can be ruled out that the genotoxic 
effects of jet fuel are not via hydrocarbon attack as shown by the DNA adducts assay and this Ames investigation, evaluating the fuel extracts with other strains of the Ames assay could detect the different mechanism of mutagenicity.

The results of this in vitro genotoxic investigation indicated that JP-8 induces DNA damage in the cell types and exposure conditions evaluated in this study. The increase in DNA damage as quantitatively detected by the comet assay, revealed a significant genotoxic insult as a result of jet fuel exposure. Using the comet assay, it was demonstrated that JP-8 exposure produces DNA damage in a concentration-dependent manner in all cellular models and exposure conditions used in this study. This genotoxic finding of JP-8 is supported by the previous investigation that suggested that the fuel could interact with DNA producing nonspecific lesions (Brusick and Matheson, 1978). Jet fuel was adequately shown to induce DNA dsbs without being mutagenic or carcinogenic. Just because there are strand breaks does not exactly classify jet fuel as a mutagen as it has been shown that the comet assay does not necessarily predict the mutagenic potential of the test compound (Speit et al., 1996, Hartmann and Speit, 1997). As is well known, the initial amount of primary DNA damage, as well as the rates and efficiencies of DNA repair mechanism also influence the mutagenic potential of the chemical. The DNA alterations leading to DNA migration in the comet assay are not necessarily the same as those leading to gene mutation due to the possibility that the DNA damage generated could be endogenous, i.e. as a consequence of error in the repair processes (Speit et al., 1996) or from radicals formed from normal metabolism.

The comet assay responses found in the present study are too small to allow any firm conclusion on the occupational exposure to jet fuel and hydrocarbons. It is possible that a constant, low rate of damage in vivo may be dealt with more efficiently that the sudden burst 
of strand breaks and oxidized bases introduced experimentally (Collins et al., 1995). In addition, genotoxic insult triggers a wide range of cellular responses including altered gene expression, delay in cell cycle progression and the stimulation of DNA repair. Eventually the accumulation of this damage over and above the cellular repair mechanisms will ultimately activate programmed cell death.

In conclusion the comet assay was a very sensitive technique to evaluate the DNA damage effects and oxidative damage in individual cells treated with jet fuel. Furthermore, it allowed the evaluation of differences in DNA damage induction and repair capability in cells with different proliferation statuses and metabolic capabilities. Even though this investigation demonstrates positive genotoxic responses to jet fuel exposure it cannot aptly define a mechanism of action. This mechanism could be deduced through the gene array and protenomics experimentations in the future. Future investigations on the cellular damage and apoptosis induced by jet fuels will provide insight into the mechanisms of cell death caused by exposure to these fuels. Studies could be conducted to further examine the mechanisms of cellular damage induced by exposure to jet propulsion fuels. There is also a need to evaluate other genetic and epigenetic mechanisms of JP-8 jet fuel toxicity.

A battery of cytogenetic, toxicogenetic and molecular techniques have been employed to monitor the genotoxic effects of jet fuel exposure in vitro to investigate the need for further analysis of the human populations who may be at increased risk for cancer because of the exposures related to occupation and lifestyle. The present findings suggest the existence of a genotoxic risk for jet fuel exposed workers. The results from the jet fuel exposed lymphocytes have shown that with an increase in additives there is an increase in genetic insult. Clearly, implying that the additives required in producing more 
technologically efficient fuels, compromise the health of the workers who come in contact with the fuels. Strong variation is seen between the fuels depending on the refinery and composition; these factors need to be more highly regulated and monitored. Further investigation in the cellular response to the fuel exposure will be required to pinpoint the actual genes involved and correlate their activity to the induced damage.

The in vitro genotoxic investigation presented here demonstrates that jet fuel induces DNA damage, which is partially oxidative in nature. This positive response for genotoxicity intensifies the need for genotoxic risk assessment of this fuel in vivo. In the future the human studies will be directed and focused on explaining the animal data and establish exposure limits for occupational and community settings, personal protective equipment requirements, and monitoring methods. Once the active and deleterious components of JP-8 are identified, development of safer high performance fuel will be within reach. 


\section{REFERENCES}

Albertini RJ, Anderson D, Douglas GR, Hagmar L, Hemminki K, Merlo F, Natarajan AT, Norppa H, Shuker DE, Tice R, Waters MD, Aitio A. IPCS guidelines for the monitoring of genotoxic effects of carcinogens in humans. Mutat Res 2000, 463:111-172.

Allen DG, Riviere JE, Monteiro-Riviere NA. Identification of early biomarkers of inflammation produced by keratinocytes exposed to jet fuels jet A, JP-8, and JP-8(100). J Biochem Mol Toxicol 2000, 14:231-237.

Allen DG, Riviere JE, Monteiro-Riviere NA. Cytokine induction as a measure of cutaneous toxicity in primary and immortalized porcine keratinocytes exposed to jet fuels, and their relationship to normal human epidermal keratinocytes. Toxicol Lett 2001a, 119:209-217.

Allen DG, Riviere JE, Monteiro-Riviere NA. Analysis of interleukin-8 release from normal human epidermal keratinocytes exposed to aliphatic hydrocarbons: delivery of hydrocarbons to cell cultures via complexation with alpha-cyclodextrin. Toxicol In vitro 2001b, 15:663-669.

Ames BN, McCann J, Yamasaki E. Methods for detecting carcinogens and mutagens with the Salmonella/mammalian-microsome mutagenicity test. Mutat Res 1975, 31:347-364.

Ames BN, Gold LS. Chemical carcinogenesis: too many rodent carcinogens. Proc Natl Acad Sci USA 1990, 87:7772-7776.

Anderson D, Yu TW, Schmezer P. An investigation of the DNA-damaging ability of benzene and its metabolites in human lymphocytes, using the comet assay. Environ Mol Mutagen 1995, 26:305-314.

Anderson D, Hughes JA, Cebulska-Wasilewska A, Wierzewska A, Kasper E. Biological monitoring of workers exposed to emissions from petroleum plants. Environ Health Perspect 1996, 104 Suppl 3:609-613.

Andreoli C, Leopardi P, Crebelli R. Detection of DNA damage in human lymphocytes by alkaline single cell gel electrophoresis after exposure to benzene or benzene metabolites. Mutat Res 1997, 377:95-104.

Angelis KJ, Dusinska M, Collins AR. Single cell gel electrophoresis: detection of DNA damage at different levels of sensitivity. Electrophoresis 1999, 20:2133-2138.

Baldwin CM, Houston FP, Podgornik MN, Young RS, Barnes CA, Witten ML. Effects of aerosolvapor JP-8 jet fuel on the functional observational battery, and learning and memory in the rat. Arch Environ Health 2001, 56:216-226.

Barnes DE, Lindahl T, Sedgwick B. DNA repair. Curr Opin Cell Biol 1993, 5:424-433.

Baynes RE, Brooks JD, Budsaba K, Smith CE, Riviere JE. Mixture effects of JP-8 additives on the dermal disposition of jet fuel components. Toxicol Appl Pharmacol 2001, 175:269-281.

Beach AC, Gupta RC. Human biomonitoring and the 32P-postlabeling assay. Carcinogenesis 1992, 13:1053-1074. 
Betti C, Davini T, Giannessi L, Loprieno N, Barale R. Comparative studies by comet test and SCE analysis in human lymphocytes from 200 healthy subjects. Mutat Res 1995, 343:201-207.

Blackburn GR, Deitch RA, Schreiner CA, Mehlman MA, Mackerer CR. Estimation of the dermal carcinogenic activity of petroleum fractions using a modified Ames assay. Cell Biol Toxicol 1984, 1:67-80.

Blackburn GR, Deitch RA, Schreiner CA, Mackerer CR. Predicting carcinogenicity of petroleum distillation fractions using a modified Salmonella mutagenicity assay. Cell Biol Toxicol 1986, 2:63-84.

Blakely WF, Fuciarelli AF, Wegher BJ, Dizdaroglu M. Hydrogen peroxide-induced base damage in deoxyribonucleic acid. Radiat Res 1990, 121:338-343.

Bradlaw JA, Casterline JL, Jr. Induction of enzyme activity in cell culture: a rapid screen for detection of planar polychlorinated organic compounds. J Assoc Off Anal Chem 1979, 62:904-916.

Breimer LH. Molecular mechanisms of oxygen radical carcinogenesis and mutagenesis: the role of DNA base damage. Mol Carcinog 1990, 3:188-197.

Broddle WD, Dennis MW, Kitchen DN, Vernot EH. Chronic dermal studies of petroleum streams in mice. Fundam Appl Toxicol 1996, 30:47-54.

Bruner RH, Kinkead ER, O'Neill TP, Flemming CD, Mattie DR, Russell CA, Wall HG. The toxicologic and oncogenic potential of JP-4 jet fuel vapors in rats and mice: 12-month intermittent inhalation exposures. Fundam Appl Toxicol 1993, 20:97-110.

Brusick, D. J. and Mateson, D. W. Mutagen and oncogen study on JP-8. AAMRL-TR-78-20. 1978. Armstrong Aerospace Medical Research Laboratory, Wright-Patterson Air Force Base, OH.

Burcham PC. Genotoxic lipid peroxidation products: their DNA damaging properties and role in formation of endogenous DNA adducts. Mutagenesis 1998, 13:287-305.

Cadet J, Berger M, Douki T, Ravanat JL. Oxidative damage to DNA: formation, measurement, and biological significance. Rev Physiol Biochem Pharmacol 1997, 131:1-87.

Carere A, Antoccia A, Crebelli R, Degrassi F, Fiore M, Iavarone I, Isacchi G, Lagorio S, Leopardi P, Marcon F. Genetic effects of petroleum fuels: cytogenetic monitoring of gasoline station attendants. Mutat Res 1995a, 332:17-26.

Carere A, Antoccia A, Crebelli R, Di Chiara D, Fuselli S, Iavarone I, Isacchi G, Lagorio S, Leopardi $\mathrm{P}$, Marcon F. Exposure to benzene and genotoxic effects among filling station attendants. Epidemiol Prev 1995b, 19:105-119.

Carere A, Antoccia A, Cimini D, Crebelli R, Degrassi F, Leopardi P, Marcon F, Sgura A, Tanzarella C, Zijno A. Genetic effects of petroleum fuels: II. Analysis of chromosome loss and hyperploidy in peripheral lymphocytes of gasoline station attendants. Environ Mol Mutagen 1998, 32:130-138. 
Carlton GN, Smith LB. Exposures to jet fuel and benzene during aircraft fuel tank repair in the U.S. Air Force. Appl Occup Environ Hyg 2000, 15:485-491.

Carmichael PL, Jacob J, Grimmer G, Phillips DH. Analysis of the polycyclic aromatic hydrocarbon content of petrol and diesel engine lubricating oils and determination of DNA adducts in topically treated mice by 32P-postlabelling. Carcinogenesis 1990, 11:2025-2032.

Collins AR, Duthie SJ, Dobson VL. Direct enzymatic detection of endogenous oxidative base damage in human lymphocyte DNA. Carcinogenesis 1993, 14:1733-1735.

Collins AR, Ma AG, Duthie SJ. The kinetics of repair of oxidative DNA damage (strand breaks and oxidized pyrimidines) in human cells. Mutat Res 1995, 336:69-77.

Collins AR, Dusinska M, Gedik CM, Stetina R. Oxidative damage to DNA: do we have a reliable biomarker? Environ Health Perspect 1996, 104 Suppl 3:465-469.

Collins AR, Dobson VL, Dusinska M, Kennedy G, Stetina R. The comet assay: what can it really tell us? Mutat Res 1997, 375:183-193.

Committee on Toxicology, National Research Council: Permissible exposure levels for selected military fuel vapors. Washington, DC, National Academy press, 1996.

Conney AH. Induction of microsomal enzymes by foreign chemicals and carcinogenesis by polycyclic aromatic hydrocarbons: G. H. A. Clowes Memorial Lecture. Cancer Res 1982, 42:4875-4917.

Cooper JR, Mattie DR. Developmental toxicity of JP-8 jet fuel in the rat. J Appl Toxicol 1996, 16:197-200.

Dössing M, Loft S, Schroeder E. Jet Fuel and liver function. Scand J Work and EnvironHealth 1985, 11:433-437.

Dudley AC, Peden-Adams MM, EuDaly J, Pollenz RS, Keil DE. An aryl hydrocarbon receptor independent mechanism of JP-8 jet fuel immunotoxicity in Ah-responsive and Ahnonresponsive mice. Toxicol Sci 2001, 59:251-259.

Duthie SJ, Collins AR. The influence of cell growth, detoxifying enzymes and DNA repair on hydrogen peroxide-mediated DNA damage (measured using the comet assay) in human cells. Free Radic Biol Med 1997, 22:717-724.

Eastman A, Barry MA. The origins of DNA breaks: a consequence of DNA damage, DNA repair, or apoptosis? Cancer Invest 1992, 10:229-240.

Egeghy PP, Tornero-Velez R, Rappaport SM. Environmental and biological monitoring of benzene during self-service automobile refueling. Environ Health Perspect 2000, 108:1195-1202.

England E, Davenport M, Fritts D. Industrial hygienist in the desert: a brief overview of safety hazards, water and food security, jet fuel exposures, and silica exposures in southwest Asia. Appl Occup Environ Hyg 1999, 14:799-804. 
Fairbairn DW, Olive PL, O'Neill KL. The comet assay: a comprehensive review. Mutat Res 1995, 339:37-59.

Filatov MV, Pantina RA, Noskin LA. Methods for registration of spontaneous DNA instability in mammalian cells. Mutat Res 1998, 403:95-101.

Furlow, B. Highly toxic fuel suspected cause of childhood leukemia cluster in Fallen, Nevada. New Scientist. 6-13-2001.

Gaworski CL, MacEwen JD, Vernot EH, Bruner RH, Cowan Jr MJ: Comparison of the subchronic inhalation toxicity of petroleum and oil shale JP-5 jet fuels. Applied Toxicology of Petroleum Hydrocarbons. Edited by Mehlman MA. Princeton, Princeton Scientific, 1984, pp. 33-47.

Gedik CM, Collins AR. The mode of action of 1-beta-D-arabinofuranosylcytosine in inhibiting DNA repair; new evidence using a sensitive assay for repair DNA synthesis and ligation in permeable cells. Mutat Res 1991, 254:231-237.

Gedik CM, Ewen SW, Collins AR. Single-cell gel electrophoresis applied to the analysis of UV-C damage and its repair in human cells. Int J Radiat Biol 1992, 62:313-320.

Grant GM, Shaffer KM, Kao WY, Stenger DA, Pancrazio JJ. Investigation of in vitro toxicity of jet fuels JP-8 and Jet A. Drug Chem Toxicol 2000, 23:279-291.

Green MH, Lowe JE, Waugh AP, Aldridge KE, Cole J, Arlett CF. Effect of diet and vitamin C on DNA strand breakage in freshly-isolated human white blood cells. Mutat Res 1994, 316:91102.

Gupta RC, Earley K. 32P-adduct assay: comparative recoveries of structurally diverse DNA adducts in the various enhancement procedures. Carcinogenesis 1988, 9:1687-1693.

Halliwell B, Aruoma OI. DNA damage by oxygen-derived species. Its mechanism and measurement in mammalian systems. FEBS Lett 1991, 281:9-19.

Hardin BD, Goad PT, Burg JR. Developmental toxicity of diethylene glycol monomethyl ether (diEGME). Fundam Appl Toxicol 1986, 6:430-439.

Harris DT, Sakiestewa D, Robledo RF, Witten M. Immunotoxicological effects of JP-8 jet fuel exposure. Toxicol Ind Health 1997a, 13:43-55.

Harris DT, Sakiestewa D, Robledo RF, Witten M. Short-term exposure to JP-8 jet fuel results in longterm immunotoxicity. Toxicol Ind Health 1997b, 13:559-570.

Harris DT, Sakiestewa D, Robledo RF, Witten M. Protection from JP-8 jet fuel induced immunotoxicity by administration of aerosolized substance P. Toxicol Ind Health 1997c, 13:571-588.

Harris DT, Sakiestewa D, Robledo RF, Young RS, Witten M. Effects of short-term JP-8 jet fuel exposure on cell-mediated immunity. Toxicol Ind Health 2000, 16:78-84.

Harris DT, Sakiestewa D, Titone D, Robledo RF, Young RS, Witten M. Jet fuel-induced immunotoxicity. Toxicol Ind Health 2001a, 16:261-265. 
Harris DT, Sakiestewa D, Titone D, Robledo RF, Young RS, Witten M. Substance P as prophylaxis for JP-8 jet fuel-induced immunotoxicity. Toxicol Ind Health 2001b, 16:253-259.

Hartmann A, Speit G. Genotoxic effects of chemicals in the single cell gel (SCG) test with human blood cells in relation to the induction of sister-chromatid exchanges (SCE). Mutat Res 1995, 346:49-56.

Hartmann A, Speit G. The contribution of cytotoxicity to DNA-effects in the single cell gel test (comet assay). Toxicol Lett 1997, 90:183-188.

Hartmann A, Kiskinis E, Fjallman A, Suter W. Influence of cytotoxicity and compound precipitation on test results in the alkaline comet assay. Mutat Res 2001, 497:199-212.

Hathway DE. Toxic action/toxicity. Biol Rev Camb Philos Soc 2000, 75:95-127.

Hays AM, Parliman G, Pfaff JK, Lantz RC, Tinajero J, Tollinger B, Hall JN, Witten ML. Changes in lung permeability correlate with lung histology in a chronic exposure model. Toxicol Ind Health 1995, 11:325-336.

Holm S, Norbeck D, Frening B, Gothe C-J. Hydrocarbon exposure from handling jet fuel at some Swedish aircraft units. Scand J work Environ Health 1987, 13:438-444.

Horváthová E, Slamenova D, Hlincikova L, Mandal TK, Gabelova A, Collins AR. The nature and origin of DNA single-strand breaks determined with the comet assay. Mutat Res 1998, 409:163-171.

Horváthová E, Slamenova D, Gabelova A. Use of single cell gel electrophoresis (comet assay) modifications for analysis of DNA damage. Gen Physiol Biophys 1999, 18 Spec No: 70-74.

IARC: Occupational exposures in petroleum refining, crude oil, and major petroleum fuels. Lyon, International Agency for Research on Cancer, IARC, 1989, pp. 203-218.

Jacobson-Kram D, Albertini RJ, Branda RF, Falta MT, Iype PT, Kolodner K, Liou SH, McDiarmid MA, Morris M, Nicklas JA. Measurement of chromosomal aberrations, sister chromatid exchange, hprt mutations, and DNA adducts in peripheral lymphocytes of human populations at increased risk for cancer. Environ Health Perspect 1993, 101 Suppl 3:121-125.

Jamal GA. Gulf War syndrome--a model for the complexity of biological and environmental interaction with human health. Adverse Drug React Toxicol Rev 1998, 17:1-17.

Kabbur MB, Rogers JV, Gunasekar PG, Garrett CM, Geiss KT, Brinkley WW, McDougal JN. Effect of jp-8 jet fuel on molecular and histological parameters related to acute skin irritation . Toxicol Appl Pharmacol 2001, 175:83-88.

Kanikkannan N, Jackson T, Sudhan SM, Singh M. Evaluation of skin sensitization potential of jet fuels by murine local lymph node assay. Toxicol Lett 2000, 116:165-170.

Kanikkannan N, Burton S, Patel R, Jackson T, Shaik MS, Singh M. Percutaneous permeation and skin irritation of JP-8+100 jet fuel in a porcine model. Toxicol Lett 2001a, 119:133-142. 
Kanikkannan N, Patel R, Jackson T, Shaik MS, Singh M. Percutaneous absorption and skin irritation of JP-8 (jet fuel). Toxicology 2001b, 161:1-11.

Kinkead ER, Wolfe RE, Flemming CD, Solomon RA, Mattie DR, Grabau JH, Marit GB. The toxicologic potential of JP-4 vapor: 90-day continuous inhalation exposure. Inhal Toxicol $1995,7: 239-253$.

Knave B, Persson HE, Goldberg JM, Westerholm P. Long-term exposure to jet fuel: an investigation on occupationally exposed workers with special reference to the nervous system. Scand J work Environ Health 1976, 2:152-164.

Knave B, Olson BA, Elofsson S, Gamberale F, Isaksson A, Mindus P, Persson HE, Struwe G, Wennberg A, Westerholm P. Long-term exposure to jet fuel II. A cross-sectional epidemiologic investigation on occupationally exposed industrial workers with special reference to the nervous system. Scand J work Environ Health 1978, 4:19-45.

Knave B, Mindus P, Struwe G. Neuropsychiatric symptoms in workers occupationally exposed to jet fuel - a combined epidemiological and casuistic study. Acta Physiol Scand 1979, 60:39-49.

Knudson, G. B, Jarrett, D. P, Director, A. E, Vaishnav, Y. N, Loats, H., Smith, W. J, Prasanna, P. G. $\mathrm{S}$, and Blakely, WF. Sister chromatid exchange assay as a biomarker for exposure to chemical warfare agents. 401-406. 1998. U.S. Army. 21st Army Science Conference.

Krichevskaya M, Malygina T, Preis S, Kallas J. Photocatalytical oxidation of de-icing agents in aqueous solutions and aqueous extract of jet fuel. Water Sci Technol 2001, 44:1-6.

Krishna G, Nath J, Ong T. Correlative genotoxicity studies of airborne particles in Salmonella typhimurium and cultured human lymphocytes. Environ Mutagen 1984, 6:585-592.

Latt SA, Allen J, Bloom SE, Carrano A, Falke E, Kram D, Schneider E, Schreck R, Tice R, Whitfield B, Wolff S. Sister-chromatid exchanges: a report of the GENE-TOX program. Mutat Res 1981, 87:17-62.

Lemasters GK, Livingston GK, Lockey JE, Olsen DM, Shukla R, New G, Selevan SG, Yiin JH. Genotoxic changes after low-level solvent and fuel exposure on aircraft maintenance personnel. Mutagenesis 1997, 12:237-243.

Lemasters GK, Lockey JE, Olsen DM, Selevan SG, Tabor MW, Livingston GK, New GR. Comparison of internal dose measures of solvents in breath, blood and urine and genotoxic changes in aircraft maintenance personnel. Drug Chem Toxicol 1999a, 22:181-200.

Lemasters GK, Olsen DM, Yiin JH, Lockey JE, Shukla R, Selevan SG, Schrader SM, Toth GP, Evenson DP, Huszar GB. Male reproductive effects of solvent and fuel exposure during aircraft maintenance. Reprod Toxicol 1999b, 13:155-166.

Löfroth G. Salmonella/ microsome mutagenicity assays of exhaust from diesel and gasoline powered motor vehicles. Environment International 1981, 5:255-.

Ma L, Hoeijmakers JH, van der Eb AJ. Mammalian nucleotide excision repair. Biochem Biophys Acta 1995, 1242:137-163. 
Major J, Jakab M, Kiss G, Tompa A. Chromosome aberration, sister-chromatid exchange, proliferative rate index, and serum thiocyanate concentration in smokers exposed to lowdose benzene. Environ Mol Mutagen 1994, 23:137-142.

Marafie EM, Marafie I, Emery SJ, Waters R, Jones NJ. Biomonitoring the human population exposed to pollution from the oil fires in Kuwait: analysis of placental tissue using ${ }^{32} \mathrm{P}$-postlabeling. Environ Mol Mutagen 2000, 36:274-282.

Marnett LJ. Oxyradicals and DNA damage. Carcinogenesis 2000, 21:361-370.

Maron DM, Ames BN. Revised methods for the Salmonella mutagenicity test. Mutat Res 1983, 113:173-215.

Martin FL, Cole KJ, Orme MH, Grover PL, Phillips DH, Venitt S. The DNA repair inhibitors hydroxyurea and cytosine arabinoside enhance the sensitivity of the alkaline single-cell gel electrophoresis ('comet') assay in metabolically-competent MCL-5 cells. Mutat Res 1999, 445:21-43.

Mattie DR, Alden CL, Newell TK, Gaworski CL, Flemming CD. A 90-day continuous vapor inhalation toxicity study of JP-8 jet fuel followed by 20 or 21 months of recovery in Fischer 344 rats and C57BL/6 mice. Toxicol Pathol 1991, 19:77-87.

Mattie DR, Marit GB, Flemming CD, Cooper JR. The effects of JP-8 jet fuel on male SpragueDawley rats after a 90-day exposure by oral gavage. Toxicol Ind Health 1995, 11:423-435.

McConkey DJ, Hartzell P, Nicotera P, Wyllie AH, Orrenius S. Stimulation of endogenous endonuclease activity in hepatocytes exposed to oxidative stress. Toxicol Lett 1988, 42:123130 .

McDiarmid MA, Jacobson-Kram D, Koloder K, Deeter DP, Lachiver RM, Scott BG, Petrucelli B, Gustavison D, Putman D. Increased frequencies of sister chromatid exchange in soldiers deployed to Kuwait. Mutagenesis 1995, 10:263-265.

McDougal JN, Pollard DL, Weisman W, Garrett CM, Miller TE. Assessment of skin absorption and penetration of JP-8 jet fuel and its components. Toxicol Sci 2000, 55:247-255.

McGregor D. The genetic toxicology of toluene. Mutat Res 1994, 317:213-228.

McKee RH, Amoruso MA, Freeman JJ, Przygoda RT. Evaluation of the genetic toxicity of middle distillate fuels. Environ Mol Mutagen 1994, 23:234-238.

McKelvey-Martin VJ, Green MH, Schmezer P, Pool-Zobel BL, De Meo MP, Collins A. The single cell gel electrophoresis assay (comet assay): a European review. Mutat Res 1993, 288:47-63.

Miller EC, Miller JA. Mechanisms of chemical carcinogenesis. Cancer 1981, 47:1055-1064.

Mirzayans R, Dietrich K, Paterson MC. Aphidicolin and 1-beta-D-arabinofuranosylcytosine strongly inhibit transcriptionally active DNA repair in normal human fibroblasts. Carcinogenesis 1993, 14:2621-2626. 
Møller P, Wallin H. Adduct formation, mutagenesis and nucleotide excision repair of DNA damage produced by reactive oxygen species and lipid peroxidation product. Mutat Res 1998, 410:271-290.

Møller P, Knudsen LE, Loft S, Wallin H . The comet assay as a rapid test in biomonitoring occupational exposure to DNA-damaging agents and effect of confounding factors. Cancer Epidemiol Biomarkers Prev 2000, 9:1005-1015.

Morimoto K, Kitamura M, Kondo H, Koizumi A. Genotoxicity of diesel exhaust emissions in a battery of in-vitro short- term and in-vivo bioassays. Dev Toxicol Environ Sci 1986, 13:85101.

Mortelmans K, Zeiger E. The Ames Salmonella/microsome mutagenicity assay. Mutat Res 2000, 455:29-60.

Mushrush G, Beal EJ, Hardy DR, Hughes JA, Cummings JC. Jet fuel system icing inhibitors: synthesis and characterization. Ind Eng Chem Res 1999, 38:2497-2502.

Nath RG, Randerath K, Li D, Chung FL. Endogenous production of DNA adducts. Regul Toxicol Pharmacol 1996, 23:22-28.

Navy Occupational Safety and Health (NAVOSH) Standards Update Board. Interim recommendations for permissible fuel exposure criteria from the Navy Environment Health Center. Navy Environmental Health Center Memorandum 6261. 4-9-1992.

Nelms, B. E, Moravec, R., and Riss, T. Measuring apoptosis in individual cells with the comet assay. Promega Notes 64, 13. 1997.

Nessel CS. A comprehensive evaluation of the carcinogenic potential of middle distillate fuels. Drug Chem Toxicol 1999, 22:165-180.

Nordholm AF, Rossi J, III, Ritchie GD, McInturf S, Hulme ME, McCool C, Narayanan L, MacMahon KL, Eggers J, Leahy HF, Wolfe RE. Repeated exposure of rats to JP-4 vapor induces changes in neurobehavioral capacity and 5-HT/5-HIAA levels. J Toxicol Environ Health A 1999, 56:471-499.

Olive PL, Banath JP, Durand RE. Heterogeneity in radiation-induced DNA damage and repair in tumor and normal cells measured using the "comet" assay. Radiat Res 1990, 122:86-94.

Olive PL, Banath JP. Sizing highly fragmented DNA in individual apoptotic cells using the comet assay and a DNA crosslinking agent. Exp Cell Res 1995, 221:19-26.

Olive PL. DNA damage and repair in individual cells: applications of the comet assay in radiobiology. Int J Radiat Biol 1999, 75:395-405.

Palfreman, J. The Last Battle of the Gulf War. Frontline Online. 1-20-1998.

Palma V, Tudon H, Buentello L, Nava S, Ostrosky P, Salamanca F. Methods for the analysis of cellular kinetics in PHA-stimulated blood lymphocytes using BrdU incorporation. A comparative study. Mutat Res 1993, 286:267-273. 
Parton K, Pfaff J, Hays AM, Witten M. Effects of JP-8 jet fuel inhalation on the liver of Fischer-344 rats. Toxicologist 1993, 13:48.

Perry P, Wolff S. New Giemsa method for the differential staining of sister chromatids. Nature 1974, 251:156-158.

Personal communication. Stephen E. Ullrich, Ph.D., Department of Immunology, M.D. Anderson Cancer Center. University of Texas, Houston, Texas.

Personal communication. Mark L. Witten, Ph.D. Department of Pediatrics, College of Medicine, University of Arizona, Tuscon, Arizona.

Personal communication. David T. Harris. Department of immunology, Arizona Cancer Center, University of Arizona, Tuscon, Arizona.

Pfaff J, Parton K, Lantz RC, Chen H, Hays AM, Witten ML. Inhalation exposure to JP-8 jet fuel alters pulmonary function and substance P levels in Fischer 344 rats. J Appl Toxicol 1995, 15:249-256.

Pfaff JK, Tollinger BJ, Lantz RC, Chen H, Hays AM, Witten ML. Neutral endopeptidase (NEP) and its role in pathological pulmonary change with inhalation exposure to JP-8 jet fuel. Toxicol Ind Health 1996, 12:93-103.

Phillips DH, Schoket B, Hewer A, Grover PL. DNA adduct formation in human and mouse skin by mixtures of polycyclic aromatic hydrocarbons. IARC Sci Publ 1990,223-229.

Phillips DH. Detection of DNA modifications by the 32P-postlabelling assay. Mutat Res 1997, 378:112.

Pitarque M, Creus A, Marcos R, Hughes JA, Anderson D. Examination of various biomarkers measuring genotoxic endpoints from Barcelona airport personnel. Mutat Res 1999a, 440:195204.

Pitarque M, Vaglenov A, Nosko M, Hirvonen A, Norppa H, Creus A, Marcos R. Evaluation of DNA damage by the Comet assay in shoe workers exposed to toluene and other organic solvents. Mutat Res 1999b, 441:115-127.

Pleil JD, Smith LB, Zelnick SD. Personal exposure to JP-8 jet fuel vapors and exhaust at air force bases. Environ Health Perspect 2000, 108:183-192.

Popp W, Vahrenholz C, Schurfeld C, Schmieding W, Hoster M, Bach I, Norpoth K. Investigations of the frequency of DNA strand breakage and cross- linking and of sister chromatid exchange frequency in the lymphocytes of patients with multiple myeloma undergoing cytostatic therapy with melphalan and prednisone. Carcinogenesis 1992, 13:2191-2195.

Porter HO. Aviators intoxicated by inhalation of JP-5 fuel vapors. Aviat Space Environ Med 1990, 61:654-656.

Proctor SP, Heeren T, White RF, Wolfe J, Borgos MS, Davis JD, Pepper L, Clapp R, Sutker PB, Vasterling JJ, Ozonoff D. Health status of Persian Gulf War veterans: self-reported 
symptoms, environmental exposures and the effect of stress. Int J Epidemiol 1998, 27:10001010.

Randerath K, Randerath E. 32P-postlabeling methods for DNA adduct detection: overview and critical evaluation. Drug Metab Rev 1994, 26:67-85.

Rao GS, Kannan K, Goel SK, Pandya KP, Shanker R. Subcutaneous kerosene toxicity in albino rats. Environ Res 1984, 35:516-530.

Reddy MV, Randerath K. Nuclease P1-mediated enhancement of sensitivity of 32P-postlabeling test for structurally diverse DNA adducts. Carcinogenesis 1986, 7:1543-1551.

Reddy MV, Blackburn GR, Schreiner CA, Mackerer CR. Correlation of mutagenic potencies of various petroleum oils and oil coal tar mixtures with DNA adduct levels in vitro. Mutat Res 1997, 378:89-95.

Ritchie GD, Still KR, Alexander WK, Nordholm AF, Wilson CL, Rossi J, III, Mattie DR. A review of the neurotoxicity risk of selected hydrocarbon fuels. J Toxicol Environ Health B Crit Rev 2001, 4:223-312.

Riviere JE, Brooks JD, Monteiro-Riviere NA, Budsaba K, Smith CE. Dermal absorption and distribution of topically dosed jet fuels jet-A, JP-8, and JP-8(100). Toxicol Appl Pharmacol 1999, 160:60-75.

Robledo RF, Witten ML. Acute pulmonary response to inhaled JP-8 Jet fuel aerosol in mice. Inhal Toxicol 1998, 10:531-553.

Robledo RF, Witten ML. NK1-receptor activation prevents hydrocarbon-induced lung injury in mice. Am j Physiol 1999, 276:L229-L238.

Robledo RF, Barber DS, Witten ML. Modulation of bronchial epithelial cell barrier function by in vitro jet propulsion fuel 8 exposure. Toxicol Sci 1999, 51:119-125.

Robledo RF, Young RS, Lantz RC, Witten ML. Short-term pulmonary response to inhaled JP-8 jet fuel aerosol in mice. Toxicol Pathol 2000, 28:656-663.

Rojas E, Lopez MC, Valverde M. Single cell gel electrophoresis assay: methodology and applications. J Chromatogr B Biomed Sci Appl 1999, 722:225-254.

Rosenthal DS, Simbulan-Rosenthal CM, Liu WF, Stoica BA, Smulson ME. Mechanisms of JP-8 jet fuel cell toxicity. II. Induction of necrosis in skin fibroblasts and keratinocytes and modulation of levels of Bcl-2 family members. Toxicol Appl Pharmacol 2001, 171:107-116.

Roser S, Pool-Zobel B, Rechkemmer G. Contribution of apoptosis to responses in the comet assay. Mutat Res 2001, 497:169-175.

Rossi J, III, Nordholm AF, Carpenter RL, Ritchie GD, Malcomb W. Effects of repeated exposure of rats to JP-5 or JP-8 jet fuel vapor on neurobehavioral capacity and neurotransmitter levels. J Toxicol Environ Health A 2001, 63:397-428. 
Salmeen IT, Pero AM, Zator R, Schuetzle D, Riley TL. Ames assay chromatograms and the identification of mutagens in diesel particle extracts. Environ Sci Technol 1984, 18:375-382.

Sawyer T, Safe S. PCB isomers and congeners: induction of aryl hydrocarbon hydroxylase and ethoxyresorufin O-deethylase enzyme activities in rat hepatoma cells. Toxicol Lett 1982, 13:87-93.

Schoket B, Hewer A, Grover PL, Phillips DH. 32P-postlabelling analysis of DNA adducts in the skin of mice treated with petrol and diesel engine lubricating oils and exhaust condensates.

Carcinogenesis 1989, 10:1485-1490.

Schreiner C, Bui Q, Breglia R, Burnett D, Koschier F, Podhasky P, Lapadula L, White R, Feuston M, Krueger A, Rodriquez S. Toxicity evaluation of petroleum blending streams: reproductive and developmental effects of hydrodesulfurized kerosene. J Toxicol Environ Health 1997, 52:211-229.

Singh N, McCoy M, Tice R, Schneider E. A simple technique for quantitation of low levels of DNA damage in individual cells. Exp Cell Res 1988, 175:184-191.

Smith, J. H. Individual sample fuel mixture composition data. \#ESL-TR-81-54, 1-50. 1981. Springfield, VA, National Technical Information Services.

Smith LB, Bhattacharya A, Lemasters G, Succop P, Puhala E, Medvedovic M, Joyce J. Effect of chronic low-level exposure to jet fuel on postural balance of US Air Force personnel. J Occup Environ Med 1997, 39:623-632.

Snyder R, Hedli CC. An overview of benzene metabolism. Environ Health Perspect 1996, 104 Suppl 6:1165-1171.

Speit G, Hanelt S, Helbig R, Seidel A, Hartmann A. Detection of DNA effects in human cells with the comet assay and their relevance for mutagenesis. Toxicol Lett 1996, 88:91-98.

Srám RJ, Rössner P, Peltonen K, Podrazilová K, Mracková G, Demopoulos NA, Stephanou G, Vlachodimitropoulos D, Darroudi F, Tates AD. Chromosomal aberrations, sister-chromatid exchanges, cells with high frequency of SCE, micronuclei and comet assay parameters in 1, 3- butadiene-exposed workers. Mutat Res 1998, 419:145-154.

Stoica BA, Boulares AH, Rosenthal DS, Iyer S, Hamilton ID, Smulson ME. Mechanisms of JP-8 jet fuel toxicity. I. Induction of apoptosis in rat lung epithelial cells. Toxicol Appl Pharmacol 2001, 171:94-106.

Struwe G, Knave B, Mindus P. Neuropsychiatric symptoms in workers occupationally exposed to jet fuel- a combined epidemiologic and caustic study. Acta Psychiat Scand 1983, 303:55-67.

Tice RR: The single cell gel/ comet assay: a microgel electrophoretic technique for the detection of DNA damage and repair in individual cells. Environmental Mutagenesis. Edited by Phillips DH and Venitt S. Oxford, Bios Scientific Publishers, 1995, pp. 315-339.

Tice RR, Agurell E, Anderson D, Burlinson B, Hartmann A, Kobayashi H, Miyamae Y, Rojas E, Ryu JC, Sasaki YF. Single cell gel/comet assay: guidelines for in vitro and in vivo genetic toxicology testing. Environ Mol Mutagen 2000, 35:206-221. 
Tucker JD, Auletta A, Cimino MC, Dearfield KL, Jacobson-Kram D, Tice RR, Carrano AV. Sisterchromatid exchange: second report of the Gene-Tox Program. Mutat Res 1993, 297:101-180.

Ullrich SE. Dermal application of JP-8 jet fuel induces immune suppression. Toxicol Sci 1999, 52:61-67.

Ullrich SE, Lyons HJ. Mechanisms involved in the immunotoxicity induced by dermal application of JP-8 jet fuel. Toxicol Sci 2000, 58:290-298.

Upreti RK, Das M, Shanker R. Dermal exposure to kerosene. Vet Hum Toxicol 1989, 31:16-20.

Vaghef H, Wisen AC, Hellman B. Demonstration of benzo (a)pyrene-induced DNA damage in mice by alkaline single cell gel electrophoresis: evidence for strand breaks in liver but not in lymphocytes and bone marrow. Pharmacol Toxicol 1996, 78:37-43.

Wilmer JL, Erexson GL, Kligerman AD. Effect of acrolein on phosphoramide mustard-induced sister chromatid exchanges in cultured human lymphocytes. Cancer Res 1990, 50:4635-4638.

Witzmann FA, Bauer MD, Fieno AM, Grant RA, Keough TW, Kornguth SE, Lacey MP, Siegel FL, Sun Y, Wright LS, Young RS, Witten ML. Proteomic analysis of simulated occupational jet fuel exposure in the lung. Electrophoresis 1999, 20:3659-3669.

Witzmann FA, Bauer MD, Fieno AM, Grant RA, Keough TW, Lacey MP, Sun Y, Witten ML, Young RS. Proteomic analysis of the renal effects of simulated occupational jet fuel exposure. Electrophoresis 2000a, 21:976-984.

Witzmann FA, Carpenter RL, Ritchie GD, Wilson CL, Nordholm AF, Rossi J, III. Toxicity of chemical mixtures: proteomic analysis of persisting liver and kidney protein alterations induced by repeated exposure of rats to JP-8 jet fuel vapor. Electrophoresis 2000b, 21:21382147.

Yamano T, Noda T, Shimizu M, Morita S, Nagahama M. Effects of diethylene glycol monomethyl ether on pregnancy and postnatal development in rats. Arch Environ Contam Toxicol 1993, 24:228-235.

Yang TT, Sinai P, Kain SR. An acid phosphatase assay for quantifying the growth of adherent and nonadherent cells. Anal Biochem 1996, 241:103-108.

Yu KO, Tillitt DE, Byczkowski JZ, Burton GA, Jr., Channel SR, Drerup JM, Flemming CD, Fisher JW. In vivo/in vitro comparison of the pharmacokinetics and pharmacodynamics of 3,3',4,4'tetrachlorobiphenyl (PCB77). Toxicol Appl Pharmacol 1996, 141:434-438.

Zeiger E, Anderson B, Haworth S, Lawlor T, Mortelmans K. Salmonella mutagenicity tests: V. Results from the testing of 311 chemicals. Environ Mol Mutagen 1992, 19 Suppl 21:2-141.

Zeiger E, Smith L. The first international conference on the environmental health and safety of jet fuel. Environ Health Perspect 1998, 106:763-764. 


\section{Appendix A Buffers, Solutions, and Experiment Chart}

\section{Ames Salmonella/ microsomal mutagenicity assay}

\section{Nutrient Broth}

$15 \mathrm{~min}$.

Add 25 g Oxoid Nutrient broth No. 2 to 1 L, mix, and sterilize by autoclaving @ $121^{\circ} \mathrm{C}$ for

\section{Nutrient Agar Plates}

12.5 g Oxoid Nutrient broth 2

$7.5 \mathrm{~g}$ Agar

$500 \mathrm{ml}$ distilled water

Add to a liter flask, mix with stir bar, autoclave at $121^{\circ} \mathrm{C}$ for $15 \mathrm{~min}$. Let cool to about $50^{\circ} \mathrm{C}$ and pour 25-30 $\mathrm{ml}$ to plates, store inverted at $4^{\circ} \mathrm{C}$

Vogel-Bonner (VB salts) medium E (50X)

Heat $650 \mathrm{ml}$ of water to $45^{\circ} \mathrm{C}$ add in order:

$10 \mathrm{~g}$ magnesium sulfate heptahydrate $\mathrm{MgSO}_{4}-7 \mathrm{H}_{2} \mathrm{O}$

$100 \mathrm{~g}$ citric acid monohydrate

$500 \mathrm{~g}$ potassium phosphate, dibasic (anhydrous) $\left(\mathrm{K}_{2} \mathrm{HPO}_{4}\right.$

$175 \mathrm{~g}$ sodium ammounium phosphate $\left(\mathrm{na}_{2} \mathrm{NH}_{2} \mathrm{PO}_{4} \cdot 4 \mathrm{H}_{2} \mathrm{O}\right)$

Make sure each component dissolves before adding the next, make up to $1 \mathrm{~L}$, autoclave $@ 121^{\circ} \mathrm{C}$ for 20 min. Store at room temperature in the dark.

Glucose Solution 10\%

Dissolve $100 \mathrm{~g}$ Dextrose-glucose to $700 \mathrm{ml}$ of water. Add additional water to bring the final volume to $1000 \mathrm{ml}$. Autoclave @ $121^{\circ} \mathrm{C}$ for $20 \mathrm{~min}$. Store at room temperature.

\section{Minimal Agar plates}

Add $15 \mathrm{~g}$ of agar in $930 \mathrm{ml}$ of water. Mix and autoclave for $20 \mathrm{~min} @ 121^{\circ} \mathrm{C}$. Cool agar to $65^{\circ} \mathrm{C}$ and add the following with continuous stirring:

$20 \mathrm{ml} 50 \mathrm{X}$ Vogel Bonner medium $\mathrm{E}$

$50 \mathrm{ml} \mathrm{40 \%} \mathrm{glucose}$

Dispense the agar medium in $100 \mathrm{x} 15 \mathrm{~mm}$ petri dishes approximately $25 \mathrm{ml} /$ plate. Once solidified store plates at $4^{\circ} \mathrm{C}$ inverted in sealed bags.

Histidine-biotin solution $(0.5 \mathrm{mM})$

$12.4 \mathrm{mg}$ D-biotin to $100 \mathrm{ml}$ of water

Dissolve by heating to boiling point and add

$9.6 \mathrm{mg}$ L-histidine-HCL

Sterile filter through $0.22 \mu \mathrm{m}$ filter and store in glass bottle at $4^{\circ} \mathrm{C}$

Top Agar

$\begin{array}{ll}\text { Agar } & 3 \mathrm{~g} \\ \mathrm{NaCl} & 2.5 \mathrm{~g} \\ \text { d-water } & 500 \mathrm{ml}\end{array}$

Mix and autoclave for $20 \mathrm{~min}$ at $121^{\circ} \mathrm{C}$. Dispense into $100 \mathrm{ml}$ portions into sterile screw cap bottles and store at $4^{\circ} \mathrm{C}$. 


\section{Ampicillin stock sol'n $8 \mathrm{mg} / \mathrm{ml}$}

$0.4 \mathrm{~g}$ ampicillin trihydrate in $50 \mathrm{ml} 0.02 \mathrm{~N} \mathrm{NaOH}$

Sterile filter through a $0.22 \mu \mathrm{m}$ membrane filter and store in a capped glass bottle at $4^{\circ} \mathrm{C}$

\section{Master plates}

Add $15 \mathrm{~g}$ of agar in $914 \mathrm{ml}$ of distilled water. Mix and autoclave for $20 \mathrm{~min}$ at $121^{\circ} \mathrm{C}$. Add with stirring:

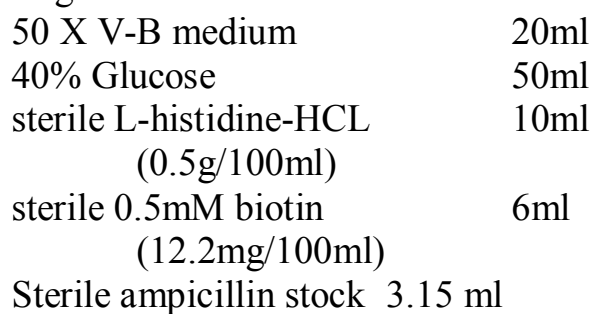

Dispense the agar medium in $100 \times 15 \mathrm{~mm}$ petri dishes approximately $25 \mathrm{ml} /$ plate. Once solidified store plates at $4^{\circ} \mathrm{C}$ inverted in sealed bags.

\section{Histidine deficient plates}

Add $5 \mathrm{~g}$ agar in $333 \mathrm{ml}$ of distilled water. Mix and autoclave for $20 \mathrm{~min}$ at $121^{\circ} \mathrm{C}$.

Add $2 \mathrm{ml}$ of $0.5 \mathrm{mM}$ biotin solution and dispense the agar medium in $100 \mathrm{x} 15 \mathrm{~mm}$ petri dishes approximately $25 \mathrm{ml} /$ plate. Once solidified store plates at $4{ }^{\circ} \mathrm{C}$ inverted in sealed bags.

Crystal Violet $0.1 \%$

Add $0.1 \mathrm{~g}$ crystal violet in $100 \mathrm{ml}$ of distilled water. Mix and store at $4{ }^{\circ} \mathrm{C}$ in a brown glass bottle in dark.

\section{Cofactors for S-9 mix}

To $900 \mathrm{ml}$ of distilled water add in order:

1.6 gD-Glucose-6-phosphate

$3.5 \mathrm{~g}$ Nicotinamide adenine dinucleotde phosphate (NADP)

$1.8 \mathrm{~g}$ Magnesium chloride $(\mathrm{MgCl})$

$2.7 \mathrm{~g}$ Potassium chloride $(\mathrm{KCl})$

$12.8 \mathrm{~g}$ Sodium phosphate, dibasic $\left(\mathrm{Na}_{2} \mathrm{HPO}_{4} \mathrm{H}_{2} \mathrm{O}\right)$

2.8 g Sodium phosphate, monobasic $\left(\mathrm{NaH}_{2} \mathrm{PO}_{4} \mathrm{H}_{2} \mathrm{O}\right.$

Make sure each component dissolves before adding the next, make up to $1 \mathrm{~L}$ and sterile filter the cofactors through a $0.45 \mu \mathrm{m}$ filter and store at $-20^{\circ} \mathrm{C}$ in $10 \mathrm{ml}$ aliquots.

\section{Cell Culture}

\section{Culture media for H411E and V79 cell culture}

Dulbecco's Modified Eagle Medium (DMEM) with high glucose, L-glutamine, $110 \mathrm{mg} / \mathrm{L}$ sodium pyruvate, pyridoxine hydrochloride (Invitrogen) supplemented with:

$5 \%$ Fetal bovine serum (FBS)

$1 \%$ penicillin/streptomycin

\section{$\underline{\text { Culture media for Hepa1c1c7 cell culture }}$}

Minimum Essential Medium Alpha Medium with L-glutamine (Invitrogen) supplemented with: $5 \%$ FBS $1 \%$ penicillin/streptomycin 
$0.5 \mathrm{mM}$ sodium pyruvate

\section{Sister Chromatid Exchange}

\section{Culture media}

RPMI-1649 (Invitrogen) supplemented with:

$5 \%$ FBS

$1 \%$ penicillin.streptomycin

$10 \mu \mathrm{g} / \mathrm{ml} \mathrm{BrdU}$

\section{$\underline{\text { Sorenson's Buffer }}$}

$9.1 \mathrm{~kg} \mathrm{KCL}$

$9.5 \mathrm{~g} \mathrm{NaPO}_{4}$

Mix with distilled water to a volume of $1 \mathrm{~L}$ and $\mathrm{pH}$ to 6.85 with $1 \mathrm{~N} \mathrm{HCL}$

\section{Comet Assay-- Antifade}

$20 \mathrm{mg}$ phenylenediamine dihydrochlroide

$2 \mathrm{ml}$ PBS

Mix and sterile filter with a $0.22 \mu \mathrm{m}$ filter to remove an undissolved chemical. Adjust $\mathrm{pH}$ to 8.0 with $0.5 \mathrm{M}$ carbonate-bicarbonate buffer ( $\mathrm{pH} 9.0$ ). Add $20 \mathrm{ml}$ of glycerol, for a total volume of approximately $22 \mathrm{ml}$. Store at $-20^{\circ} \mathrm{C}$ in the dark.

\section{${ }^{32}$ P-postlabeling}

Micrococcal endonuclease/ spleen phosphodiesterase (MN/SPD) buffer

$2 \mu \mathrm{g} \mathrm{SPD} / \mu 1$ used (centrifuged at 14,000 rpm and ammonium sulfate supernatant removed) $1 \mu \mathrm{g} \mathrm{MN} / \mu 1$ used

$20 \mathrm{mM}$ sodium succinate

$10 \mathrm{mM}$ calcium chloride $\mathrm{pH} 6.0$

$\underline{\text { Nuclease } \mathrm{P}_{1} \text { solution }}$

$2 \mu 1$ of $4 \mu \mathrm{g} / \mu 1$ nuclease $\mathrm{P}_{1}$

$0.9 \mu 11 \mathrm{M}$ sodium acetate $\mathrm{pH} 5.0$

$4.1 \mu 11 \mathrm{mM}$ zinc chloride

\section{Labeling Buffer}

$100 \mu \mathrm{Ci}$ of $3000 \mathrm{Ci} / \mathrm{mmol}$ of $\left[\right.$ gamma- ${ }^{32} \mathrm{P}$ ]ATP

8 units of T4 polynucleotide kinase

$1.25 \mu 10.1 \mathrm{M}$ bicine

$1.25 \mu 10.1 \mathrm{M} \mathrm{MgCl}_{2}$

$1.25 \mu 10.1 \mathrm{M}$ dithiothreitol

$1.25 \mu 110 \mathrm{mM}$ spermidine

D1 Buffer Dissolve $142 \mathrm{~g}$ sodium phosphate in $1000 \mathrm{ml}$ dwater, $\mathrm{pH}$ to 6.0

D3 Buffer Dissolve $225.3 \mathrm{~g}$ urea and $157.5 \mathrm{~g}$ lithium formate in $500 \mathrm{ml}$ dwater, $\mathrm{pH}$ to 3.5

Wicking solution Dissolve 3.025 Tris and $17 \mathrm{~g}$ lithium chloride in $500 \mathrm{ml}$ dwater, $\mathrm{pH}$ to 8.0

D4 Buffer Dissolve 30.8g Tris, 33.9g lithium chloride and 255.3g urea in $500 \mathrm{ml}$ dwater, $\mathrm{pH}$ to 8.0 
Tabulation of Experiments

\begin{tabular}{|c|c|c|c|}
\hline Experiment Type & Cell Type & Exposure & Exposure Type \\
\hline Ames Assay & S. typhimurium & JP-5, JP-8, JP-8+100 & DMSO extracts \\
\hline $\begin{array}{l}\text { Sister Chromatid } \\
\text { Exchange Assay }\end{array}$ & $\begin{array}{c}\text { Primary } \\
\text { Lymphocytes }\end{array}$ & JP-5, JP-8, JP-8+100 & Direct \\
\hline $\begin{array}{l}\text { Acid Phosphatase } \\
\text { Cytotoxicity Assay }\end{array}$ & $\begin{array}{c}\text { H411E, } \\
\text { Hepa1c1c7, V79 } \\
\end{array}$ & Deicers & Direct \\
\hline \multirow{3}{*}{ Comet Assay } & \multirow{3}{*}{ H411E } & JP-5, JP-8, JP-8+100 & Direct \\
\hline & & JP-8 & Indirect $0.1 \% \mathrm{EtOH}$ \\
\hline & & JP-8 & Indirect $0.5 \% \mathrm{EtOH}$ \\
\hline Comet Assay & $\begin{array}{c}\text { Primary } \\
\text { Lymphocytes }\end{array}$ & JP-5, JP-8, JP-8+100 & Direct \\
\hline Comet Assay & Hepa1c1c7 & JP-8 & Indirect $0.1 \% \mathrm{EtOH}$ \\
\hline Comet Assay & V79 & JP-8 & Indirect $0.1 \% \mathrm{EtOH}$ \\
\hline Oxidative Comet Assay & H411E & JP-8 & Indirect $0.1 \% \mathrm{EtOH}$ \\
\hline DNA adducts Assay & H411E & JP-8 & Indirect $0.1 \% \mathrm{EtOH}$ \\
\hline
\end{tabular}


Appendix B Jet Fuel Components/Previous Publications and Oxidized Base Examples

Summary of Composition Data with Estimated Weights Percent for JP-8 and JP-5 Jet Fuels

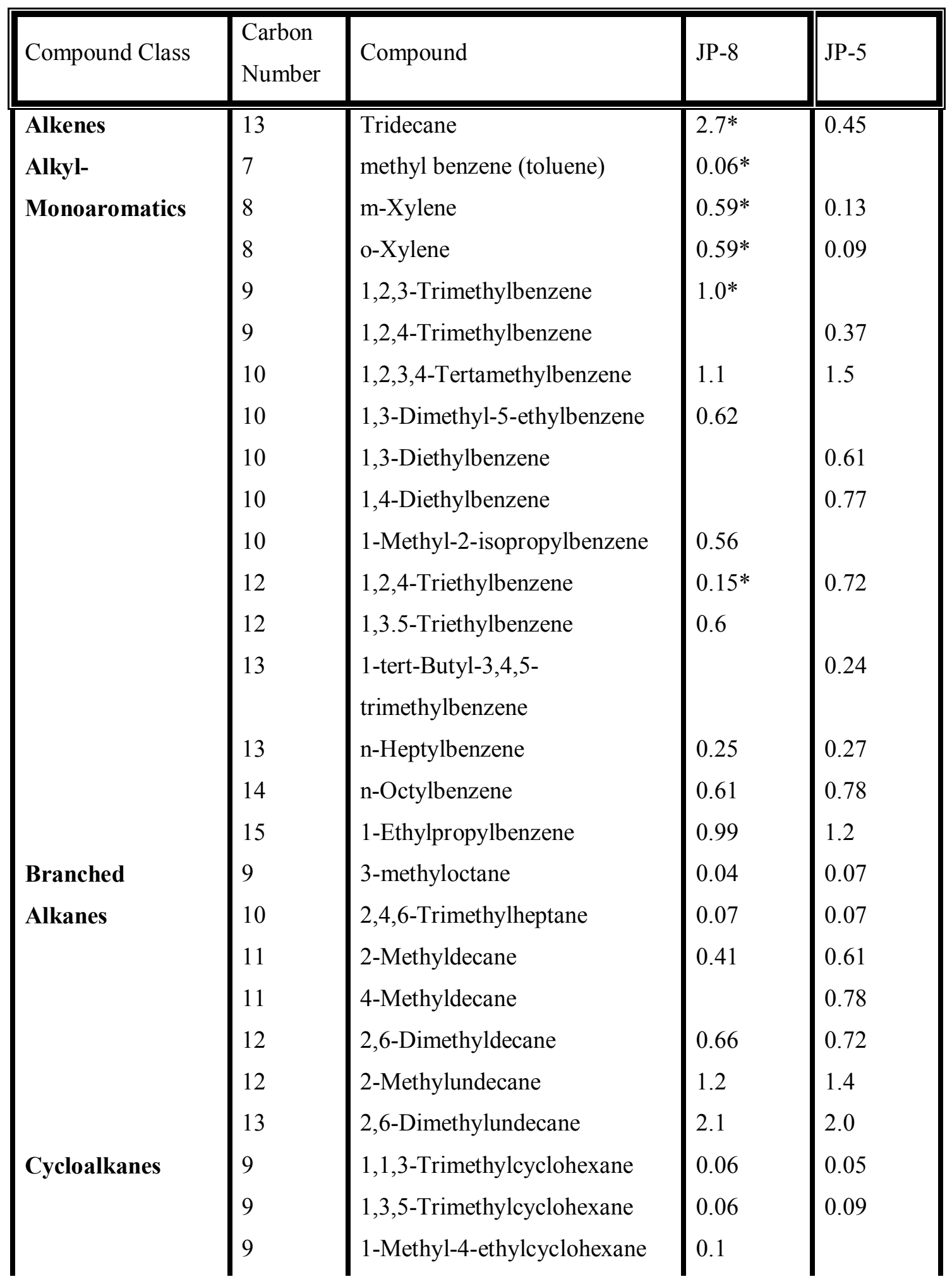




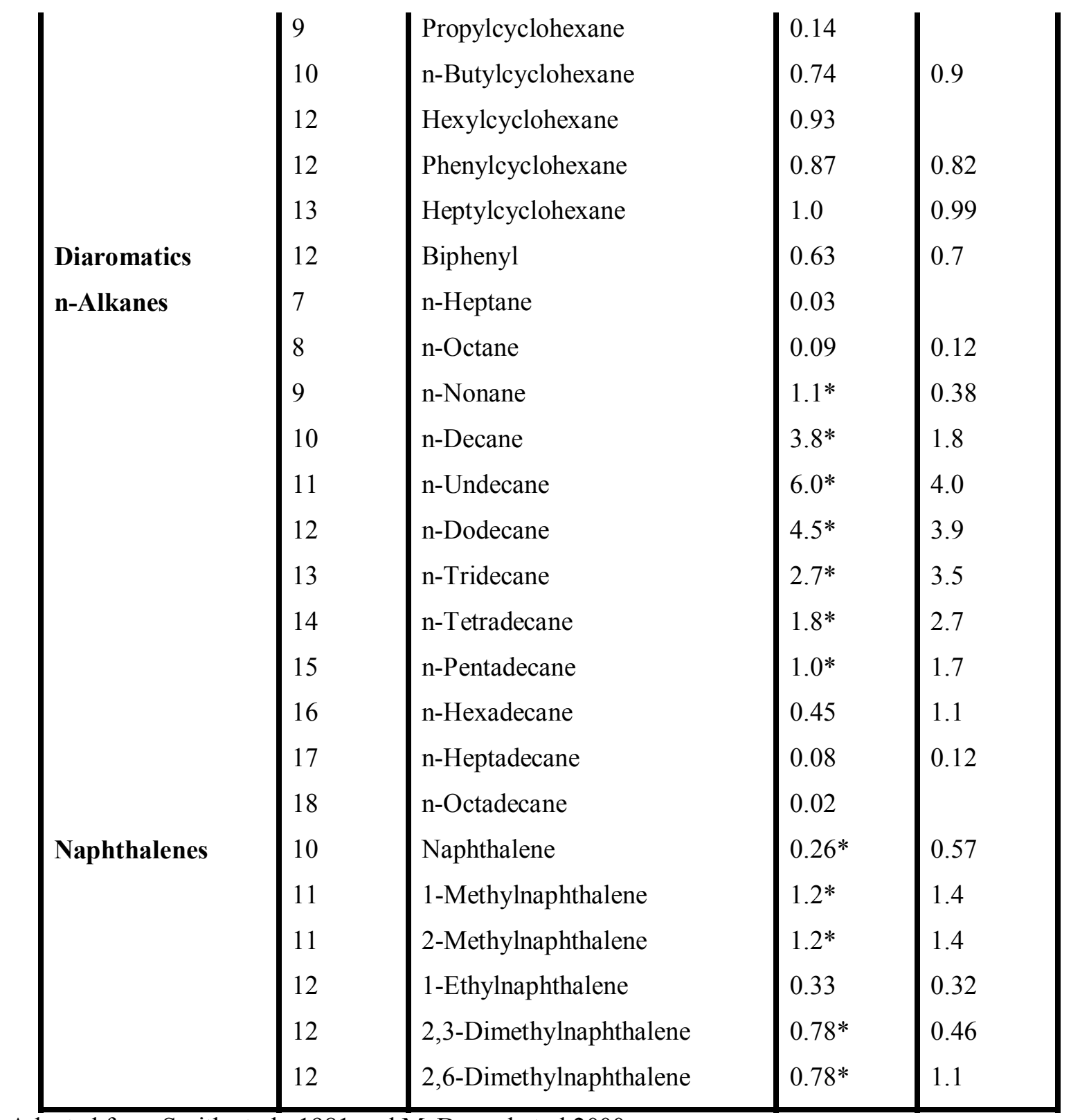

Adapted from Smith et al., 1981 and McDougal et al 2000.

*Relative proportions of major hydrocarbon components of JP-8 batch used in this study as analyzed by Gas chromatography

Note: Blanks indicate that the compound is not a measurable component of that fuel type 
Previous Jet Fuel Publications (including exposure specifications)

\begin{tabular}{|c|c|c|c|c|c|c|}
\hline Paper & Route & Levels & Species & $\begin{array}{c}\text { Type/ } \\
\text { Duration }\end{array}$ & Endpoint & Fuel \\
\hline $\begin{array}{l}\text { Mattie et al. } \\
1991\end{array}$ & Vapor & $\begin{array}{l}0-1000 \\
\mathrm{mg} / \mathrm{m}^{3}\end{array}$ & $\begin{array}{l}\text { F344 rats, } \\
\text { C57B1/6 mice }\end{array}$ & 90d constant & $\begin{array}{l}\text { General } \\
\text { Toxicity }\end{array}$ & JP-8 \\
\hline $\begin{array}{l}\text { Mattie et al, } \\
1995\end{array}$ & Oral & $\begin{array}{l}\mathrm{0-3000} \\
\mathrm{mg} / \mathrm{kg}\end{array}$ & $\begin{array}{l}\text { F344 rats, } \\
\text { C57Bl/6 mice }\end{array}$ & $90 \mathrm{~d}$ constant & $\begin{array}{l}\text { General } \\
\text { Toxicity }\end{array}$ & JP-8 \\
\hline $\begin{array}{l}\text { Gaworski et } \\
\text { al. } 1984\end{array}$ & Vapor & $\begin{array}{l}150 \& 750 \\
\mathrm{mg} / \mathrm{m}\end{array}$ & $\begin{array}{l}\text { F344 rats, } \\
\text { C57BL/6 mice }\end{array}$ & $90 \mathrm{~d}$ constant & $\begin{array}{l}\text { General } \\
\text { Toxicity }\end{array}$ & JP-5 \\
\hline $\begin{array}{l}\text { Bruner et al. } \\
1993\end{array}$ & Vapor & $\begin{array}{l}0-5000 \\
\mathrm{mg} / \mathrm{m}^{3}\end{array}$ & F 344 rats & $\begin{array}{l}6 \mathrm{~h} / \mathrm{d} 5 \mathrm{~d} / \mathrm{wk} 12 \\
\mathrm{~m}\end{array}$ & $\begin{array}{l}\text { General } \\
\text { Toxicity }\end{array}$ & JP-4 \\
\hline $\begin{array}{l}\text { Cooper and } \\
\text { Mattie }\end{array}$ & Oral & $\begin{array}{l}0-2000 \\
\mathrm{mg} / \mathrm{kg}\end{array}$ & Rats & $11 \mathrm{~d}$ & $\begin{array}{l}\text { Repro- } \\
\text { ductive }\end{array}$ & JP-8 \\
\hline $\begin{array}{l}\text { Nordholm et } \\
\text { al. } 1999\end{array}$ & Vapor & $2 \mathrm{mg} / \mathrm{L}$ & SD rats & $6 \mathrm{~h} / \mathrm{d} 14 \mathrm{~d}$ & $\begin{array}{l}\text { Neuro- } \\
\text { toxicity }\end{array}$ & JP-4 \\
\hline $\begin{array}{l}\text { Rossi et al., } \\
2001\end{array}$ & Vapor & $\begin{array}{l}1000-1200 \\
\mathrm{mg} / \mathrm{m}^{3}\end{array}$ & SD rats & $\begin{array}{l}6 \mathrm{~h} / \mathrm{d} 5 \mathrm{~d} / \mathrm{wk} \\
6 \mathrm{wk}\end{array}$ & $\begin{array}{l}\text { Neuro- } \\
\text { toxicity }\end{array}$ & JP-8, JP-5 \\
\hline $\begin{array}{l}\text { Baldwin et al., } \\
2001\end{array}$ & $\begin{array}{l}\text { Aeroso } \\
\text { 1/Vapor }\end{array}$ & $\begin{array}{l}1000-2500 \\
\mathrm{mg} / \mathrm{m}^{3}\end{array}$ & $\begin{array}{l}\text { Brown } \\
\text { Norway Rats }\end{array}$ & $1 \mathrm{~h} / \mathrm{d} 5 \mathrm{~d} / \mathrm{wk} 28 \mathrm{~d}$ & $\begin{array}{l}\text { Neuro- } \\
\text { toxicity }\end{array}$ & JP-8 \\
\hline $\begin{array}{l}\text { Harris et al. } \\
1997 \mathrm{a}, \mathrm{b}, \mathrm{c}, 200 \\
0\end{array}$ & $\begin{array}{l}\text { Aeroso } \\
1\end{array}$ & $\begin{array}{l}100-2500 \\
\mathrm{mg} / \mathrm{m}^{3}\end{array}$ & C57Bl/6 Mice & $1 \mathrm{~h} / \mathrm{d} 7 \mathrm{~d}$ & $\begin{array}{l}\text { Immuno- } \\
\text { toxicity }\end{array}$ & JP-8 \\
\hline $\begin{array}{l}\text { Ullrich et al. } \\
1999,2000\end{array}$ & $\begin{array}{l}\text { Direct } \\
\text { Dermal }\end{array}$ & $\begin{array}{l}50 \mu 1 \\
250-300 \mu 1\end{array}$ & $\begin{array}{l}\mathrm{C} 3 \mathrm{H} / \mathrm{HeN} \\
\text { mice }\end{array}$ & $\begin{array}{l}5 \mathrm{~d} \\
\text { One time }\end{array}$ & $\begin{array}{l}\text { Immuno- } \\
\text { toxicity }\end{array}$ & JP-8 \\
\hline $\begin{array}{l}\text { Witzmann et } \\
\text { al. } 2000 \mathrm{a}\end{array}$ & $\begin{array}{l}\text { Aeroso } \\
1\end{array}$ & $\begin{array}{l}1000 \\
\mathrm{mg} / \mathrm{m}^{3}\end{array}$ & SD rat & $\begin{array}{l}\text { 6h/d 5d/wk } 6 \\
\text { wks }\end{array}$ & $\begin{array}{l}\text { Renal and } \\
\text { liver }\end{array}$ & JP-8 \\
\hline $\begin{array}{l}\text { Witzmann et } \\
\text { al. } 2000 \mathrm{~b}\end{array}$ & $\begin{array}{l}\text { Aeroso } \\
1\end{array}$ & $\begin{array}{l}1000 \\
\mathrm{mg} / \mathrm{m}^{3}\end{array}$ & SW mice & $1 \mathrm{~h} / \mathrm{d} 5 \mathrm{~d}$ & Renal & JP-8 \\
\hline $\begin{array}{l}\text { Witzmann } \\
\text { et.al. } 1999\end{array}$ & Aerosl & $\begin{array}{l}1000-2500 \\
\mathrm{mg} / \mathrm{m}^{3}\end{array}$ & SW mice & $\begin{array}{l}1 \mathrm{~h} / \mathrm{d} 7 \mathrm{~d} \text { short } \\
\text { term }\end{array}$ & Pulmonary & JP-8 \\
\hline $\begin{array}{l}\text { Robledo et al. } \\
2000\end{array}$ & $\begin{array}{l}\text { Aeroso } \\
1\end{array}$ & $\begin{array}{l}0-118 \\
\mathrm{mg} / \mathrm{m}^{3}\end{array}$ & B6.A.D. mice & $\begin{array}{l}1 \mathrm{~h} / \mathrm{d} 7 \mathrm{~d} \text { short } \\
\text { term }\end{array}$ & Pulmonary & JP-8 \\
\hline $\begin{array}{l}\text { Robledo et al. } \\
1999\end{array}$ & $\begin{array}{l}\text { Indirec } \\
\mathrm{t}\end{array}$ & $\begin{array}{l}0-0.67 \\
\mathrm{mg} / \mathrm{ml}\end{array}$ & $\begin{array}{l}\text { BEAs-2B cells } \\
\text { In vitro }\end{array}$ & & Pulmonary & JP-8 \\
\hline $\begin{array}{l}\text { Pffaff et al. } \\
1995\end{array}$ & $\begin{array}{l}\text { Aeroso } \\
\text { 1/Vapor }\end{array}$ & $\begin{array}{l}495 \text { or } 520 \\
\mathrm{mg} / \mathrm{m}^{3}\end{array}$ & F344 rats & $1 \mathrm{~h} / \mathrm{d} 7 \mathrm{~d}$ or $28 \mathrm{~d}$ & Pulmonary & JP-8 \\
\hline $\begin{array}{l}\text { Pffaff et al. } \\
1996\end{array}$ & $\begin{array}{l}\text { Aeroso } \\
\text { 1/Vapor }\end{array}$ & $\begin{array}{l}469-1263 \\
\mathrm{mg} / \mathrm{m}^{3}\end{array}$ & F344 rats & $\begin{array}{l}1 \mathrm{~h} / \mathrm{d} 7 \mathrm{~d} \\
28 \mathrm{~d}, 56 \mathrm{~d}\end{array}$ & Pulmonary & JP-8 \\
\hline $\begin{array}{l}\text { Hays et al. } \\
1995\end{array}$ & $\begin{array}{l}\text { Aeroso } \\
1\end{array}$ & $\begin{array}{l}500-1094 \\
\mathrm{mg} / \mathrm{m}^{3}\end{array}$ & F344 rats & $\begin{array}{l}1 \mathrm{~h} / \mathrm{d} 7 \mathrm{~d}, \\
28 \mathrm{~d}, 56 \mathrm{~d}\end{array}$ & Pulmonary & JP-8 \\
\hline $\begin{array}{l}\text { Allen et al. } \\
2001\end{array}$ & $\begin{array}{l}\text { Indirec } \\
t\end{array}$ & $0.10 \%$ & $\begin{array}{l}\text { Porcine } \\
\text { keratinocytes }\end{array}$ & $\begin{array}{l}1-24 \mathrm{~h} \\
\text { in vitro }\end{array}$ & Dermal & JP-8 \\
\hline $\begin{array}{l}\text { Allen et al. } \\
2000\end{array}$ & $\begin{array}{l}\text { Indirec } \\
\mathrm{t}\end{array}$ & $0.10 \%$ & $\begin{array}{l}\text { Human } \\
\text { Epidermal } \\
\text { keratinocytes }\end{array}$ & $\begin{array}{l}24 \mathrm{~h} \\
\text { (in vitro) }\end{array}$ & Dermal & $\begin{array}{l}\text { Jet A, JP-8, } \\
\text { JP }-8+100\end{array}$ \\
\hline $\begin{array}{l}\text { Riviere et al. } \\
1999\end{array}$ & $\begin{array}{l}\text { Direct } \\
\text { Dernal }\end{array}$ & $\begin{array}{l}\text { Neat } 25 \\
\mu 1 / 5 \mathrm{~cm} 2\end{array}$ & $\begin{array}{l}\text { Porcine Skin } \\
\text { Flaps }\end{array}$ & $5 \mathrm{~h}$ & Dermal & $\begin{array}{l}\text { Jet A, JP-8, } \\
\text { JP }-8+100\end{array}$ \\
\hline
\end{tabular}




\begin{tabular}{|c|c|c|c|c|c|c|}
\hline $\begin{array}{l}\text { Kanikkannan } \\
\text { et al. } 2000\end{array}$ & $\begin{array}{l}\text { Direct } \\
\text { Dermal }\end{array}$ & Neat & $\mathrm{CBA} / \mathrm{Ca}$ mice & One application & Dermal & $\begin{array}{l}\text { Jet A, JP-8, } \\
\text { JP }-8+100\end{array}$ \\
\hline $\begin{array}{l}\text { Kanikkannan } \\
\text { et al. 2001a, b }\end{array}$ & $\begin{array}{l}\text { Direct } \\
\text { Dermal }\end{array}$ & $\begin{array}{l}\text { Neat } 1 \mathrm{ml} \\
\text { and } 250 \mu 1\end{array}$ & $\begin{array}{l}\text { Pig ears, } \\
\text { human skin, } \\
\text { Yucatoan } \\
\text { minipigs }\end{array}$ & $1-24 \mathrm{~h}$ & Dermal & $\begin{array}{l}\text { JP-8, JP - } \\
8+100\end{array}$ \\
\hline $\begin{array}{l}\text { McDougal et } \\
\text { al. } 2000\end{array}$ & $\begin{array}{l}\text { Direct } \\
\text { Dermal }\end{array}$ & Neat $20 \mu 1$ & F344 rat skin & One application & Dermal & JP-8 \\
\hline $\begin{array}{l}\text { Kabbur et al., } \\
2001\end{array}$ & $\begin{array}{l}\text { Direct } \\
\text { Dermal }\end{array}$ & $\begin{array}{l}\text { Neat } \\
250 \mu 1\end{array}$ & F344 rat & $\begin{array}{l}\text { One application } \\
\text { for } 1 \mathrm{hr}\end{array}$ & Dermal & JP-8 \\
\hline $\begin{array}{l}\text { Dössing et al. } \\
1985\end{array}$ & & & Human & & Liver & \\
\hline $\begin{array}{l}\text { Knave et al. } \\
1978 \text { a, b, c, }\end{array}$ & & & & & & \\
\hline $\begin{array}{l}\text { Struwe et al. } \\
1983, \text { Smith et } \\
\text { al. } 1997\end{array}$ & & & Human & & $\begin{array}{l}\text { Nuero- } \\
\text { toxicity }\end{array}$ & MC-77 \\
\hline $\begin{array}{l}\text { Lemasters et } \\
\text { al. 1997, } \\
1999 \text { a }\end{array}$ & & & Human & & $\begin{array}{l}\text { Geno- } \\
\text { toxicity }\end{array}$ & JP-4 \\
\hline $\begin{array}{l}\text { Andreoli et al. } \\
1997\end{array}$ & & & Human & & $\begin{array}{l}\text { Geno- } \\
\text { toxicity }\end{array}$ & $\begin{array}{l}\text { Benzene } \\
\text { Petroleum }\end{array}$ \\
\hline $\begin{array}{l}\text { Lemasters et } \\
\text { al. } 1999\end{array}$ & & & Human & & $\begin{array}{l}\text { Repro- } \\
\text { ductive }\end{array}$ & JP-4 \\
\hline $\begin{array}{l}\text { Holm et al. } \\
1997\end{array}$ & & & Human & & $\begin{array}{l}\text { Hydrocar- } \\
\text { bon Exp }\end{array}$ & MC-77 \\
\hline $\begin{array}{l}\text { Pleil et al., } \\
2000\end{array}$ & $\begin{array}{l}\text { Vapor, } \\
\text { Aeroso } \\
1\end{array}$ & $\begin{array}{l}\text { Biomoni- } \\
\text { toring }\end{array}$ & Human & $\begin{array}{l}\text { Normal Work } \\
\text { Day }\end{array}$ & Breath & JP-8 \\
\hline $\begin{array}{l}\text { Brusick and } \\
\text { Matheson, } \\
1978\end{array}$ & Direct & $0.1-5 \mu 1$ & $\begin{array}{l}\text { Salmonella } \\
\text { typhimurium }\end{array}$ & $48 \mathrm{~h}$ & $\begin{array}{l}\text { Geno- } \\
\text { toxicity }\end{array}$ & JP-8 \\
\hline $\begin{array}{l}\text { Brusick and } \\
\text { Matheson, } \\
1978\end{array}$ & Direct & $\begin{array}{l}0.01-0.16 \\
\mu 1 / \mathrm{ml}\end{array}$ & $\begin{array}{l}\text { In vitro Mouse } \\
\text { lymphoma } \\
\text { cells }\end{array}$ & $24 \mathrm{~h}$ & $\begin{array}{l}\text { Geno- } \\
\text { toxicity }\end{array}$ & JP-8 \\
\hline $\begin{array}{l}\text { Brusick and } \\
\text { Matheson, } \\
1978\end{array}$ & Direct & $\begin{array}{l}0.1-5 \\
\mu 1 / \mathrm{ml}\end{array}$ & $\begin{array}{l}\text { WI-38 cells } \\
\text { In vitro }\end{array}$ & $30 \mathrm{~min}$ & $\begin{array}{l}\text { Geno- } \\
\text { toxicity }\end{array}$ & JP-8 \\
\hline $\begin{array}{l}\text { Brusick and } \\
\text { Matheson, } \\
1978\end{array}$ & Oral & $\begin{array}{l}0.13-1.3 \\
\mathrm{ml} / \mathrm{kg}\end{array}$ & CD-1 mice & Once a day/ 5d & $\begin{array}{l}\text { Geno- } \\
\text { toxicity }\end{array}$ & JP-8 \\
\hline $\begin{array}{l}\text { Brusick and } \\
\text { Matheson, } \\
1978\end{array}$ & Oral & $\begin{array}{l}0.13-1.3 \\
\mathrm{ml} / \mathrm{kg}\end{array}$ & $\begin{array}{l}\text { CRL:COBS } \\
\text { CD(SD)Br } \\
\text { Rats }\end{array}$ & Once a day/ 5d & $\begin{array}{l}\text { Geno- } \\
\text { toxicity }\end{array}$ & JP-8 \\
\hline
\end{tabular}

Abbreviations

F344 rats $=$ Fischer 344 rats

$\mathrm{h}=$ hour

$\mathrm{d}=$ day

wk $=$ week

Indirect $=$ solubolized in $\mathrm{ETOH}$ 
<smiles>CC1(O)NC(=O)NC1=O</smiles>

5-hydroxy-5-methylhydrantoin<smiles>O=c1[nH]cc(CO)c(=O)[nH]1</smiles>

5-hydroxymethyluracil<smiles>Nc1nc(=O)[nH]c(O)c1O</smiles>

5, 6 -dihydroxycytosine<smiles>O=C1NC(=O)C(O)N1</smiles>

5-hydroxyhydrantoin<smiles>NC1=NC(=O)NCC1O</smiles>

5-hydroxycytosine<smiles>NC1=NC(=O)NC(O)C1O</smiles>

cytosine glycol<smiles>CC1(O)C(=O)NC(=O)NC1O</smiles>

thymine glycol<smiles>O=c1[nH]cc(O)c(=O)[nH]1</smiles>

5-hydroxyuracil<smiles>O=c1[nH]c(O)c(O)c(=O)[nH]1</smiles>

5, 6 -dihydroxyuracil<smiles>Nc1ncnc(N)c1NC=O</smiles>

4, 6 -diamino-5formamidopyrimidine<smiles>Nc1ncnc2[nH]c(O)nc12</smiles>

8-hydroxyadenine<smiles>Nc1nc(N)c(NC=O)c(=O)[nH]1</smiles>

2, 6 -diamino-4-hydroxy5-formamidopyrimidine<smiles>Nc1nc2[nH]c(O)nc2c(=O)[nH]1</smiles>

8-hydroxyguanine 